APLI CAÇÃO DE METODOLOGI A PARA DETERMINAÇスO DE ESTI AGENS NA BACI A DO RIO CORUMBATAI

ALGUERDO GENEVICIUS

Orientador Prof. Dr. Rubens Scardua

Dissertação apresentada à Escola Superior de Agricultura "Luiz de Queiroz", da Universidade de Săo Paulo, para obtenção do título de Mestre em Irrigação e Drenagem.

PI RACI CABA

Estado de Săo Paulo - Brasil

Outubro - 1989 
Ficha catalográfica preparada pela Seção de Livros da Divisão de Biblioteca e Documentação - PCAP/USP

Genevicius, Alguerdo

G328a Aplicação de metodologia para determinação de es tiagens na Bacia do Rio Corumbataí, Piracicaba, 1991, $87 p$, ilus,

Diss,(Mestre) - ESALQ

Bibliografia.

1. Estiagem - Determinação-Bacia do Rio Corumbataí 2. Estiagem - Determinação - Metodologia 3, Hidrologia aplicada I, Escola Superior de Agricultura "Luiz de Queiroz", Piracicaba 


\section{APLI CAÇÃO DE METODOLOGIA PARA DETERMINAÇÃO \\ DE ESTIAGENS NA BACIA DO RIO CORUMBATAÍ}

ALGUERDO GENEVICIUS

APROVADA EM: $11-12-89$

COMISSÃO JULGADORA:

- Prof. Dr. Rubens Scardua

ESALQ/USP

Prof. Dr. Decio Eugenio Cruciani

ESALQ/USP

Prof. Dr. Arthur Mattos

EESC/USP

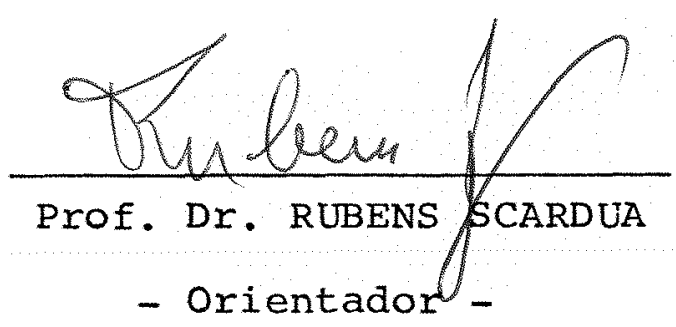


Orereço a minha esposa

Dette. aos meus

filhos Fernanda,

Ricardo e Ana Paula. 


\section{AGRADECI MENTOS}

Ao Prof. Dr. Rubens Scardua pela orientaçăo.

Ao Prof. Dr. Fernando Lordelo Olitta pela coordenação do curso.

Ao Consel ho Nacional de Pesquisa - CNPq, pela concessão da bolsa de estudo para a realização do curso.

Ao Prof. Dr. Arthur Mattos, do Departamento de Hidráalica e Saneamento da Escola de Engenharia de São Carlos da Universidade de Så Paulo pelas sugestôes e orientação.

Aos colegas do curso pela amizade.

Aos alunos Jairo Ferreira Alves e José Alberto Matioli do Centro Superior de Educaça Tecnológica - CESET da UNICAMP - Limeira, pela colaboração no serviço de processamento de dados e editoraçăo da tese.

Ao Departamento de Aguas e Energia Eletrica do Estado de Sao Paulo - DAEE, pelo fornecimento dos boletins plu e fluviometricos da bacia.

Á Companhia Energetica do Estado de São Paulo - CESP, pelo fornecimento dos boletins plu e fluviometricos da bacia. 
SUMARIO

Página

LISTA DE FIGURAS ................... vi

LISTA DE TABELAS $\ldots \ldots \ldots \ldots \ldots \ldots \ldots \ldots \ldots \ldots \ldots \ldots \ldots \ldots \ldots$

LISTA DE SIMBOLOS ................... $\quad x$

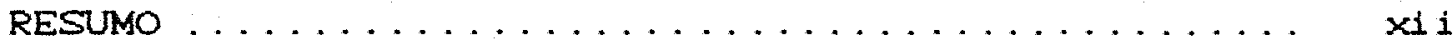

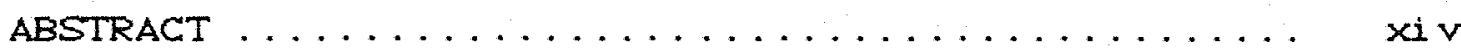

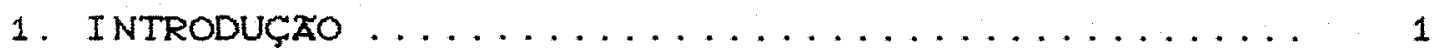

2. REVISAO BIBLI OGRAFICA .............. 5

3. METODOLOGI A ...................... 10

3. 1 Deser 1 çáo do modelo ................ 10

3. Z Determinação de tsc ................ 14

3. 3 Determinaçăo de $Q_{0}$ et $\ldots \ldots \ldots \ldots \ldots \ldots$

3. 4 Determi nação de $a \ldots \ldots \ldots \ldots \ldots \ldots \ldots . \ldots \ldots$

4. BACIA DO RIO CORUMBATAI ............. 18

4.1 Localização e sistema de drenagem ....... 18

4. 2 Caracteristicas físicas da bacia ....... 22

4. 3 Aptidao agricola das terras da bacia ..... 23

4.4 Geologia .................... 24

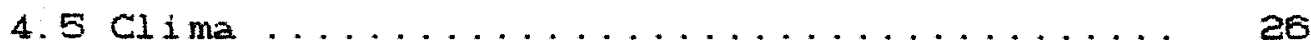


4.6 Pluviometria ................. 27

4.7 Fluviometria $\ldots \ldots \ldots 30$

5. RESULTADOS ........................ 60

6. CONCLUSOES ...................... 83

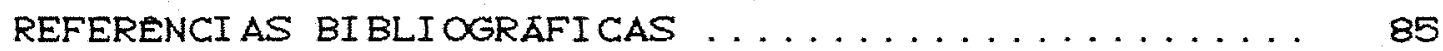




\section{LISTAS DE FIGURAS}

Figura 3.1 Tangente inferior.

Figura 4.1.1 Bacia do Rio Corumbatal - Sistema de drenagem.

Figura 4.1.2 Bacia do Rio Corumbatal - principals cidades.

Figura 4.6.1 Localização dos postos fluviometricos e pluviometricos na bacia do Rio Corumbatal.

Figura 4.6.2 Área de influencia dos Postos pluviometricos na Bacia do Rio Corumbatal.

Figura 5.1 Curva de freqüencia do número de dias sem chuva (tsc) - Bacia do Rio Corumbatal.

Figuras 5.2 a

5.7 Hidrograma das vazóes medias de 7 dias consecutivos - Rio Corumbatal - Fazenda Recreio.

Figura 5.8 Valores de a - Bacia do Rio Cor umbatal.

Figura 5.9 Reta de regressáo linear entre $t$ e tsc Bacia do Rio Corumbatal.

Figura 5.10 Reta de regressão 11 near entre LnQ o Fm - 
Bacia do Rio Cor umbatal.

Figura 5.11 Curva de frequéncia da precipitaçăo média antecedente - Bacia do Rio Corumbatai.

Figura 5.12 Curva de frequencia das vazbes de estiagem Bacia do Rio Cor umbatai. 


\section{LISTA DE TABELAS}

Tabela 4.1.1 Área da bacia hidrografica do Rio Corumbatal.

Tabela 4.5.1 Dados climáticos da região de Piracicaba. Representativos da bacia hidrografica do Rio Cor umbatal.

Tabela 4.6 .1

a 4.6. 21 Precipitaços medias-diárias e mensais do Rio Corumbatal - Metodo de Thiesser.

Tabelas 4.7 .1

a 4.7.6 Fluviograma anual de vazßes mélias de 7 dias consecutivos do Rio Corumbatal.

Tabela 5.1 Número de dias consecutivos sem chuva $(t s c)$ na bacia do Rio Corumbatal.

Tabela 5. 2 Frequencla do número de dias sem chuva $(t s c)$ na bacia do Rio Cor umbatal.

Tabela 5.3 Curva de depleção do Rio Corumbatai Fazenda Recreio.

Tabela 5.4 Valores de $t, t s c, Q_{0}$ e Pm para o período em que existem valores observados de $t \in Q_{0}$.

Tabela 5.5 Precipitaçăo media total antecedente de 
6 meses - Bacia do Rio Corumbatai.

Tabela 5.6 Distribuição da frequencia da precipitaçăo média antecedente - Pm - Bacia do Rio Cor umbatal. 


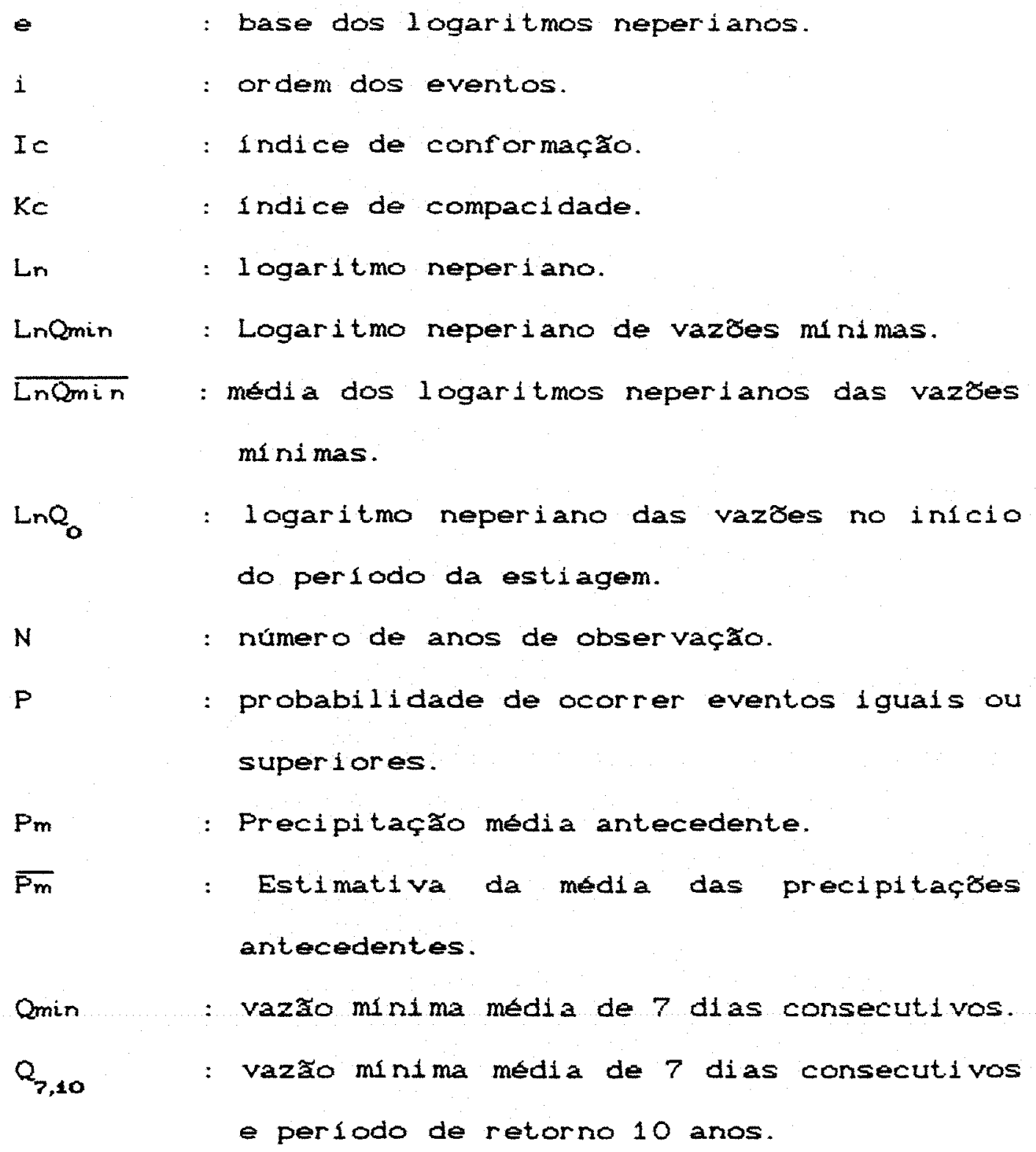




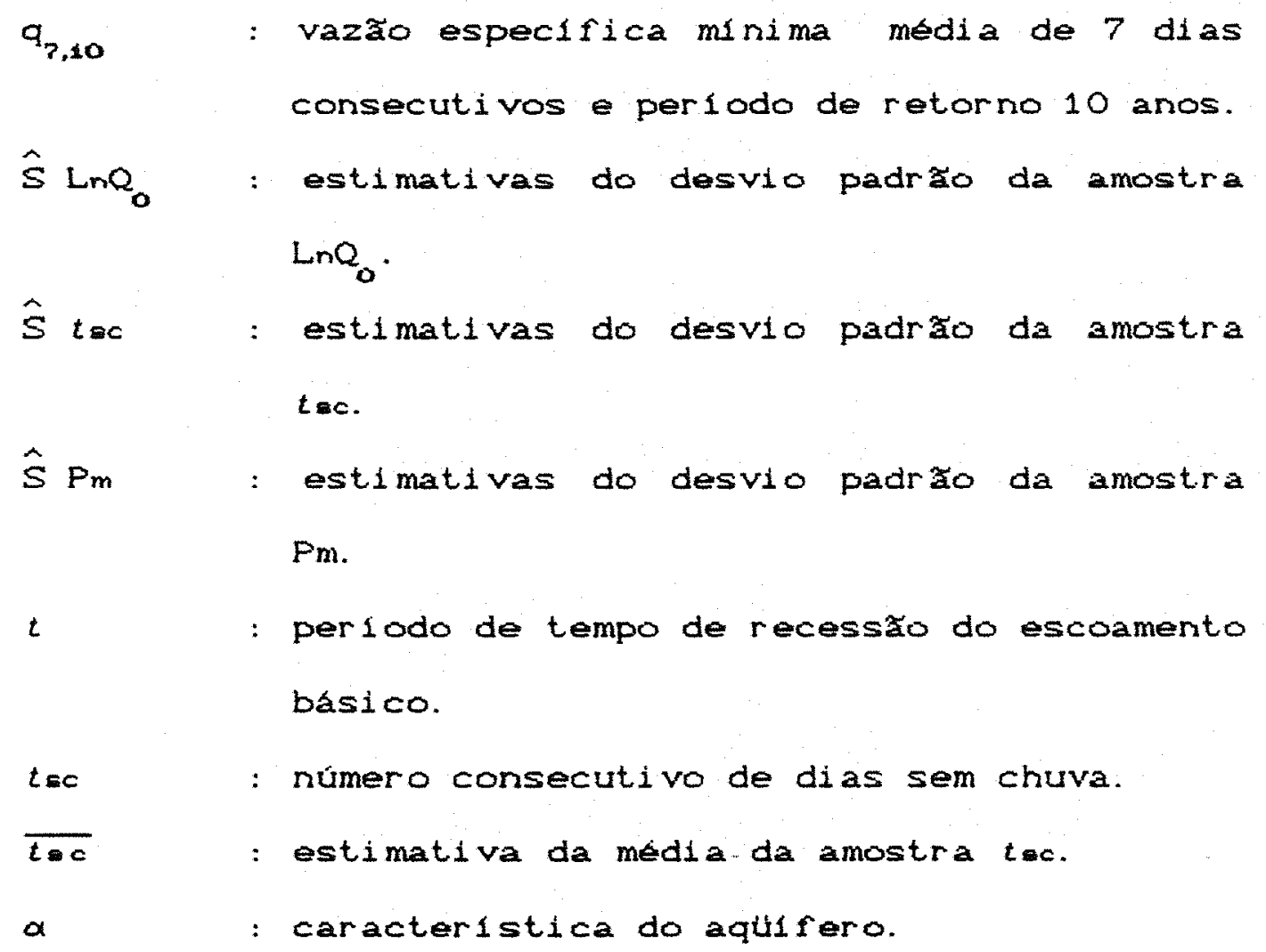


APLICAÇAO DE METODOLOGI A PARA DETERMI NAÇAO DE ESTI AGENS NA BACIA DO RIO CORUMBATAI.

\author{
Autor: ALGUERDO GENEVICIUS
}

Orientador: PROF. DR. RUBENS SCARDUA

RESUMO

Ao longo do presente trabalho aborda-se a aplicação de metodologia desenvolvida por ARTHUR MATTOS em sua tese apresentada a Escola de Engenharia de SFo Carlos da Universidade de Săo Paulo para obtenção do título de Doutor em Hidrálica e Saneamento, cuja temática abrange a previsão de estiagens em rios perenes, usando poucos dados de vazão. e longas series de precipitaçăo.

Para apli cação do metodo foi escolhido o Rio Corumbatal, afluente pela margem direlta do Rio Piracicaba, um dos principals formadores da bacia hidrografica do medio Tiete superior.

Como resultado final, o metodo permite a estimativa de vazóes minimas de estiagem caracterizadas pela sua magnitude, duração e frequencia ou periodo de retorno. 
Para essa estimativa foram utilizados dados de precipitações diarias em sete postos pluviometricos da bacia, num total de vinte e um anos de observaçres, e de dados de vazóes medias diárias na seção do rio, na fazenda Recreilo, representada pelo posto fluviometrico 4D-OZ1 operado pelo Departamento de Aguas e Energia Eletrica do Estado de Sáo Paulo - DAEE num total de sels anos de observação.

Determinou-se como resultado da aplicação da metodologia, a vazão minima media de 7 dias consecutivos e periodo de retorno de 10 anos naquela seção do rio. que representa uma bacia de drenagem de $1.648 \mathrm{~km}$. 
"DROUGHT ESTIMATION FOR THE CORUMEATAI RIVER BASIN"

Author: ALGUERDO GENEVICIUS

Adviser: PROF. DR. RUBENS SCARDUA

AESTRACT

In this work the author proposes to apply the methodology developed by ARTUR MATTOS in his doctor thesis, presented at "Escola de Engenharia de Sá Carlos da Universidade de sao Paul o", in which the author studes the prevision of drought in perennial rivers, whith small numbers of data and long series of precipitation.

For the method application was choser the Corumbatal river, tributary by the right edge of Piracicaba river, one of the most important contributor of the hydrographic basin of the medium upper Tiets.

As a final result, the method allows a minimum flow estimation of drought characterized by its magnitude, duration and frequency or return time.

For this estimation it was utilized daily precipitation data in seven pluviometric station in the 
basir., with twarty ore years ef observations, aru daily average flows in the river section, in "Fazenda Recreio", represented by the fluviometric station 4D-0e1 operated by "Departamento de Águas e Energia Elétrica do Estado de Sá Paulo - DAEE" in a total of six years observations.

It was determined as a result of the methodology application, the minimum average flow of seven consecutive days and a return time of 10 years in that river section which represents a drainage basin of 1.648 $\mathrm{km}^{2}$. 
1. INTRODUÇXOO

Um dos aspectos fundamentais da Hidrologia Aplicada são as previsóes de eventos extremos com determinada probabilidade de ocorrencia, traduzidas pelo risco desses eventos serem igualados ou superados, ou de ocorrer em valores iguais ou menores a esses eventos num ano qualquer. A esse risco associado o periodo de retorno dos eventos.

- estabelecimento dessas previsźes $\Leftrightarrow$ suporte fundamental de diversas obras importantes no campo da engenharia, sem as quais, ou se inadequadamente formuladas, resultarão em aspectos negativos no desenvol vimento dos diferentes projetos.

Considera-se de grande interesse no campo da engenharla de recursos hidricos, a previsão das vazóes máximas de cheias dos cursos d'água, sem a qual. os projetos relativos a ocupação e aproveitamento de várzeas seriam conduzidos de manetra inadequada, porquanto o estabelecimento de cotas dos diques de proteção seriam feitos de modo inseguro; particularmente nos projetos de 
irrigação, inadimissivel a omissão de estudos detal hados do manancial abastecedor quanto aos aspectos relativos aos valores criticos de estiagens cuja magnitude, duração e frequencia de ocorréncia não previstas poderão acarretar graves prejuizos aos empreendimentos dessa natureza.

Com relaçăo às "previşres de cheias", que podem comprometer obras hidraulicas, inclusive obras destinadas a drenagem de terras para uso agricola. no decorrer da história da cléncia hidrologica, muitos métodos foram desenvolvidos, que vão desde metodos puramente estocasticos, até metodos puramente empiricos, passando por metodos estatisticos e semi-empiricos.

A preocupação dos estudiosos, desde os tempos mais remotos, tendeu mais para o campo dirigido a previsão das chelas; 1 sto ate parece logico, tendo em vista que as inundaçzes provenientes dessas cheias, sempre ocorreram, e, com relação a prejuizos foram ate preponderantes quando comparáveis às grandes secas. periodo no qual se leva em conta o equilibrio do trinomio: qualidade, quantidade e demanda de agua.

Atualmente, a demanda de agua aumenta, face ao desenvol vimento e processo de crescimento acelerado dos paises; sua qualidade, cada vez mais, fica comprometida. sendo relegada a um segundo plano. dando prioridade aos crescimentos industrial agricola; sua quantidade 
permanece constante. Em vista disso os estudos de estiagem. nos quais o controle da disponibilidade da agua ao longo do tempo se baseara, passaram a ter na atualidade importancia primordial, procurando-se preve-los na sua magnitude e extensão no tempo, aliados a quantificação da probabilidade da sua ocorrencia, a fim de tornarem os projetos mais seguros.

Nos rios perenes, o estudo das vazöes de estiagem passa, portanto, a ser de suma 1 mportancia, e seus resultados năo so definirão as formas como as aguas poderão ser captadas (fio d'agua ou reservação) bem como indicarão as possibilidades de regularizaçóses atraves de barramento para diferentes usos, inclusive na irrigaçăo.

No Brasil, registradores de precipitaçð̃es intensas (pluviografos) para uso em projetos que envolvem vazbes de cheias para previsaes em pequenas bacias hidrograficas são raros. Mais rara ainda a existencia de seçres hidrométricas em pontos de cursos d'água que drenam bacias, princlpalmente as pequenas bacias, cuja amplitude de vazßo (diferenças entre maximas e minimas) chega, muitas vezes, a dezenas ou centenas. Mesmo nas grandes bacias, principalmente no nosso estado onde sao feitas medidas sistematicas de vazres, as series histól las disponivels năo são tão representativas; por outro lado, longas series historicas de precipitaçరes registradas em pluviómetros são 
abundantes; mesmo assim e possivel, muitas vezes, para uma dada seção de um curso d'agua que drena uma bacia hidrografica, contarmos com poucos dados de medidas de vazão (4, 5. 6 anos) e longas series de precipitaçăo registradas por pluviometros que representam a bacia.

o objetivo desse trabalho $e$ o de aplicar metodologia para previsóes de estiagem em rios perenes, atraves do uso de poucos dados de vazão e longas séries de precipitação, metodologia essa apresentada em Tese de Doutoramento na Escola de Engenharia de Sto Carlos da Universidade de Sä Paulo pelo professor Arthur Mattos. 
2. REVI SAO BI BLI OGRAFI CA

Procurou-se verificar na literatura os principais metodos relacionados com o objetivo deste trabalho, incluindo não so os utilizados para a determinação da curva de frequencia das vazóes minimas quando se dispore de longas ou curtas series historicas de vazőes observadas, bem como quando não existe dado nenhum, cujo estudo se traduz na regionalizaçăo, ou seja, na transferencia da informaçăo atraves de dados da regiăo. para a bacia em estudo.

Na decada de 60 o Geological Survey desenvol veu um estudo de estimativa de escoamento minimo a partir de caracteristicas climato-fisiograficas nos Estados Unidos e encontrou erros padraes de estimativa superiores a $100 \%$ na maioria das bacias analizadas - RICGS (16), em 1973 .

FRYE $P$ RUNNER (10), em 1970, analisando as vazres minimas de 7 dias consecutivos e periodo de retorno de 10 anos no Rio Ohio, concluíram que as caracteristicas do escoamento minimo em seç̋̃es sem dados não podem ser 
determinadas com precisão por regressão.

WRI GHT (17), em 1970, apresentou uma equaçăo de avaliação das medias das vazóos minimas usando a declividade e a área da bacia como variavels independentes. O erro resultante foi associado a indices geologicos.

RIGGS (16), em 1973, sugere que sejam realizadas algumas mediçôes na seçăo sem dados em um periodo de vazóes minimas. As vazóes medidas săo relacionadas as frequencias das vazóes observadas simultaneamerte em postos vizinhos que tenham curva de frequencia definida. Os pontos da curva de frequencia conhecida são transferidos para a seçăo desejada atraves da relação obtida. CARTER e PUTNAM (O1), em 1977, obtiveram relaçôes desse tipo para 102 seçóes da Georgia.

CHANG e BOYER (O4), em 1977, relacionaram a vazão minima de 7 dias, periodo de retorno 10 anos, com o perímetro da bacia, comprimento do canal, fator de forma da bacia e fatores climaticos que descrevem a temperatura de setembro, e o número de dias sem chuva para regibes montanhosas e úmidas. O erro padrăo de regressão obtido foi de cerca de $30 \%$ da media.

- INSTITUTE OF HYDROLOSY (11), em 1980 . desenvolveu um estudo regional de vazão minima para a Inglaterra. O estudo compreendeu a regionalização dos parametros de vazão com $95 \%$ de permanéncla obtidos na curva 
de duração de 10 dias, e média das vazöes minimas para duraçăo de 10 dias. O estudo visou estabelecer a curva de duraçăo e a curva de frequencia para postos sem dados.

LANNA ET ALLI (12), em 1983, estabeleceram curvas adimensionais de frequencia para trés regiöes da bacia do rio Jacul. O fator de adimensionalização é a média das vazós minimas com duração $t$. Esta variavel foi correlacionada atraves de regressão multipla linear com a area da bacia, a densidade de drenagem a duração. Essas relaçőes permitem a determinação da vazão minima com uma determinada duração, para uma bacia sem dados.

RAMOS (15), em 1973, determinou una formula relacionando vazăo de estiagem de 30 dias, com periodo de retorno de 2 anos com a precipitação media anual.

UERARA (18), em 1979, para diversos rios do Estado de sao Paulo, aplicou as distribuiçóes de Galton-Gibrat, Gumbel, Log Gumbel, Gumbel Limitada, Log Pearson tipo III e Log-Normal para determinar a que melhor se ajustava a cada região do Estado.

DEPARTAMENTO DE AGUAS E ENERGI A ELETRICA DO ESTADO DE SAO PAULO (O5), em 1981, fornece elementos que possibilitam a quantificação dos recursos hidricos superficiais em pequenas bacias hidrograficas, onde năo se dispre de observaçres fluviometricas ou o periodo de observaçóes e tão pequeno que impossibilite um estudo 
estatistico das vazres minimas.

CETESB, COMPANHIA DE TECNOLOGIA DE SANEAMENTO AMBIENTAL COPs, em 1981, aborda no estudo de avaliação regional de disponibilidades hidricas, duas questzes consideradas fundamentais. A primelra refere-se a avaliação da disponibilidade hídrica média numa dada bacia, a partir da precipitação media anual; a segunda questão consiste na estimativa dos volumes de armazenamento, necessarios para assegurar descargas regularizadas, em condiçós pré-estabelecidas de garantia.

CETESB, COMPANHIA DE TECNOLOGIA DE SANEAMENTO AMBIENTAL (O3), em 1981, em estudo regional de regularização de descargas, apresenta um método de obtençăo de parámetros hidrológicos regionalizados para estimativa de descargas regularizavels em funçáo dos volumes uteis de armazenamento necessarios. considerando-se uma regularização amual. Permite tambem a estimativa dos defluvios medios de " $t$ " meses consecutivos minimos anuais com determinado periodo de retorno, utels para aproveltamento a flo d'agua.

DEPARTAMENTO DE AGUAS E ENERGIA ELETRICA DO ESTADO DE SAO PAULO (OB), em 1986, determina a regressão entre a precipitaçăo media multianual no periodo em que existem dados de vazão e a descarga media observada. Determinadas as retas de regressáo, e possivel, para uma 
determinada area de drenagem, calcular a chuva media atraves do mapa de Isoietas a a respectiva vazăo media, e dal a vazão minima media de 7 dias consecutivos e 10 anos de periodo de retorno.

DEPARTAMENTO DE AGUAS E ENERGIA ELETRICA DO ESTADO DE SAO PAULO CO73, em 1988, apresenta estudos que tem tem por finalidade estimar para pequenas bacias no Estado de Sáo Paulo, as seguintes variáveis hidrologicas: descarga media de longo periodo, vazão $\mathrm{minima} \mathrm{em} \mathrm{função} \mathrm{do}$ periodo de retorno, curva de permanencia e volume de regularizaçăo intra-anual para uma dada vazăo firme, e com determi nado risco de não atendi mento em um ano qual quer.

MATTOS (13), em 1982, desenvolve, a partir da equação de Boussinesq e com o uso de poucos dados de vazão e muitos dados de precipitação, metodologia para previsão de estiagens, testando-a para a Bacia do Rio Piracicaba, e, aplicando-a para a Bacia do Rio Jacare-Guanú, ambas no Estado de Sao Paulo. 
3. A METODOLOGIA

$$
\text { De forma sintetizada faremos as }
$$

consideraçōes sobre o modelo matemático cbaseado na equação da curva de recessão do escoamento básico proposto por BOUSSINESQ em 18773, descrito por A. MATTOS, no desenvolvimento da sua metodologia para previsão de estiagem em rios perenes com poucos dados de vazão e muitos dados de precipitação. metodologia esta, que neste trabalho. foi aplicada ao Rio Corumbatal conforme o objetivo descrito.

3.1 Deserição do modelo

A equação de Boussinesq pode ser expressa por:

$$
\begin{gathered}
Q=Q_{0} \cdot e^{-a \cdot t}(3.1) \text { sendo: } \\
Q \in \text { a vazáo em } \mathrm{m}^{3} / \mathrm{s} \text { no fim de } t \text { dias apos o }
\end{gathered}
$$

termino do escoamento superficial;

$Q_{0} \Leftrightarrow$ a vazão no instante em que cessa o escoamento superficial;

e a base dos logaritmos neperianos; 
a uma constante caracteristica particular do aquifero que pode ser determinada com poucas observaçós fluviometricas;

$t e$ o periodo de estiagem considerado.

Entzo a equação de Boussinesq permite determinar a vazão minima que o curso d'agua atingira no final de um periodo de estiagen de $t$ dias, tempo este correlacionado com o periodo de tempo sem recarga do lencol que coincide com o periodo de tempo sem chuva, quando se considera, que as recargas do lençol freatico de uma bacia hidrografica são as precipitaçóes que ocorrem sobre ela.

A depleção do escoamento básico ocorrendo de forma lenta e gradativa, justifica que observaçbes diárias são suficientes para a analise do problema, sendo portanto utilizado o dia como unidade de contagem do tempo. Desta forma considerou-se o período de tempo sem chuva, como o numero de dias sem chuva $\left(t_{s c}\right)$, definindo-o como a sequéncia máxima de dias em que a precipitação é inferior a um limite preffixado, estabelecendo como 1 imite, precipitaç̧es diarias de $10 \mathrm{~mm}$, considerando portanto como dias sem chuva, as precipitaços iguais ou inferiores a esse 1 imite; a ausencia dessas precipitaç̧es, sendo a máxima anual csequencia máxima de dias sem chuva que ocorre em cada anos, a vazão correspondente do curso d'agua será a 
vazão minima no fim da estiagem, sendo representada pela equação:

$$
Q=Q_{0} \cdot e^{-\alpha \cdot t=0}
$$

onde 'se devera possuir longa serie historica de observaçöes para permitir a determinação da sua curva de frequencia, normalmente distribuidas, com media e desvio padrăo esti mados por:

$$
\begin{aligned}
& t_{s c}=\frac{1}{N} \cdot \sum_{i=1}^{N} \cdot t_{s c i} \\
& \hat{S}_{t \Omega c}=\left[\frac{1}{N-1} \cdot \sum_{i=1}^{N}\left(t_{s c i}-\bar{t}_{s c}\right)^{2}\right]^{1 / 2} \quad(3.4)
\end{aligned}
$$

A curva de frequencia do número de dias sem chuva representa a curva de frequencia da estiagem e permite determinar a duração da seca esperada para um dado periodo de retorno.

o ponto inicial para a contagem do periodo de recessáo, e para a determinação da vazáo inicial $Q_{0}$ se obtém correlacionando a vazão $Q_{0}$ com as precipitaçós antecedentes. No fím da estaçăo das chuvas, a vazão registrada na hidrografa e devida exclusivamente à agua subterranea, e neste instante. o nivel do lençol subterraneo estara na sua altura máxima. Sendo este nivel consequencia das chuvas antecedentes ocorridas na bacia durante a estação chuvosa, pode-se afirmar que a vazáo que 
marca o infcio do periodo de recessão função dessas chuvas antecedentes.

Sendo $P_{m}$ as precipitaçßes mensais antecedentes então tem-se:

$$
\begin{aligned}
Q=P_{m} e^{-\alpha . t s c} & \text { (3.5) } \\
& \text { A curva de frequencia de } P_{m} \text { e facilmente }
\end{aligned}
$$
determinada, considerando-se que longas series historicas de precipitação săo quase sempre disponi veis.

A equação (3.5) pode ser escrita:

$$
L_{n} Q=L_{n} \cdot P_{m}-\alpha \cdot t=c \text { (3.6), sendo }
$$

que o termo $L_{n} P_{m}$ se ajusta a uma distribuiça normal cuja media e desvio padráo podem ser estimadas por:

$$
\begin{aligned}
& \bar{P}_{m}=\frac{1}{N} \cdot \sum_{i=1}^{N} \cdot L_{n} \cdot P_{m i} \quad(3.7) e \\
& \hat{S}_{p m}=\left[\frac{1}{N-1} \cdot \sum_{i=1}^{N} \cdot\left(L_{n} \cdot P_{m i}-\bar{P}_{m}\right)^{2}\right] 2(3.8)
\end{aligned}
$$

Sendo na equação (3.6) $L_{n} Q$, a diferença entre duas variavels aleatorias normais e independentes, entao $L_{n} Q=L_{n}$ Qmin tambem normalmente distribuldo com media e desvio padrão dados atraves das estimativas:

$$
\overline{L_{n} Q m i n}=\overline{P_{m}}-\alpha \cdot \bar{t}=c
$$

$$
e
$$




$$
\Xi_{\mathrm{LnO}}=\left[{\overline{s_{p m}}}^{2}-\alpha^{2} \cdot{\overline{s_{t s c}}}^{e}\right]^{1} \mathrm{e} \text { c3.10) }
$$

As equaçoses $(3.9)$ e 3.10$)$ permitem a construção da curva de firequencia das vazóes minimas que o curso d'água atinge no fim da estiagem, definindo portanto essa curva, a magnitude da seca esperada.

A determinação e análise das curvas de frequenci da duração e da magnitude das secas requeren a existencia de longas series de dados de precipitacáa diaria e alguns anos de observaçós diarias de vazăo.

No nosso estudo foram selecionados 21 anos de observaçóes de precipitaçöes diárias na bacia do Rio Corumbatal, e 6 anos de observaçóes diárias de vazão nesse rio, na Fazenda Recrelo, posto fluviometrico 4D-oel, operado pelo Departamento de Águas e Energia Eletrica do Estado de São Paulo.

\subsection{Determinação de tsc}

O numero consecutivo de dias sem chuva (tsc) fol obtido partindo-se da determinação da precipitaçăo media diaria na bacia para cada ano considerado ctotal de 21 anos aplicando-se o Metodo de Iniessen, para os 7 postos fluviometricos, que com suas áreas de influência representam as precipitaçoes na bacia. 
3. 3 Determinaçao de $Q_{0} e t$

A determinaçáo de $Q_{0}$ e $t$ para cada ano de observação fol felta utilizando-se os dados de vazbes diárias da serie historica disponível ao longo de cada ano. Frequentemente é utilizada a vazão média. minima de 7 dias de duração ( 7 dias consecutivos) e 10 anos de periodo de retorno. A determinaçăo dessa vazão foi o objetivo do nosso trabalho, procedendo-se para a determinação de $Q_{0}$ e de $t$ da seguinte maneira:

- Adicionam-se os primeiros 7 dias do ano e determina-se a media entre eles: retira-se, a seguir, desta série o primeiro dia e adiciona-se o valor correspondente ao ol tavo dia. determi nando-se a média dessa segunda série. Procede-se dessa forma ate o último dia de cada ano em estudo. A menor série obtida representará a vazão minima, media de 7 dias consecuti vos.

- A partir dessa vazáo mínima, média de 7 dias consecutivos, determina-se a hidrografa anual, cujos demais valores são determi nados calculando-se as médi as de cada um dos conjuntos dos 7 dias consequentes antecedentes ao conjunto dos 7 dias que deu a media minima do ano.

- o infcio do periodo de recessão será determinado pelo ponto de contato entre uma tangente inferior traçada a partir da vazåo minima, e a hidrografa anual. Este ponto de contato corresponde 20 infcio do 
perlodo de recessão (final do escoamento superficiall e a vazao a ele associado sera a vazão $Q_{0}$.

Os hidrogramas anuais, assim obtidos. fornecerão uma serie de valores de $Q_{0}$ (serie curta) que se correlacionarão com as precipitaçбes precedentes Csoma das precipitaçßes mensais medias na bacial.

Esses hidrogramas anuais fornecerão também o tempo " $t$ " de duraçăo da recessão, que se correl acionará com - número de dias sem chuva "t $c^{\prime \prime}$.

3. 4 Determi nação de $\alpha$

Para cada ano representado pelas hidrografas. determina-se o valor de a correspondente, que coincide com o coeficiente angular da tangente inferior Crig. 3.1). As varias tangentes, correspondentes a cada ano. plotadas num papel semi-logaritmico e deslocadas em relação ao ei xo dos tempos até que tendam a combinarem-se. determinarăo uma tangente única que as represente, como uma linha media. O coeficiente angular dessa tangente media será a caracteristica " $\alpha$ " constante do lençol subterraneo. 


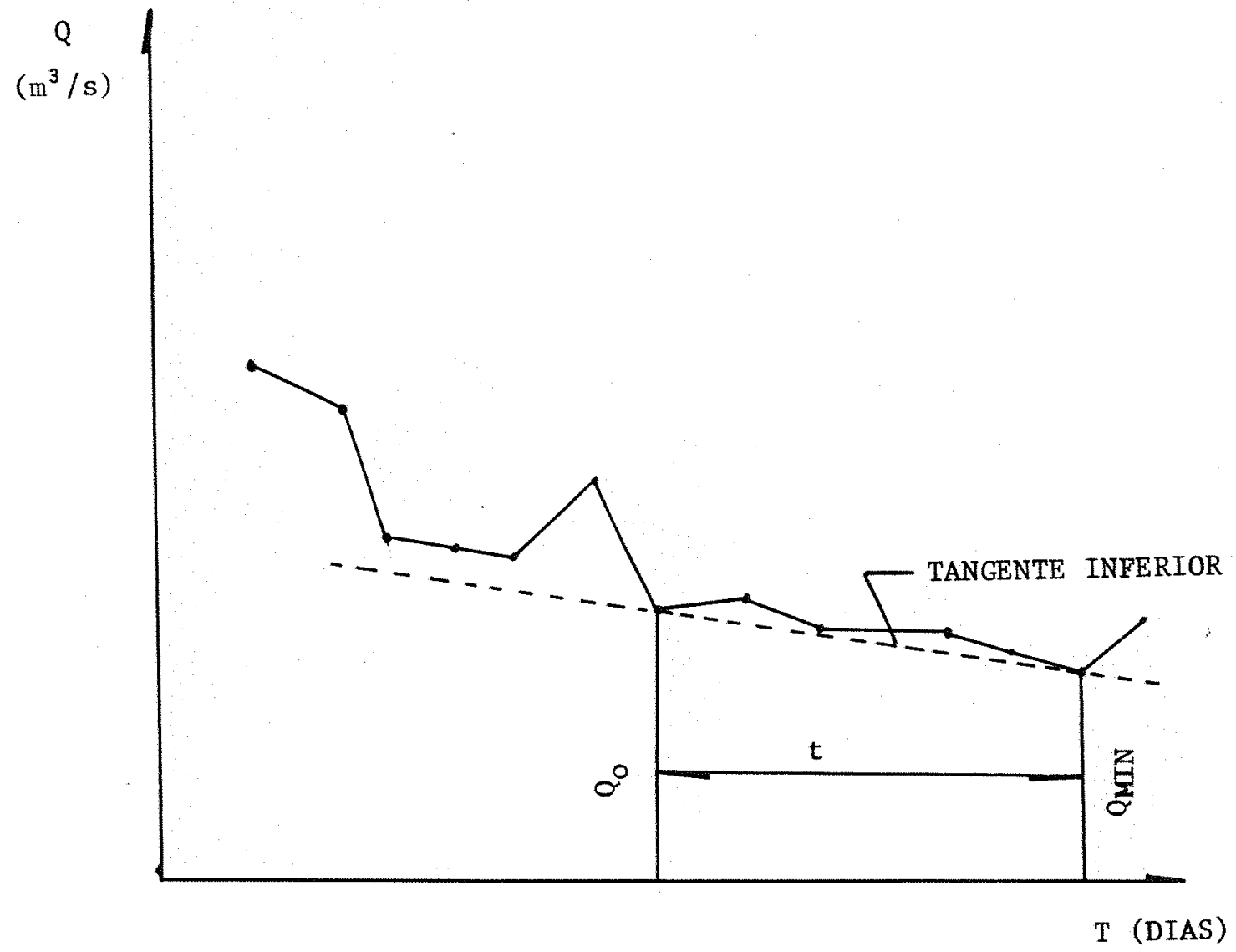

FIG. 3.1 - TANGENTE INFERIOR 
4. BACIA DO RIO CORUMBATAI

4.1 Localizaçăo e sistema de drenagem

O Rio Cor umbatai tem suas nascentes situadas na regiăo do municipio de Analandia, desenvolvendo-se a partir dal em direção ao Rio Piracicaba, do qual e afluente pela sua margem direlta, onde desemboca em Santa Terezimha, importante distrito da cidade de Piracicaba. Constitui portanto, juntamente com os rios Camanducaia, Jaguari e Atibaia, principais formadores do Rio firacicaba, um 1 mportante sistema de drenagem do medio Tiete superior.

Tem como principais afluentes os ribeirbes Claro, da Jacutinga, Agua Vermelha e os rios da Cabeça e Passa Cinco (fig. 4.1.1), este constituindo-se, segundo estudos recentemente realizados pelo Departamento de Águas e Energia Eletrica do Estado de São Paulo - DAEE, em futuro manaricial abastecedor da cidade de Piracicaba, que hoje utiliza o Rio Corumbatai para captação de parte de sua demanda para uso urbano.

De sua bacia fazem parte as cidades de Analandia, Corumbatal, Rio Claro, Santa Gertrudes e outros 


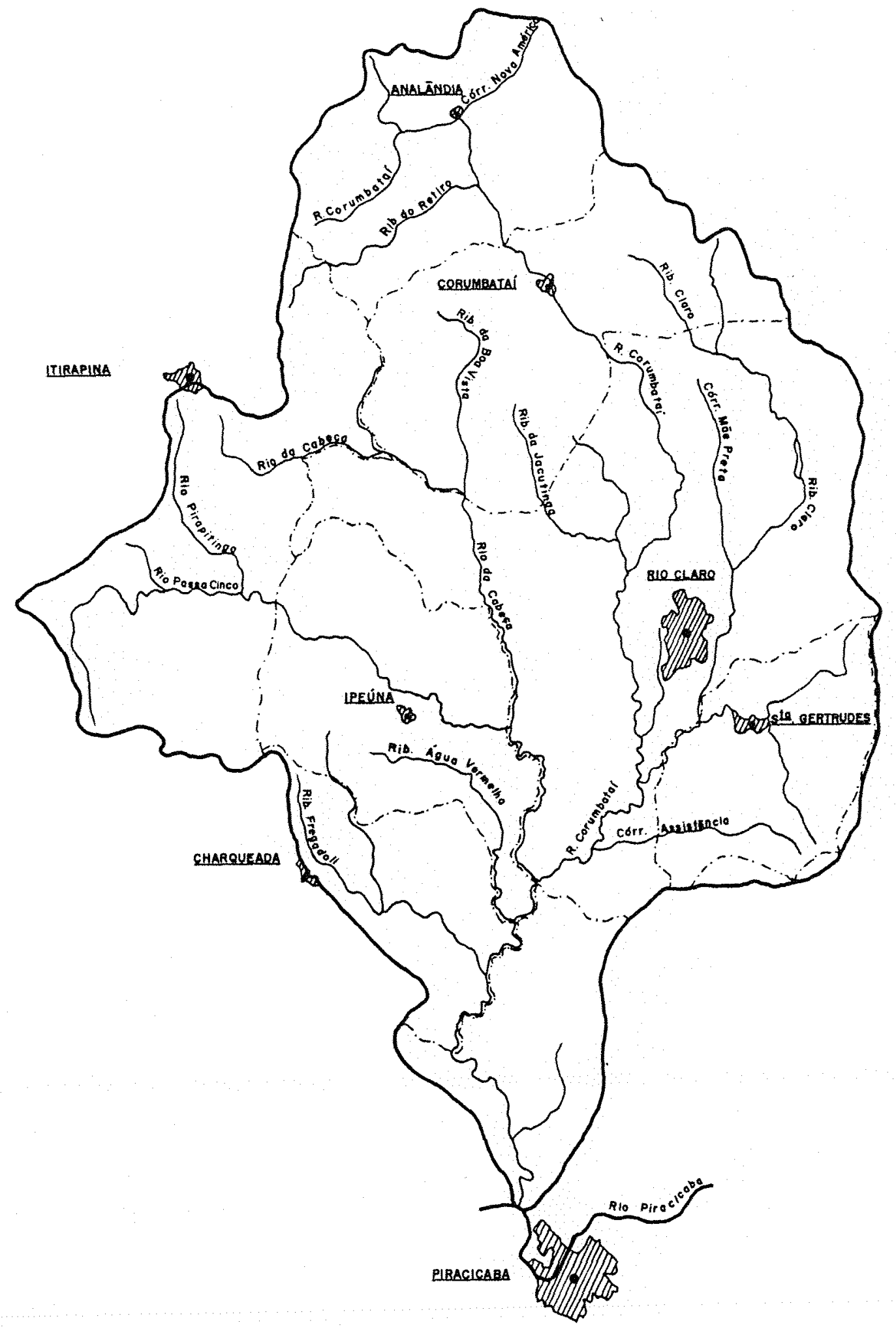

FIG. 4.1.1 - BACIA DO RIO CORUMBATAT SISTEMA DE DRENAGEM 


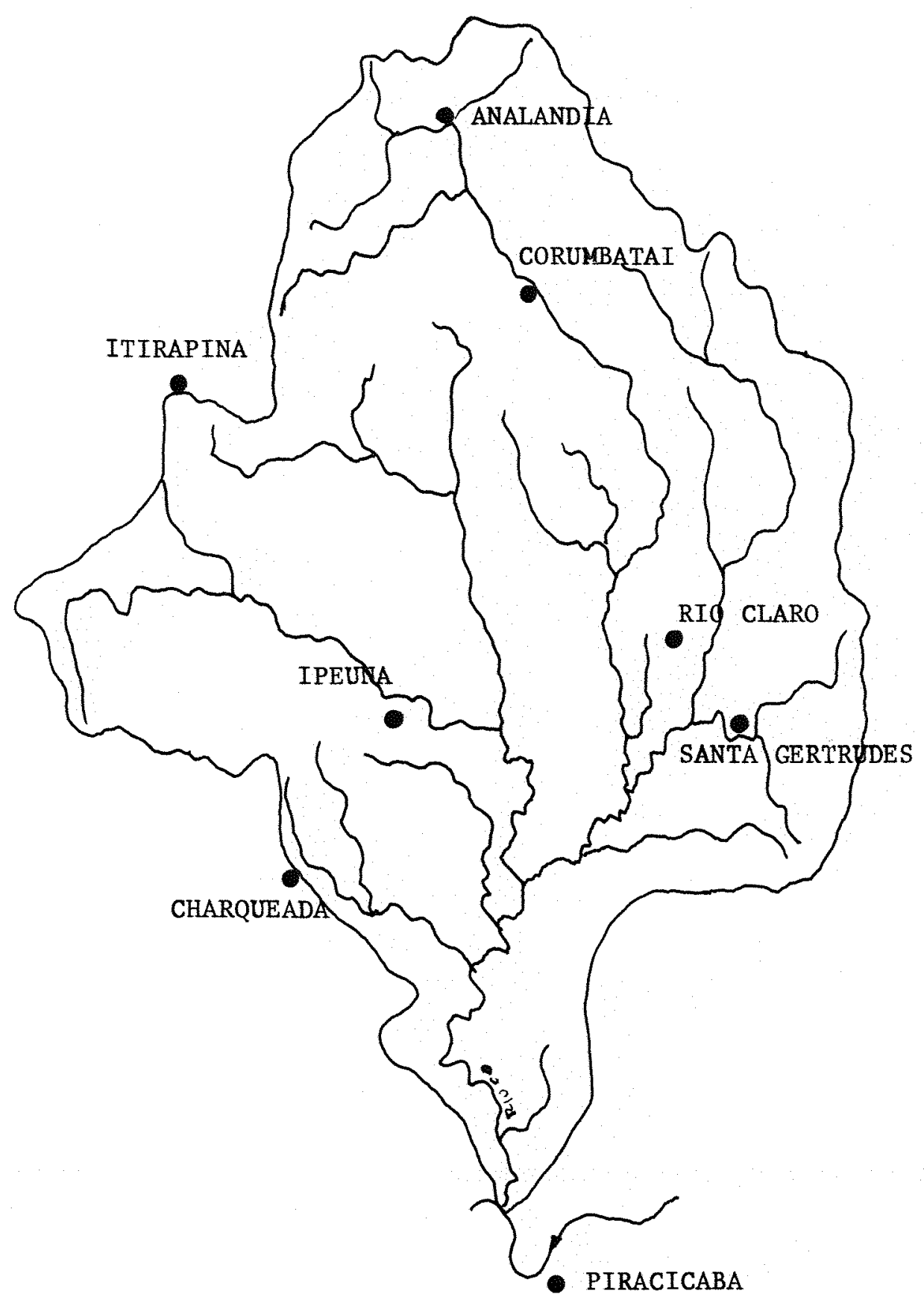

FIG. 4.1.2 - BACIA DO RIO CORUMBATAI PRINCIPAIS CIDADES 
municipios de menor porte Cfig.4.1.23. Parte de sua bacia constitui tambem "Area de Proteçäo Ambiental" do Estado de Sa Paulo - APA.

Situa-se entre os paralelos de $22^{\circ} 00^{\circ} e$ $22^{\circ} 45^{\circ}$ de latitude Sul e os meridianos de $47^{\circ} 45^{\prime}$ e $47^{\circ} 30^{\circ}$ de longitude Deste.

A srea de sua bacia hidrografica e de $1.500 \mathrm{~km}^{2}$, determinada em mapas do IBGE, escal a 1.50.000, estando 1 ndicados e 1 dentificados na tabela (4.1.1).

Tabela 4.1.1 - Area da bacia hidrografica do Rio Cor umbatai

\begin{tabular}{|c|c|}
\hline TRECHO OU SUB-BACIA & AREA $\left(\mathrm{km}^{2}\right)$ \\
\hline 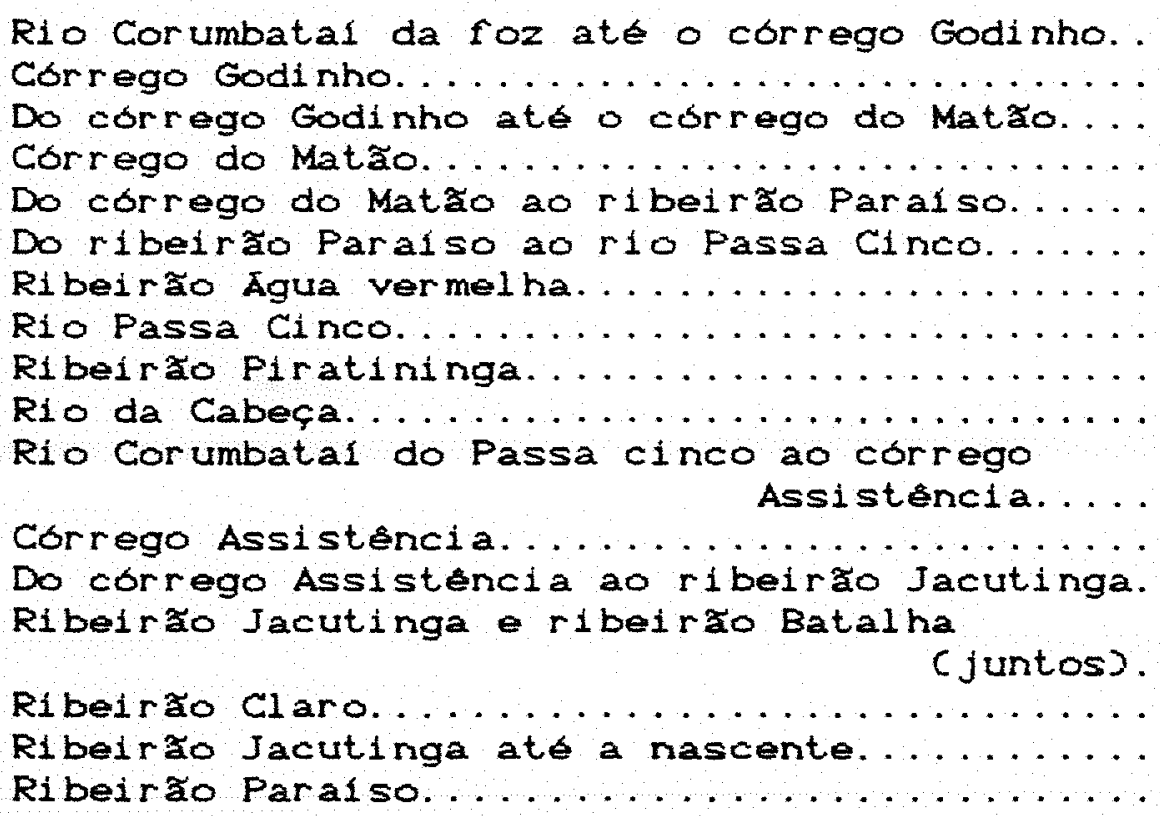 & $\begin{array}{r}12,00 \\
21,30 \\
34,80 \\
26,20 \\
34,40 \\
19,30 \\
53,80 \\
263,40 \\
41,50 \\
214,30 \\
10,00 \\
48,80 \\
148,30 \\
56,40 \\
284,70 \\
391,80 \\
89,00\end{array}$ \\
\hline Area total & $1750 \mathrm{~km}^{2}$ \\
\hline
\end{tabular}


o Rio Cor umbatal, com area de drenagem ate o local de estudo de $1.648 \mathrm{~km}^{2}$, definida pela Fazenda Recreio, posto fluviometrico 4D-021 do Departamento de Aguas e Energia Eletrica do Estado de Sro Paulo - DAEE, tem altitude maxima de $1.058 \mathrm{~m}$ ra Serra do Cuscuzeiro e $510 \mathrm{~m}$ aproximadamente naquel a fazenda.

4. Z Caracteristicas fislcas da bacia

As caracteristicas fisicas principais da bacla do Rlo Cor umbatal são representadas por:

1. Area de drenagem:

Ate sua foz no Rio Piracicaba......... $1.750 \mathrm{~km}^{2}$ Ate 0 local de Estudo (Fazenda Recreio) ... $\cong 1.648 \mathrm{~km}^{2}$ 2. Altitude:

Altitude $\max \operatorname{ma} \ldots \ldots \ldots \ldots \ldots \ldots \ldots .058 \mathrm{~m}$.

Altitude no local de estudo (Fazenda Recreio). .510 m. Altitude $\mathrm{minl} m \mathrm{a}$ (Foz)...............5500 m.

3. Outras caracteristicas 1 mportantes:

Por se constituirem indicadores comparativos 1 mportantes com respeito a indicaçăo de malor ou menor potenclalidade de picos de cheias elevadas, foram definidos os Indices de Conformação "Ic" e de Compacidade "Kc". traduzidos, respectivamente. como a relaçäo eritre a area da bacla hidrografica e o quadrado do seu comprimento axial 
(IC), e, a relaçzo entre o perimetro da bacia hidrografica e a circunferencia de circulo de area igual a area da bacia (Kc).

Esses Indices, em termos quantitativos, e desde que outros fatores interferentes inexistam, indicam maior potencialidade na produçáo de plcos de chelas elevadas, com o crescer de Ic e o decrescer de $\mathrm{Kc}$.

Os valores determi nados foram:

Indice de Conformaça CICJ...............26

Indice de Compaci dade $(k C) \ldots \ldots \ldots \ldots \ldots . . \ldots \ldots$

4. 3 Aptidáo agricola das terras da bacia

Em "Aptidao Agricola das terras de Sao Paulo" (Estudos basicos para o planejamento agricola da Secretaria Geral do Ministerio da Agricultura - SUPLAN, na maior parte a aptidão enquadrada como regular no nivel de manejo " $B$ ", baseado em praticas agricolas que refletem um nivel tecnologico medio. Caracteriza -se esse nivel, pela aplicação modesta de capital e de resultados de pesquisa de manejos, melhoramentos e conservaça das condiçós do solo - das lavouras. As praticas agricolas está condicionadas principalmente, ao trabal ho braçal e a tração animal.

A nivel de exigencia das terras para a aplicação de fertilizantes e corretivos classificou-se como 
"alto", ou seja, terras com altas exigencias de fertilizantes e moderada necessidade de calagem para manutença e corregáo de seu estado nutricional.

A nivel de exigéncia das terras para aplicaça de praticas conservacionistas rotulou-se de "medio a alto" onde, na exigencia media cpredomina na bacias coincide com as terras com limitaça ligeira a moder ada quanto a suscetibilidade a erosăo, necessitando de medidas intensivas para a sua conservação.

A nivel de possibllidade das terras para a mecanização, foi classificada de medio a baixo. respectivamente definidos como terras com 1 im taçăo 11 geira a moderada quanto ao uso de máquinas e 1 mplementos agricolas, ou moderada a forte, quanto ao uso desses equi pamentos.

4. 4 Geologia

4.4.1 For maçôs

Na srea da bacia ocorrem as seguintes formaç̧es geologicas da bacia sedimentar do Parana : Formação Itarare - constitue-se de um pacote espesso, com varios ambientes de formaçăo: marinhos. lacustres, fluviais, praianos, deltaicos, eolicos, etc. 
Caralteriza-se pelas eurrercias de siltites, argilitus, folhelhos, sedimentos ritmicos e diamictitos corigem glacials.

Formação Tatul - Predominantemente constituida por siltitos, subordinadamente ocorrem camadas de arenitos, calcarios e folhelhos, representando sedimentaçáo muito unifor me.

Formação Irati - Constitui-se de folhelhos pirobetuminosos, folhelhos cinzentos a roxos acinzentados. podendo apresentar cimentação calcária. As cores vermel has arroxeadas predomi nam na parte media-superior.

Rochas Intrusivas Basicas - Cassociadas a formaça Serra Gerall - corpos intrusivos, com a mesma composiçăo dos basaltos da formação Serra Geral, na forma de diques.

Aluvioes - na forma de várzea e terraços, são formados por cascalhos e arelas inconsolidadas.

\section{4.2 Geomor fologia}

Segundo a Divisão Geomorfológica do Estado de Sá Paulo (1984), a regla enquadra-se dentro da Provincia Geomorfologica denominada de Depressão Periferica - zona do medio Tiete, caracterizada pelo predominio de colinas amplas e collnas medias. Nas 
proximidades da cidade de Analandia ocorrem relevos arestiformes, associados aos arenitos da Formação Botucatu. 4.5 Cl1 ma

o clima da regiao (bacia hidrografica) e classificado de acordo com o sistema de Koeppen como Cwa. isto e. clima subtropical com uma estaçăo mais seca de inverno bem definida com temperatura do mes mais quente maior que $22^{\circ} \mathrm{C}$.

Na tabela 4.5.1 abaixo são relatados os dados climáticos de temperatura media do ar $c^{\circ} \mathrm{C}$, precipitação media mensal (mm/mes) e evaporação potencial media (mm dia) estimada pelo metodo de Penman, da estação de Piracicaba que e bem representativa da area da bacia. 
TABELA 4.5.1 - Dados climáticos da região de Piracicaba. SP. representativa da bacia hidrografica do Cor umbatal.

\begin{tabular}{|c|c|c|c|}
\hline MES & $\left(c^{\bar{x}}\right)$ & $\left(\begin{array}{c}\bar{p} \\
(m / m e=0\end{array}\right.$ & $\left(\mathrm{mm}^{\bar{E}} / \mathrm{dia}\right)$ \\
\hline JAN & 24.0 & 217 & 5.2 \\
\hline FEV & 24.7 & 183 & 5.2 \\
\hline MAR & 23.9 & 136 & 4.5 \\
\hline$A B R$ & 21.0 & 65 & 3.6 \\
\hline MAI & 17.6 & 52 & 2. 6 \\
\hline JUN & 16.8 & 46 & 2. 1 \\
\hline JUL & 17.2 & 26 & 2. 3 \\
\hline$A C O$ & 18.9 & 30 & 3.2 \\
\hline SET & 20.3 & 60 & 4.1 \\
\hline OUT & 2e. 2 & 108 & 4.7 \\
\hline NOV & 22.9 & 132 & 5.3 \\
\hline DEZ & 23.8 & 202 & 5.2 \\
\hline ANO & 21.1 & 1250 & 4.0 \\
\hline
\end{tabular}

4.6 Pluviometria

Para o estudo foram utilizados sete postos pluviometricos, distribuidos uniformemente na bacia hidrografica, operados pelo Departamento de Aguas e Energia 
Eletrica do Estado de Sáo Paulo.

A localização destes postos. com indicaçăo do respectivo codigo estăo indicados na figura $(4.6 .1)$.

Os postos escolhidos foram os seguintes:

CODI $Q O$

D4-058

$\mathrm{D} 4-043$

D4-036

$D 4-054$

D4-016

D4-012

D4-035
MUNI CI PIO

SANTA GERTRUDES

CORUMBATAI

I TI RAPINA

CHARQUEADA

RIO CLARO

RIO CLARO

ANALANDI A

A aplicação da metodologia para a determinação dos parametros pluviometricos, que definirăo conjuntamente com os fluviometricos, a estiagem no Rio Corumbatal, correspondente a seção de estudo, situada na Fazenda Recreio. implicou na determinação das precipitaçóes diarias. medias e totais mensals medias na bacia, sendo utilizado para tal. o metodo das linhas poligonais de THI ESSEM.

As áreas de influencia de cada posto utilizado estao indicadas na fig. (4.6.2) e quantificadas na mesma figura. As tabelas (4.6.1) a (4.6.21) indicam os resultados obtidos (medias diarias e totais mensais medios 


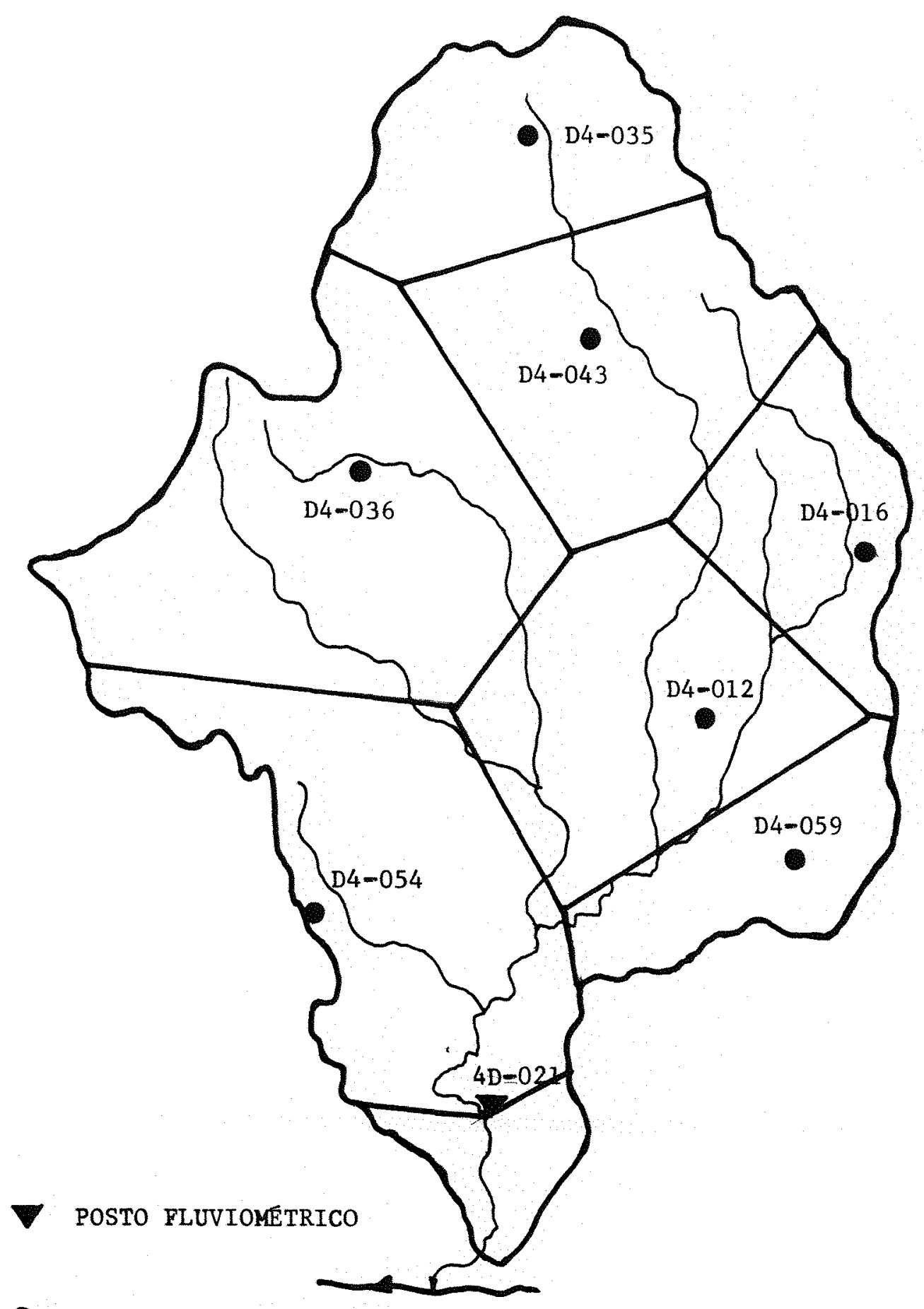

- POSTO PLUVIOMETRICO

FIC. 4.6.1 - LOCALIZAÇÃO DOS POSTOS FLUVIOMETRICO E PLUVIOMETRICOS NA BACIA DO RIO CORUMBATAI 
da aplicação do metodo de Thiessem as precipitaçóes puntuais registradas nas áreas de influencia dos sete postos considerados, no periodo de 1958 a 1978. correspondendo a vinte e um anos de observação.

4. 7 Fluviometria

Os dados de fluviometria, para a seçáo de estudo na Fazenda Recreio, correspondem as observaçoes diarias no posto 4D-OZ1 al instalado e operado pelo Departamento de Águas e Energia Elétrica do Estado de São Paulo. Esse posto fluviometrico registra as vazðas médias diarias nessa seção desde o ano de 1973, sendo utilizadas nesse trabalho, as informaç̧es a partir desse ano e ate 1978 inclusive, correspondendo portanto a sels anos de obser vação.

Com esses dados foram determinadas as vazZes medias para a duração de sete dias corsecutivos [tabelas de $(4.7 .1)$ a $(4.7 .6)]$, e para cada ano de observaça foram levantados os hidrogramas correspondentes.

Os parametros determinados a partir dos dados fluviometricos definirão conjuntamente com os dados pluviometricos, a estiagem no Rio Corumbatai, correspondente a vazós minimas medias de sete dias consecutivos. Essa estiagem, associada ao risco 


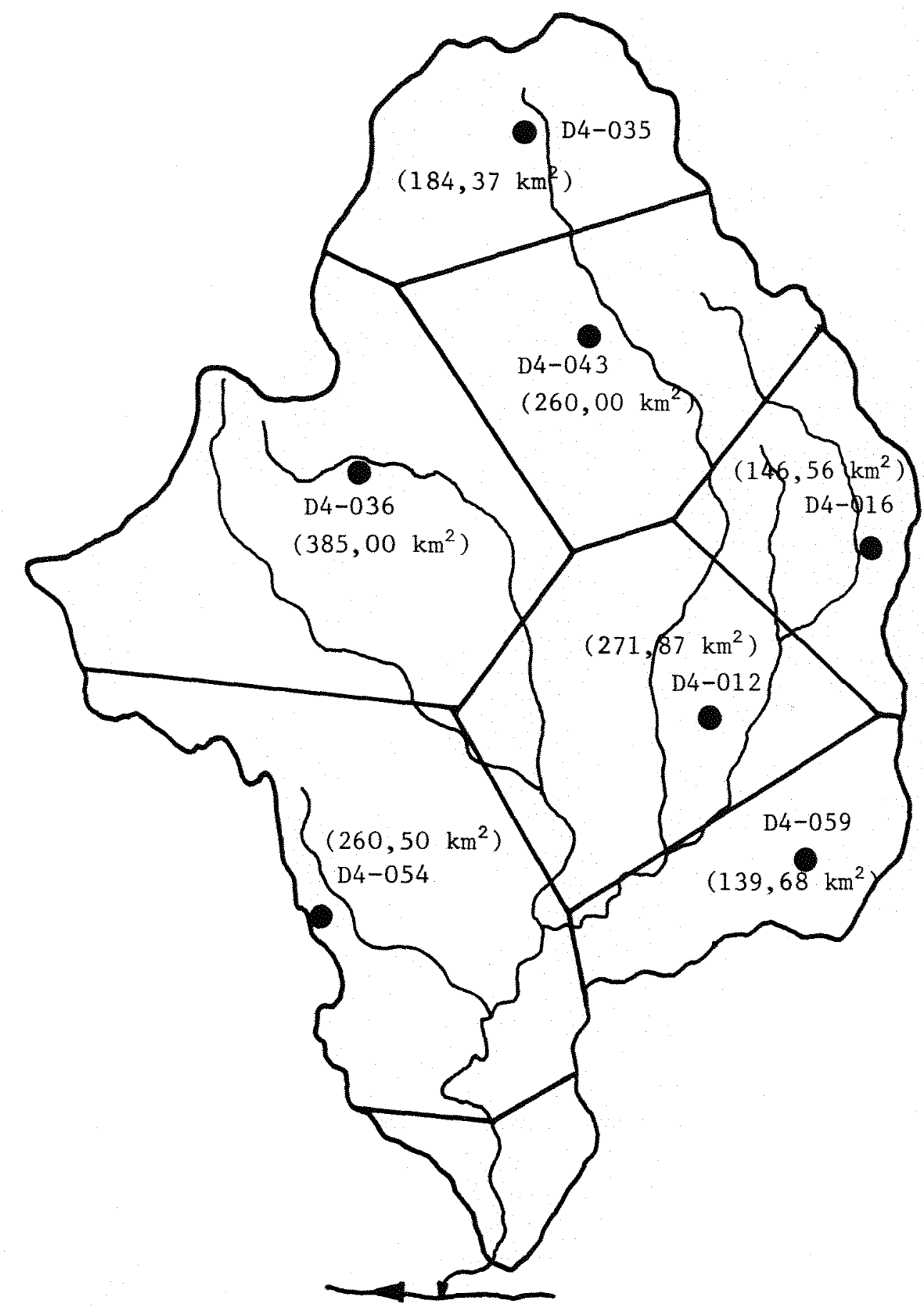

- posto pluViométrico

FIG. 4.6.2 - ĀREA DE INFLUÊNCIA DOS POSTOS PLUVIOMÉTRICOS NA BACIA DO RIO CORUMBATAI 
correspondente ao periodo de retorno de 10 anos, atende as normas e procedimentos de derivação dos recursos hidricos no Estado de Sá Paulo exigido pelo Departamento de Aguas Energia Elétrica a partir do Decreto Estadual no $23.933 / 85$. Analises para outras duraçóes da estiagem poderão ser feitas, determinando hidrogramas para periodos de interesse ao projeto como $1,10,15,30,60$ dias consecutivos usando o mesmo procedimento utilizado para o periodo de 7 dias. 


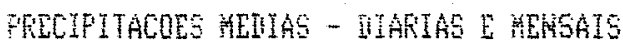

HETUM IE THISSEF
BACIA DO HIO CORUHEATAI
And : 1050

TABELA * $5.6,1$

\begin{tabular}{|c|c|c|c|c|c|c|c|c|c|c|c|c|}
\hline Iia & $\operatorname{Jan}$ & Fen & Har & Atr & Hai & Iut & jul & Ago & $5 e t$ & Gut & hou & lie $\pi$ \\
\hline : & 0.47 & 0.39 & $1: .47$ & 31.86 & 5.34 & 0.00 & 0.00 & 500 & 0.00 & 0.01 & 0.00 & 1.5 \\
\hline 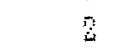 & 0.84 & 0.04 & 13.18 & 7.78 & 13.75 & 0.00 & 0,00 & 0.00 & 0.00 & 0.00 & 0,00 & 0.00 \\
\hline 3 & 0.00 & 0,53 & 4,73 & 0.00 & 13.98 & 0.00 & 0,00 & 1.68 & 0.00 & 0,00 & 0.00 & 0.00 \\
\hline 4 & 0.00 & 13.20 & $5,3 E$ & 0,00 & 25,34 & 0.00 & 0.00 & 2.87 & 0.00 & 0.00 & 1.80 & 1,18 \\
\hline 5 & 0.00 & 3.96 & 0.60 & 0.00 & 3.07 & 0.00 & 0.00 & 0.39 & 0.03 & 1.61 & 0.33 & 0,00 \\
\hline$\frac{1}{3}$ & 0.00 & 9.84 & 3.26 & 0.65 & 0.80 & 0.00 & 0.00 & 0.00 & 0,00 & 5.11 & 0.00 & 1.60 \\
\hline 7 & 0.35 & 8.15 & 22,54 & 0.00 & 0.61 & 0.00 & 0.00 & 0.00 & 2.29 & 5.29 & 3,71 & 1.85 \\
\hline 8 & 7.76 & 3.03 & 6.25 & 0.07 & 0.25 & 0.00 & 0.00 & 0.00 & 1.55 & 0.00 & 0,00 & 1,02 \\
\hline 9 & 0.00 & 3.94 & 1,65 & 5.96 & 0.75 & 0.00 & 0.09 & 0.00 & 3.06 & 4,25 & 1.14 & 0.00 \\
\hline 10 & 0.00 & 0.68 & 0.00 & 4.75 & 0.00 & 0.00 & 0.00 & 0.00 & 0.00 & 4.81 & 0.04 & 25,27 \\
\hline 11 & 3.75 & 0.00 & 0.00 & 1.33 & 0.16 & 0.00 & 0.00 & 0.00 & 0.00 & 5,84 & 0.00 & 19.20 \\
\hline 12 & 2.53 & $4 \times 54$ & 0.00 & 1.99 & $1.0 \%$ & 0,00 & 0.00 & 0,00 & 10.06 & 0.05 & 2,64 & 8.25 \\
\hline 13 & 8.74 & 4.08 & 0.00 & 12,29 & 0,00 & 11.95 & 0,00 & 0.00 & 21.72 & 3.63 & 8.46 & 7,13 \\
\hline 14 & 16.74 & 5.32 & 1.59 & 4.56 & 0.00 & 86.82 & 0,00 & 0.00 & 14.00 & 0,00 & 1.36 & 3.29 \\
\hline 15 & 17.33 & 0,45 & 1043 & 0.00 & 0.00 & 19.03 & 0,60 & 0,00 & 2.58 & 0,00 & 0.15 & 23,14 \\
\hline 16 & 15.42 & 0.00 & 10.90 & 0.00 & 4.28 & 2,03 & 0.16 & 0,00 & 0.00 & 0.00 & 0.00 & 21.19 \\
\hline 17 & 20.08 & 0.00 & 26.42 & 7.50 & 1.98 & 1.04 & 10.11 & 0.00 & 0.00 & 8.06 & 3,03 & 19.19 \\
\hline 19 & 23,33 & 0,02 & 17.74 & 8.07 & 0.00 & 2.45 & 2.12 & 0.00 & 0.00 & 3.4 & 33,44 & 13,17 \\
\hline 19 & 7.90 & 3.03 & 1.08 & 19.11 & 0.49 & 0.00 & 0.08 & 0.00 & 1.02 & 0.15 & 14.37 & 5.40 \\
\hline 20 & 1.91 & 7.27 & 0.00 & 2.45 & 1.06 & 0.00 & 0.00 & 0.00 & 1.27 & 0.66 & 4,99 & 21,54 \\
\hline 21 & $23_{n} 38$ & 7.99 & 0.00 & 0.30 & 21.53 & 0.00 & 0.00 & 0.00 & 0.00 & 1.88 & 0.88 & 28.17 \\
\hline 22 & 37.17 & 12.37 & 3.26 & 0.70 & 26.66 & 0,00 & 0.00 & 0.00 & 0.00 & 2.31 & 12.60 & 6.06 \\
\hline 23 & 27.90 & 1,06 & 0.00 & 0.00 & 8,17 & 0,00 & 0.00 & 0.00 & 1.30 & 300 & 7.80 & 0.00 \\
\hline 24 & 6.96 & 9.19 & 0.00 & 2.13 & 4.97 & 0.00 & 0.00 & 0.34 & 8.76 & 4.44 & 27.32 & 0.00 \\
\hline 55 & 13.13 & 11.40 & 1,42 & 0.04 & 5.5 & 0.00 & 0.00 & 0.00 & 5.85 & 9.53 & 12.70 & 0.57 \\
\hline 36 & 29.09 & 17.52 & 3.54 & 0.00 & 5.66 & 0.00 & 0.00 & 0.00 & 6.34 & 21.56 & 0.00 & 0.00 \\
\hline 27 & 23.73 & 17.30 & 0.00 & 0.00 & 6.48 & 0.00 & 000 & 0.00 & 0,00 & 22.81 & 0.00 & 0.00 \\
\hline 50 & 23,70 & 12,56 & 0.00 & 0,00 & $5,0 \%$ & 0.00 & 0.00 & 0.00 & 0.00 & 17.51 & $7 \times 27$ & 0.00 \\
\hline 29 & 15.23 & 0.00 & 3.67 & 0.00 & 0.00 & 0.00 & 0.00 & 3,45 & 0.00 & 3.91 & 1.40 & 0.29 \\
\hline 30 & 0.00 & 0,00 & 14.41 & 3,09 & 0.00 & 0.00 & 0.00 & 0,52 & 0.00 & 0.08 & 9.96 & 0.00 \\
\hline 31 & 0.00 & 0,00 & 41,20 & 0.00 & 0,60 & 0,00 & 0.00 & 0.00 & 0.00 & 4.36 & 0,00 & 0,00 \\
\hline & $7=\frac{8}{3} \frac{5}{1}$ & & 30 & 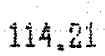 & 6.70 & 63.32 & 13.16 & 9.25 & 79.56 & $13 \% .39$ & $155_{8} 06$ & 209.06 \\
\hline
\end{tabular}


ERTOPITACOES MEITAS - UIATAS E MEHSAIS

AHO : 1959

WETEIO DE THIESEN

BACIA III TIN CONUHBATAI

TAEELA: $: 5.6 .2$

\begin{tabular}{|c|c|c|c|c|c|c|c|c|c|c|c|c|}
\hline Пì̃ & $\operatorname{Jan}$ & Fei & Mar & Ab: & hai & Jisi & $J u$ & Ago & Set & Wut & Hou & ile: \\
\hline & & & 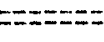 & 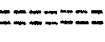 & & 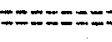 & & $z=z=:=z$ & & & & \\
\hline$\vdots$ & 1.23 & 3.52 & 0,00 & 23.00 & 0.00 & 1.91 & 0,00 & 5.95 & 0.00 & 0.00 & 1.39 & 0,00 \\
\hline 2 & 4,67 & $15 \times 35$ & 0.00 & 3,70 & 0.03 & 2.20 & 0.05 & 4.01 & 0.00 & 0.00 & 0.05 & 1.71 \\
\hline 3 & 2.89 & 7.69 & 0.00 & $0.5 \frac{5}{8}$ & 2,80 & 0,60 & 0.00 & 0.70 & 0.04 & 0.00 & 0,13 & 12,62 \\
\hline 4 & 15.39 & $\varphi_{8} 11$ & 0.20 & 0.30 & 0.99 & 0.00 & 0,00 & 0,00 & 0.07 & 0.00 & 495 & 17.79 \\
\hline$\overline{7}$ & 13.64 & 9.52 & 0.73 & 0.16 & 0.00 & 2.70 & 0,00 & $0, \infty$ & 0.0 & 0,00 & 0.03 & 2,86 \\
\hline 6 & 18,04 & 7.45 & 6.29 & 2.34 & 0.00 & 10.87 & 0,00 & 1.09 & 0,00 & 0.00 & 0.23 & 0.60 \\
\hline$\vec{i}$ & 1.00 & 4.80 & 8.06 & 0.00 & 0.00 & 0,09 & 0.00 & 1.03 & 0.00 & 0.00 & 3,67 & 1,63 \\
\hline 3 & 4.85 & 6.04 & 5.69 & 0.00 & 0.00 & 0.00 & 0.00 & 2.54 & 0.00 & 0.00 & 16.63 & 5.77 \\
\hline 9 & 10.39 & 4.00 & $8.4 \frac{49}{4}$ & 0,00 & 0.00 & 0,00 & 0.00 & 2,32 & 0.00 & 0.00 & 6.08 & 15.26 \\
\hline 11 & 8.43 & 0.00 & 0.47 & 0.00 & 0.00 & 0,00 & 0,00 & 0.00 & 0.00 & 1.91 & 7.48 & 14,87 \\
\hline 11 & 12.58 & 0.11 & 0.66 & 0,00 & 0.08 & 0.00 & 0.00 & 3.11 & 0.00 & 5.97 & 4.97 & 3,08 \\
\hline 12 & 23,04 & 0.09 & 1.61 & 0.00 & 0.42 & 0.00 & 0.00 & 14.14 & 0.09 & 13.85 & 5.36 & 0,00 \\
\hline 13 & 19.34 & 0.08 & 7.26 & 0.00 & 0.00 & 0,00 & 0,00 & $14 x 21$ & 0.00 & 30.66 & 13.37 & 3,65 \\
\hline 14 & 19.38 & 1.35 & 10.02 & 0.00 & 0.73 & 0.00 & 0.00 & 2,46 & 0.00 & 1.74 & 0.00 & 0,43 \\
\hline 15 & 13,42 & 8.54 & 3.12 & 0.00 & 0,79 & 0.00 & 0.00 & 2.40 & 0.00 & 0.45 & 0,15 & 3.81 \\
\hline 16 & 3.76 & 4.07 & 0,42 & 0.00 & 0.00 & 0.00 & 0.00 & 0,00 & 1.01 & 0.00 & 0.54 & 2.04 \\
\hline 17 & 6,5 & 25.17 & 4.12 & 0.85 & 0.00 & 0.00 & 0.00 & 0.00 & 0.00 & 0,06 & 0.05 & 7.55 \\
\hline 18 & 13.46 & 25.94 & 18.91 & 0.00 & 4.40 & 0,00 & 0,00 & 0,00 & 0.00 & 9.37 & 0.09 & 17.11 \\
\hline is & 14,13 & 10.60 & 15,15 & 0,13 & 9.30 & 0.00 & 0.00 & 0.00 & 0.00 & 9.57 & 3,25 & 15.57 \\
\hline 20 & 4.07 & 0,00 & 11.90 & 0.00 & 8.57 & 0,00 & 0.00 & 0.00 & 0.70 & 1.83 & 6.53 & 3.01 \\
\hline 21 & 0,00 & 0.76 & 15.37 & 0.34 & 2.98 & 0.00 & 0.00 & 0.00 & 0.74 & 11.00 & 7.06 & 20.25 \\
\hline 28 & 2.87 & 0.00 & 9.46 & 4.00 & 1.32 & 0.00 & 0.00 & 0.00 & 0.00 & 5.14 & 0.74 & 19.73 \\
\hline 23 & 3.10 & 0.00 & 9.55 & 13,13 & 0,00 & 0.00 & 0.00 & 0.00 & 0.00 & 0.00 & 1.16 & 4.81 \\
\hline 24 & 5.48 & 7.56 & 17.19 & 6.76 & 0.32 & 0.00 & 0.00 & 0.00 & 0.00 & 0.00 & $3 . \sqrt[43]{3}$ & 17.86 \\
\hline 25 & 11,50 & 7.00 & $5 \times 42$ & 2,94 & 0.68 & 0.00 & 0.00 & 0,00 & 1.42 & 0.34 & 13.11 & 15.80 \\
\hline 20 & 0.20 & 5.53 & 10,17 & 0.92 & 0.00 & 0.00 & 0.51 & 0.00 & 5.80 & 0.00 & 33.57 & 1,60 \\
\hline 27 & 1.17 & 7.37 & 1.65 & 1.35 & 0.00 & 0.00 & 0.00 & 0.00 & 2.18 & 0.64 & 3.63 & 0.04 \\
\hline 28 & 0,00 & 0,08 & 4.35 & 0.00 & 0,00 & 0,00 & 0.00 & 0.00 & 0.00 & 0.38 & 4.96 & 5.98 \\
\hline 29 & 0.00 & 0,00 & 0,34 & 0.00 & 1,31 & 0,00 & 0.00 & 0.00 & 0.00 & 4.60 & 8.44 & 0.41 \\
\hline 30 & 5.25 & 0.00 & 5,79 & 0.02 & 2.96 & 0.00 & 0.84 & 0,00 & 0.00 & 1.01 & 0.00 & 0.00 \\
\hline 31 & 6.58 & 0.00 & 12.74 & 0,00 & 1.24 & 0.00 & 0.90 & 0.00 & 0.00 & 1.67 & 0.00 & 0.00 \\
\hline
\end{tabular}


FRLCIFTTACOES MEITAS - DIARIAS E MENSAIS

METODO ME THIESSEH
BACIA DO RU CORUMATAI
AHL: : 1960

THEELA: 5.6 .5

\begin{tabular}{|c|c|c|c|c|c|c|c|c|c|c|c|c|}
\hline Iis & Jăl & rel & Mar & At: & $\mathrm{MaI}$ & Jun & $J_{11}$ & AgO & Set & Wut & Hot & Tiez \\
\hline & & & & & & 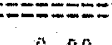 & an & $0 \times$ & & & & \\
\hline 1 & 3.51 & 6.40 & 5.35 & 0.00 & 17,94 & 0.00 & 0.00 & 0.00 & 2.20 & 3.94 & 4.51 & 1.19 \\
\hline 2 & 3.34 & 19.39 & 3.33 & 1.59 & 0.82 & 0.00 & 0,00 & 0.00 & 0.06 & 7.48 & 2.94 & 0.00 \\
\hline 3 & 0.00 & 47.25 & 7.59 & 0.14 & 0,00 & 0.00 & 6.60 & 0.00 & 0.00 & 0.83 & 0.75 & 0.00 \\
\hline 4 & 2.24 & 4,66 & 3.01 & 0.00 & 0.00 & 0,00 & 0.00 & 0.00 & 0.00 & 1,12 & 2.41 & 0.00 \\
\hline 5 & 4.45 & 0.00 & 2,66 & 0.00 & 0.00 & 0.00 & 0.00 & 0.00 & 0.00 & 0.13 & 4.02 & 0.00 \\
\hline 6 & 23.90 & 0.00 & 0.97 & 7.12 & 0.00 & 0,00 & 0.00 & 0,00 & 0.00 & 0.00 & 0.47 & 0.52 \\
\hline 7 & 38.90 & 6.42 & 0.00 & 0.45 & 0,00 & 0.00 & 0.00 & 0.00 & 0.00 & 10.53 & 14.78 & 4.10 \\
\hline 8 & 23.84 & 17.83 & 0.00 & 5.81 & 0.00 & 0.00 & 0.00 & 0,00 & 0.00 & 3.28 & 23,12 & 0.00 \\
\hline 9 & 19.70 & 2,5 & 0.00 & 13.86 & 0.86 & 0.00 & 0.00 & 0.00 & 0.00 & 0.00 & 1.18 & 0.00 \\
\hline 10 & 5.54 & 7,30 & 0.00 & 5.94 & 1.68 & 0.00 & 0.00 & 0.60 & 0.00 & 0.00 & 7.05 & 0.00 \\
\hline 11 & 14.46 & 59.63 & 3.27 & 0.00 & 0.39 & 0.00 & $0.0 \mathrm{o}$ & 0.00 & 0.00 & 0.00 & 8.03 & 0.00 \\
\hline 12 & 2.69 & 3.5 & 0.35 & 0.00 & 0.00 & 0.00 & 0.00 & 0.00 & 0.00 & 0.22 & 15.95 & 8.94 \\
\hline 15 & 9.38 & 2,80 & 2.84 & 0.00 & 0.00 & 0.00 & 0.00 & 0.00 & 0.00 & 2.76 & 15,40 & 17,10 \\
\hline 14 & 0.00 & 8.95 & 17.64 & 0.00 & 5,05 & 9.67 & 0.00 & 0.00 & 0.00 & 5.17 & 5.41 & 3.79 \\
\hline 15 & 1.68 & 8.18 & 3.20 & 0.00 & 19.29 & 20.11 & 0.00 & 7.24 & 0.00 & 0.00 & 0,4 & 16.16 \\
\hline 16 & 2,41 & 6.36 & 0.50 & 0.00 & 14.18 & 0.00 & 0,00 & 15,18 & 0.0 & 4.62 & 0.00 & 21.36 \\
\hline 17 & $18.0 \%$ & 0.14 & 2.83 & 0.00 & 0.00 & 0.14 & 0.00 & 0.65 & 0.00 & 21.69 & $\theta_{n} \theta_{2}$ & 25.23 \\
\hline 18 & 21.90 & 10.73 & 0.00 & 0.03 & 0,00 & 0.35 & 0.00 & 0,00 & 0.00 & 0.13 & 1.99 & 54,29 \\
\hline 10 & 15.57 & 10.65 & 0.41 & 3.83 & 2.66 & 0.09 & 0.00 & 0.00 & 0.00 & 0.19 & 14,37 & 41.02 \\
\hline 20 & 25.49 & 19.82 & 1.18 & 11,56 & 7.95 & 0.00 & 0.00 & 0.00 & 0,00 & 17.41 & 35,91 & 19.95 \\
\hline $2 i$ & 13.33 & 36.39 & 8.60 & 0.00 & 4.41 & 0.00 & 0.00 & 0.00 & 0,00 & 5.63 & 15.23 & 39.95 \\
\hline 2 & 15.07 & 14.18 & 8.27 & 0.00 & 0.43 & 0,17 & 0.00 & 0.03 & 0.00 & 24,18 & 3.77 & 10,30 \\
\hline 23 & 18.64 & 3,05 & 5.14 & 0.00 & 0.00 & 5.93 & 0.00 & 0.00 & 0.00 & 5.99 & 0,00 & 5.21 \\
\hline 24 & 4.25 & 4.16 & 9.03 & 0,00 & 0.00 & 13.58 & 0.00 & 0,00 & 0.00 & 0.00 & 1,40 & 6,53 \\
\hline 25 & 0.00 & 16.80 & 1.46 & 0.00 & 0.00 & 0.00 & 0.00 & 0.00 & 0.00 & 19.08 & 4.49 & 10.31 \\
\hline 26 & 0,00 & 4.71 & 0.00 & 0.00 & 0.00 & 2.56 & 0.00 & 0.00 & 0,00 & 24,00 & $9.4 \overline{8}$ & 9,15 \\
\hline 27 & 2.98 & 5.92 & 0.00 & 0.00 & 0.00 & 4.07 & 0.00 & 0.00 & 0,00 & 14.35 & 1.76 & 0.09 \\
\hline 28 & 4,60 & 43.24 & 0.00 & 1.04 & 0,00 & 0.40 & 0,00 & 0.00 & 0.92 & 1.06 & 4,00 & 11.56 \\
\hline 29 & 1,50 & 32.01 & 0,00 & 2.25 & 0.00 & 0.00 & 0,00 & 0.00 & 0.07 & 0.02 & 14.42 & 11,87 \\
\hline 30 & 0.00 & 0.00 & 0.00 & 4.73 & 0.00 & 0.00 & 0.00 & 0.00 & 283 & 0.30 & 0.94 & 9.36 \\
\hline 31 & 2.06 & 0.00 & 0.00 & 0.00 & 0.00 & 0.00 & 0.00 & 0.00 & 0.00 & 1.67 & 0,00 & 3.73 \\
\hline & & & & & .64 & 57.07 & 0.00 & 23.10 & 6.8 & & 215,21 & 341.71 \\
\hline
\end{tabular}


PRECIPITACOES MEIIAS - IIAKIAS E MEHSAIS

ANO : 1961

WLTOUO DE THTESSEN

BACIA IO RIO CONURBATAL

TABELA: $: 5.6$.

\begin{tabular}{|c|c|c|c|c|c|c|c|c|c|c|c|c|}
\hline Mia & Jen & Fen & Prar & Atur & $\mathrm{MaI}$ & Jun! & JuI & AgO & Set & Lut & hou & IE: \\
\hline & & & & & & & & & & & & \\
\hline 1 & $b_{4} 40$ & 12.61 & 12,95 & 0.00 & 0.00 & 0.00 & 0,00 & 0,00 & 0.00 & 0.00 & 1,94 & 5.48 \\
\hline 2 & 5.63 & 5.42 & 0.00 & 0.00 & 5.41 & 0,00 & 0.00 & 0,00 & 0.00 & 0,00 & 11.70 & 6.69 \\
\hline a & 10.33 & 2.16 & 0.00 & 0.43 & 30.45 & 0,00 & 0.00 & 0.00 & 0.00 & 2.56 & 19.48 & 10.99 \\
\hline 4 & 9.86 & 15.51 & 0.00 & 5.58 & 24.04 & 0.81 & 0.00 & 0.00 & 0.00 & 0.00 & 25.72 & 17.90 \\
\hline 5 & 5.19 & 13.43 & 0.00 & 10,77 & 11.14 & 0.00 & 0.00 & 0.00 & 0.00 & 0.00 & 3,57 & 0.01 \\
\hline 6 & 7.06 & 2.65 & 1.57 & 5.46 & 0.02 & 0.09 & 0.00 & 0.00 & 0.00 & 0.00 & 3.97 & 0.40 \\
\hline 7 & 10.33 & 2,53 & 0.0 & 0.00 & 0.21 & 0.00 & 0.00 & 0.00 & 0.00 & 0.00 & 9.23 & 11.86 \\
\hline 8 & 7.75 & 9.37 & 8.54 & 0.19 & 1,51 & 0.00 & 0.00 & 0.00 & 0.00 & 0.19 & 0.00 & 18.34 \\
\hline 9 & 7.59 & 0.39 & 14.95 & 1.36 & 0.77 & 0.00 & 0.14 & 0.00 & 0.00 & 0.00 & 0.00 & 2.11 \\
\hline 10 & 3,47 & 6.45 & 0.55 & 0.61 & 6.10 & 0.31 & 0.00 & 0.00 & 0.00 & 0.00 & 5.77 & 0.37 \\
\hline 11 & 0.02 & 12.84 & 12.40 & 5.45 & 0.00 & 0.00 & 0.00 & 0.00 & 0.00 & 1.26 & 5.38 & 0.00 \\
\hline 12 & 0.96 & 51.79 & 14.92 & 0.03 & 0.00 & 0.56 & 0.00 & 0.00 & 0.00 & 0.07 & 8,36 & 1.95 \\
\hline 13 & 6.31 & 49.39 & 6.30 & 0,00 & 0.00 & 0.37 & 0.00 & 0.00 & 0.00 & 0.60 & 0.58 & 9.78 \\
\hline 14 & 6.49 & 1.06 & 2.91 & 0,00 & 0.00 & 0.33 & 0.00 & 0.00 & 0.00 & 0.57 & 8,93 & 5.48 \\
\hline 15 & 1.56 & 0.07 & 5.69 & 0.00 & 0.00 & 2.55 & 0.00 & 0.00 & 0.00 & 4.54 & $9.2 \mathrm{~A}$ & 0.52 \\
\hline 16 & 4.31 & 6.16 & 12.82 & 0.00 & 0,00 & 0.27 & 0.00 & 0.00 & 0,00 & 4.27 & 0.00 & 6.69 \\
\hline 17 & 1.80 & 21.56 & 3.00 & 0.00 & 0.00 & 0.00 & 0.00 & 0.00 & 0.00 & 1.54 & 0.00 & 12.34 \\
\hline 18 & 3.92 & 10.25 & 11.28 & 0.00 & 0.00 & 0.00 & 0.00 & 0,00 & 0.00 & 1,32 & 0,00 & 11,18 \\
\hline 19 & 3.22 & 9.21 & 8.14 & 0.08 & 0.00 & 0.00 & 0.00 & 0.00 & 0.00 & 1.30 & 2.00 & 9.55 \\
\hline 30 & 0.21 & 14.59 & 3,09 & 4.88 & 0.00 & 0,00 & 0.00 & 0.00 & 0.00 & 1.60 & 0.14 & 8.18 \\
\hline 21 & 1,74 & 4.26 & 2.88 & 0.47 & 0.00 & 0.05 & 0.00 & 0.00 & 0.00 & 0.00 & 4.62 & 7.67 \\
\hline 22 & 0.41 & 10.01 & 0.00 & 2.48 & 0.00 & 0.00 & 0.00 & 0.00 & 0.00 & 0.00 & 7.01 & 2.30 \\
\hline 23 & 5.40 & 16.00 & 0.00 & 0.12 & 1.84 & 0.00 & 0.00 & 0.00 & 0.00 & 0.00 & 8.00 & 1.19 \\
\hline 24 & 2.23 & 8.34 & 0.00 & 1.30 & 0.70 & 0.00 & 0.00 & 0.00 & 0,00 & 1.36 & 3.39 & 0.54 \\
\hline 25 & 0.51 & 1.36 & 0.00 & 12.72 & 0.00 & 0.00 & 0.00 & 1.80 & 0.00 & 0.47 & 4.22 & 6.69 \\
\hline 26 & 0.00 & 2.73 & 0,00 & 16.97 & 0,00 & 0.00 & 0.00 & 9.11 & 0.00 & 7.75 & 0.53 & 9.01 \\
\hline 27 & 0.00 & 5.57 & 0.00 & 0.00 & 0.00 & 0.00 & 0,00 & 2.31 & 0.00 & 11.93 & 4.96 & 1.83 \\
\hline 28 & 0.08 & 6.33 & 0.00 & 0.00 & 0,00 & 0.00 & 0.00 & 0.00 & 0.22 & 1.50 & 1.56 & 5.02 \\
\hline 29 & 5.92 & 0.00 & 0.00 & 0.00 & 0.00 & 0.00 & 0.00 & 0.00 & 0.88 & 3.67 & 3.53 & 14.93 \\
\hline 30 & 1.31 & 0.00 & 0.00 & 0.00 & 0.00 & 0.00 & 0.00 & 0.24 & 0.00 & 4.18 & 0.00 & 1,18 \\
\hline 31 & 1.87 & 0.00 & 0.00 & 0.00 & 0.00 & 0.00 & 0.00 & 0.00 & 0.00 & 3.05 & 0.00 & 1.81 \\
\hline & .78 & & 30.07 & 64.10 & 92.19 & 5.34 & 0.14 & 13.46 & 1.10 & 54.03 & 152.85 & 191.99 \\
\hline
\end{tabular}




\begin{tabular}{|c|c|c|c|c|c|c|c|c|c|c|c|c|}
\hline Hia & Jan & Teu & har & Atr & Ha 1 & Jun & Jul & AgO & $5 e t$ & out & Hou & lle: \\
\hline 1 & 0.00 & 0.25 & 0.59 & 0.28 & $0 . x$ & 0.00 & 0.00 & 0.00 & 0.00 & 7.97 & 3,77 & 242 \\
\hline 2 & 0.76 & 0.18 & 13.11 & 1,96 & 9.30 & 13,09 & 0.00 & 0.00 & 0.00 & 16.67 & 0.00 & 2.45 \\
\hline 3 & 5.35 & 9.67 & 9.80 & 0,00 & 12.53 & 7.00 & 0.00 & 0.00 & 0,13 & 11.86 & 0,00 & 8.04 \\
\hline 4 & 1.66 & 30.21 & 0.81 & 0.00 & 0.77 & 3.21 & 0.00 & 0.00 & 1.27 & 11.65 & 0.00 & 4.37 \\
\hline 5 & 0.00 & 27.21 & 15,64 & 0.00 & 0.00 & 0.21 & 0.07 & 0.00 & 10,9 & 3.61 & 0.00 & 12,17 \\
\hline 6 & 0.03 & 26.81 & 2.20 & 0.00 & 0.00 & 1.89 & 0.08 & 0.00 & 0.00 & 0.00 & 3.51 & 4.63 \\
\hline 7 & 4,38 & 1.04 & 0.85 & 0.00 & 0.00 & 4.47 & 0.00 & 0.00 & 0.00 & 0.00 & 2,38 & 0.00 \\
\hline 8 & $14,7 ?$ & 10.40 & 0.00 & 0,00 & 0.00 & 2,60 & 0.00 & 0.03 & 9.57 & 5.82 & 6.83 & 1.50 \\
\hline 9 & 18.47 & 4.64 & 0.00 & 0.81 & 0.00 & 0.43 & 1.38 & 0.00 & 13.36 & 2.31 & 10.21 & 11,65 \\
\hline 10 & 1.04 & 24.81 & 13,68 & 0.00 & 0.00 & 0.00 & 2.18 & 0.96 & 3.40 & 12.71 & 0.00 & 11.12 \\
\hline 11 & 1.82 & 11.77 & 38.93 & 0.00 & 0.00 & 0.00 & 0.00 & 1.13 & 2,36 & 13.89 & 0.00 & 22.71 \\
\hline 12 & 2.54 & 0.31 & 19.95 & 0.00 & 0.01 & 0.00 & 0.00 & 0.00 & 0.45 & 0.00 & 0.00 & 0.00 \\
\hline 13 & 14.47 & 9.88 & 37.39 & 0.65 & 0.00 & 0.00 & 0.00 & 1.33 & 0.00 & 0.00 & 0.00 & 2,13 \\
\hline 14 & 10,63 & 1.57 & 6.55 & 0.20 & 0.02 & 0.00 & 0.00 & 0.59 & 0.00 & 2,12 & 0.00 & 2.94 \\
\hline 15 & 11.44 & 0.30 & 9.41 & 1.63 & 0.00 & 0,00 & 0.00 & 0.39 & 0.00 & 13.69 & 1.72 & 17.86 \\
\hline 16 & 14,20 & 5.44 & 14,81 & 1.51 & 0,00 & 0.00 & 0.78 & 0,00 & 0,00 & 29.30 & 20.94 & 18.75 \\
\hline 17 & 9.46 & 6.41 & 19.27 & 7.35 & 0.00 & 0.00 & 1.66 & 0.00 & 0.00 & 18.39 & 14.22 & $12,4 t$ \\
\hline $1 \bar{Q}$ & 2.00 & 1.54 & 13.02 & 0.00 & 0,00 & 0,00 & 1,17 & 0.00 & 0.22 & 10.10 & 5,64 & 0.69 \\
\hline 19 & 5.58 & 12,8 & 1.29 & 0.00 & 0.00 & 0.00 & 0.00 & 0.00 & 1.15 & 0.00 & 5,45 & 0.93 \\
\hline 20 & 5.45 & 37.13 & 0.00 & 0.00 & 0.00 & 0.02 & 0.00 & 10,08 & 0.00 & 0.00 & 6.49 & 2.66 \\
\hline 21 & 2,02 & 8.91 & 0.00 & 0.00 & 0.00 & 0.00 & 0.38 & 22.50 & 0.14 & 0.03 & 0.00 & 3.68 \\
\hline 22 & 6.69 & 8.59 & 17.39 & 0.00 & 0.00 & 0.00 & 0.09 & 5.10 & 0.00 & 3.96 & 0.00 & 2.76 \\
\hline 23 & 1,04 & 4.51 & 6.09 & 0.00 & 0.00 & 0.00 & 0.02 & 0.00 & 0.00 & 2.77 & 0.00 & 0.10 \\
\hline 24 & 2.21 & 0.00 & 3.55 & 0.00 & 0.00 & 0.00 & 0.00 & 0,00 & 0.00 & 0.00 & 0.00 & 4.69 \\
\hline 25 & 0.00 & 0.00 & 0.09 & 0.00 & 0.00 & 0.00 & 0.00 & 0.00 & 0.00 & 1.65 & 0.00 & 4,61 \\
\hline 26 & 0.00 & 0.62 & 0.00 & 0.46 & 0.36 & 0.00 & 0.00 & 0.00 & 0,08 & 6.13 & 0.98 & 13.42 \\
\hline 27 & 0.00 & 0.00 & 0.00 & 2,64 & 0.05 & 0,00 & 0.00 & 0.00 & 2.50 & 4,92 & 4.33 & 27.64 \\
\hline 28 & 0.00 & 0.00 & 0.00 & 2.86 & 0,00 & 0.00 & 0.01 & 0.00 & 6.15 & 11.91 & 15,01 & 24.86 \\
\hline 29 & 0.00 & 0.00 & 0.00 & 0.00 & 0.00 & 0.00 & 0.92 & 0.00 & 0,00 & 4.97 & 0.00 & 18.20 \\
\hline 30 & 148,12 & 258,12 & 303,95 & 20.73 & 22,5 & 32.91 & 11.47 & 43.49 & 51,98 & 200,05 & 101.53 & 258,85 \\
\hline 31 & 0.00 & 0.00 & 0.00 & 0.00 & 0.00 & 0.00 & 0.00 & 0.00 & 0.00 & 0.00 & 0.00 & 0.00 \\
\hline & .95 & & & 1,10 & 44.51 & 65.83 & 20.21 & 85.6 & 3.72 & 398.20 & 03.07 & 498.28 \\
\hline
\end{tabular}




\begin{tabular}{|c|c|c|c|c|c|c|c|c|c|c|c|c|}
\hline Dis & Jan & Fey & $\mathrm{ABT}$ & Abr & Mai & Jun & JuI & AgO & Set & Qut & Hov & jlez \\
\hline 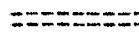 & $z=z=:-z$ & $:==$ & $=z$ & 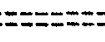 & $z==0$ & $=$ & $z=:=-$ & $z=z$ & $z=$ & & 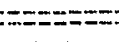 & \\
\hline$\hat{1}$ & 34.55 & 0,63 & 0.00 & 0.00 & 0.00 & 0.00 & 0.00 & 0.00 & 0.00 & 0.00 & 2.29 & 2.40 \\
\hline 2 & 18.83 & 10,17 & 0.00 & 0.00 & 0,00 & 0,00 & 0.00 & 0,00 & 0.00 & 0,00 & 7.07 & 5.93 \\
\hline 3 & 1.46 & 1.94 & 4.86 & 0.00 & 0.00 & 0.00 & 0,00 & 0.00 & 0.00 & 0.00 & 0.00 & 2.29 \\
\hline 4 & 0.00 & 6.46 & 3.42 & 0.00 & 0.00 & 0.00 & 0.00 & 0.00 & 0.00 & 0.00 & 0.00 & 17.50 \\
\hline 5 & 0,00 & 8,50 & 2.17 & 0.00 & 0.00 & 0,00 & 0,00 & 0.00 & 0,00 & 0.41 & 7.49 & 11.80 \\
\hline 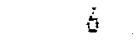 & 0.00 & 12.70 & 16,28 & 0.41 & 0.00 & 0.00 & 0.00 & 0.00 & 0.00 & 5.44 & 0.28 & 8.14 \\
\hline 7 & 0.27 & 11.85 & 16.07 & 0.00 & 0.00 & 0.00 & 0.00 & 0,00 & 0.00 & 2.00 & 9.61 & 3,99 \\
\hline 8 & 3.35 & 0.00 & 5.50 & 4,18 & 0.00 & 0.00 & 0.00 & 0.00 & 0.00 & 0.00 & 8.41 & 8.44 \\
\hline 9 & 0.96 & 0.00 & 0,04 & 0.07 & 0.00 & 0.00 & 0.00 & 0.00 & 0.00 & 0.25 & 2.97 & 2.31 \\
\hline 10 & 6.06 & 0.00 & 2.90 & 1.47 & 0.00 & 0.00 & 0,00 & 0.00 & 0.00 & 0.00 & 1.18 & 0.77 \\
\hline 11 & 13,47 & 0.00 & 5,60 & 0.00 & 0.00 & 0.00 & 0.00 & 0.00 & 0.00 & 0.00 & 0.00 & 0.68 \\
\hline 12 & 6.52 & 0.65 & 0.00 & 0.00 & 0.00 & 0.00 & 0.00 & 0,00 & 0.00 & 0.00 & 0.00 & 0.00 \\
\hline 13 & 0.33 & 0.28 & 0.00 & 0.00 & 0.00 & 0.00 & 0.00 & 0.00 & 0.00 & 0.00 & 13.89 & 0.00 \\
\hline 14 & 2.23 & 8.62 & 0.00 & 0.00 & 0.00 & 0.00 & 0.00 & 0.00 & 0,00 & 0.57 & 6.60 & 0.00 \\
\hline 15 & 14.05 & 0.35 & 0.00 & 0.70 & 0,00 & 0.00 & 0.00 & 0.25 & 0.00 & 2.52 & 24.49 & 0.00 \\
\hline 16 & 12.01 & 7.71 & 0,00 & 5.78 & 0,00 & 0.00 & 0.00 & 0,62 & 0.00 & 0.00 & 10.51 & 0.00 \\
\hline 17 & 9.64 & 1.20 & 0.00 & 1.17 & 0.04 & 0.00 & 0.00 & 0.85 & 0.00 & 9.40 & 26.76 & 0.14 \\
\hline 18 & 16.67 & 7.74 & 0,90 & 0.00 & 0.00 & 0.00 & 0.00 & 0.00 & 0.00 & 8.03 & 21.58 & 1.99 \\
\hline 19 & 6.17 & 6.58 & 0.90 & 0.00 & 0.00 & 0.00 & 0.00 & 0,00 & 0.00 & 1.26 & 7.89 & 3.80 \\
\hline 20 & 8.35 & 42.56 & 0.13 & 0,00 & 0.00 & 0.00 & 0,00 & 0,00 & 0.00 & 0.00 & 13.37 & 9.73 \\
\hline 21 & 0.52 & 7.74 & 0.22 & 0.00 & 0.00 & 0.00 & 0,00 & 0.00 & 0.22 & 27.80 & 7.01 & 0,00 \\
\hline $2 z$ & 26,40 & 1.86 & 0.00 & 0.00 & 0.00 & 0.00 & 0.00 & 0.00 & 2.43 & 83.28 & 0.00 & 0.00 \\
\hline 23 & 8.51 & 4.23 & 7.45 & 0.00 & 0.00 & 0.00 & 0.00 & 0.00 & 0.00 & 12.84 & 0.00 & 0.00 \\
\hline 24 & 1,54 & 5.54 & 4.55 & 0.00 & 0.00 & 0.00 & 0.00 & 0,00 & 0.00 & 0.00 & 0.00 & 0,00 \\
\hline 25 & 8.35 & 1.23 & 9.11 & 0.00 & 0.00 & 0.00 & 0.00 & 0.00 & 0.00 & 10.69 & 0.00 & 0.00 \\
\hline 26 & 2,41 & 0.00 & 2.74 & 0.00 & 0.00 & 0.00 & 0.00 & 0.00 & 0.00 & 14.24 & 4.70 & 0.00 \\
\hline 87 & 2.04 & 0.00 & 7.35 & 0.00 & 0.00 & 0.00 & 0.00 & 0.00 & 0.06 & 15.88 & 0.66 & 0.00 \\
\hline 28 & 0.04 & 0.00 & 0.00 & 0.00 & 0.00 & 0.00 & 0.00 & 0.00 & 0.00 & 5.30 & 2.69 & 0.00 \\
\hline 29 & 0.00 & 0.00 & 0,00 & 0.00 & 0,00 & 0,00 & 0.00 & 0.00 & 0.00 & 0,00 & 1.45 & 0.41 \\
\hline 30 & 0.80 & 0.00 & 0.00 & 0.00 & 0.00 & 0.00 & 0,00 & 0.00 & 0.19 & 0.00 & 1.05 & 3.34 \\
\hline 31 & 0.28 & 0.00 & 0.00 & 0.00 & 0.00 & 0.00 & 0.00 & 0.00 & 0.00 & 0,00 & 0.00 & 0.40 \\
\hline & 206.83 & 42.56 & 90.13 & 13.78 & 0.04 & 0.00 & 0.00 & 1.72 & 2.90 & 133.92 & 181.88 & 84.15 \\
\hline
\end{tabular}


FRECIFITACOES HLUTAS - UIARTAS E MEASAIS

AHO : 1964

MITONO IE THIESEE

BACIA DO RIO COFUMBATAI

TABELA : 5.6 .7

\begin{tabular}{|c|c|c|c|c|c|c|c|c|c|c|c|c|}
\hline II: & Jan & $f \in u$ & har & Ator & $\mathrm{MaI}$ & Jun & Jul & Ago & Set & [ut: & Hov & Le: \\
\hline 1 & 4.50 & 2.56 & 0.96 & 0.93 & 22.62 & 0.00 & 0.00 & 0.00 & 0.00 & $12.8 \mathrm{~g}$ & 1.42 & 25.73 \\
\hline$g$ & 1,40 & 11.68 & 0.05 & 0.67 & 0.00 & 0.00 & 0.80 & 0.00 & 0.14 & 1,33 & 0.00 & 14,02 \\
\hline 3 & 0.97 & 0.97 & 0.00 & 3.74 & 0,00 & 0.00 & 11.46 & 0.49 & 0.72 & 0.03 & 0.00 & 4.78 \\
\hline 4 & 0.00 & 4.82 & 0.00 & 5.75 & 0.74 & 0.00 & 6.47 & 4.95 & 0.00 & 0.02 & 0.00 & 2.41 \\
\hline 5 & 0.00 & 0.00 & 0.98 & 3.00 & 6.74 & 0.00 & 0.00 & 0.00 & 0.00 & 0.05 & $3.4 t$ & 0.00 \\
\hline 6 & 0.00 & 0.00 & 0.70 & 0.00 & 5.70 & 0.00 & 0.00 & 0.00 & 0,00 & 7.66 & 12,47 & 0.00 \\
\hline 7 & 0.87 & 8.86 & 4.12 & 0.00 & 0.00 & 0.00 & 0,00 & 0.00 & 0.00 & 32.02 & 1,80 & 0.09 \\
\hline 8 & 7.16 & 2,73 & 2.95 & 0.00 & 0.00 & 0.00 & 0.08 & 0.00 & 0.00 & 3,3 & 0.00 & 0,00 \\
\hline$\frac{G}{i}$ & 2,31 & 10.43 & 0.04 & 0.00 & 0.00 & 0,00 & 0.00 & 0.00 & 0.00 & 0.00 & 0,00 & 4,37 \\
\hline 10 & 0.00 & 14.43 & 0.00 & 0.00 & 0.00 & 0.33 & 0.00 & 0.00 & 0.00 & 0.20 & 1.20 & 4.82 \\
\hline 11 & 0.00 & 10.29 & 0.00 & 0.00 & 0.00 & 0.02 & 0.00 & 0.14 & 0.00 & 0.00 & 0.00 & 10.55 \\
\hline 12 & 0.00 & 16.17 & 0.00 & 0.00 & 0.13 & 0.00 & 0.00 & 3.92 & 0.00 & 0.41 & 0.00 & 5,17 \\
\hline 13 & 1.07 & 15,66 & 0.00 & 0.00 & 2.91 & 0.25 & 0.00 & 0.00 & 0.00 & 0.00 & 0.00 & 23.75 \\
\hline 14 & 0.00 & 17.84 & 0.09 & 0.00 & 4.05 & 3.00 & 0.00 & 0.00 & 0.00 & 0.00 & 0,38 & 24.79 \\
\hline 15 & 0.00 & 14.64 & 0.85 & 0.00 & 0.00 & 3.41 & 0.00 & 0.00 & 0.00 & 0.00 & 2.63 & 13.52 \\
\hline 16 & 0.24 & 11,00 & 0,16 & 0,00 & 0,00 & 0,10 & 0.60 & 0,00 & 0,00 & 0.0 & 3,36 & 16.87 \\
\hline 17 & 0.37 & 7.03 & 0.00 & 1.54 & 0.00 & 0.02 & 0.00 & 0.00 & 0.00 & 0.0 & 0.14 & 7.31 \\
\hline 18 & 0.00 & 4.77 & 0.00 & 5,00 & 0.00 & 0.00 & 0.00 & 1.36 & 0,00 & 0.0 & 5.44 & 9.33 \\
\hline 19 & 2.52 & 10.46 & 0.00 & 1.45 & 0,00 & 0.00 & 0.14 & 1.48 & 0,00 & 5.33 & 6.94 & 6,40 \\
\hline 20 & 0,00 & 21.77 & 0.00 & 0.41 & 0.00 & 0.00 & 0.42 & 5.91 & 0.00 & 16. & 12,13 & 2,02 \\
\hline 21 & 0.19 & 4.62 & 0.00 & 0.07 & 0.16 & 0.00 & 0.00 & 1.73 & 1.04 & 7.28 & 38.03 & 4.18 \\
\hline 28 & 9.58 & 0,00 & 0.00 & 0.00 & 0.26 & 0.00 & 0.00 & 0.00 & 2.53 & 1.48 & 0.87 & 16.01 \\
\hline 23 & 22,59 & 0.16 & 0.00 & 0.16 & 0.89 & 0.00 & 0.00 & 0.00 & 1,41 & 0.00 & 0.00 & 21.74 \\
\hline 24 & 5.60 & 4.35 & 0.00 & 0.00 & 0.00 & 0,02 & 7.79 & 0.00 & 9.18 & 0,00 & 0,00 & 24.00 \\
\hline 25 & 11,78 & 0.21 & 0.00 & 0,00 & 0,00 & 0.00 & 17.79 & 0.00 & 27.61 & 0.00 & 0.00 & 10.20 \\
\hline 26 & 14,17 & 0.00 & 0.00 & 0,00 & 0.00 & 0.21 & 2.80 & 0.00 & 13.49 & 11.30 & 0.00 & 5,07 \\
\hline 27 & 2.64 & 0.00 & 0.40 & 0.09 & 0,00 & 0.28 & 0.90 & 0.76 & $1.9 \%$ & 11.61 & 0.00 & 5.80 \\
\hline 28 & 0,00 & 0.94 & 0.03 & 0.00 & 0.00 & 0.59 & 0.30 & 0,00 & 6.86 & 0.00 & 0.00 & 2,00 \\
\hline 29 & 0.00 & 0.00 & 2.95 & 0.00 & 0.00 & 0.00 & 0.00 & 0.00 & 5.07 & 7.05 & 1.01 & 8.22 \\
\hline 30 & 0.00 & 0.00 & 5.97 & 5.90 & 0.00 & 0.05 & 0.00 & 0.00 & 5.20 & 19.83 & 5.68 & 0.66 \\
\hline 31 & 0.00 & 0.00 & 1.87 & 0.00 & 0.00 & 0,00 & 0.00 & 0.00 & 0.00 & 9.23 & 0.00 & 0.00 \\
\hline dias & 87.96 & 195.79 & 21.92 & 27.79 & 44,21 & 8.28 & 49.63 & 20.74 & 74.64 & 147.16 & 97.28 & 277,61 \\
\hline
\end{tabular}




\begin{tabular}{|c|c|c|c|c|c|c|c|c|c|c|c|c|}
\hline He & $\operatorname{lan}$ & Fev & War & Abt & tha $i$ & Tur & Jul & figo & Set & out & Hou & Dez \\
\hline 1 & 1.07 & 43.23 & 11.55 & 0.00 & 0.00 & 0.00 & 0.00 & 9.05 & 0.00 & 49.47 & 0.49 & 2.44 \\
\hline 2 & 0.00 & 1.68 & 2.56 & 0.00 & 0,00 & 0.00 & 0,00 & 0.00 & 0.00 & 21.60 & 0,00 & 4,39 \\
\hline 3 & 2,57 & 8.80 & 13.27 & 0.09 & 0.00 & 0.06 & 0.00 & 0.14 & 0.00 & 0.00 & 0.00 & 11,42 \\
\hline 4 & 9.09 & 8.94 & 1.77 & 0.00 & 0.00 & 0.00 & 2.39 & 0.07 & 0.00 & 0.00 & 0.00 & 1,50 \\
\hline 5 & 10.80 & 11.23 & 6,42 & 0.00 & 0.00 & 0.00 & 7.94 & 0,00 & 0.00 & 0.00 & 1.33 & 6.44 \\
\hline 6 & 0.00 & 4.56 & 2.58 & 0.54 & 0.00 & 0,00 & 3.09 & 0.11 & 0.00 & 0.00 & 18.16 & 14.39 \\
\hline 7 & 0,00 & 3.59 & 0.22 & 0.00 & 0.00 & 0.00 & 5.33 & 2.86 & 0.00 & 0.00 & 10.69 & 21.74 \\
\hline 8 & 15,32 & 0.00 & 0.67 & 0.00 & 0.00 & 0.69 & 1.50 & 0,00 & 0.00 & 7.92 & 7.25 & 14.98 \\
\hline 9 & 20.57 & 0.00 & 16.05 & 2,02 & 0.00 & 1.64 & 5.43 & 0.00 & 0.00 & 5.25 & 8.57 & 22.92 \\
\hline 10 & $2.4 \%$ & 0.00 & 17.57 & 9.76 & 0.00 & 0,08 & 6.07 & 0.00 & 0.00 & 3.98 & 1.53 & 15.10 \\
\hline 11 & 5.54 & 0.00 & 0.00 & 0,00 & 0.78 & 0.13 & 1.47 & 0.00 & 0.00 & $8.5 \%$ & 0.00 & 6.80 \\
\hline 12 & 2.27 & 1.66 & 0.00 & 0.00 & 4.54 & 0.28 & 0.00 & 0.02 & 0,00 & 0.87 & 0.25 & 2.16 \\
\hline 13 & 8.59 & 12.62 & 0.11 & 0.00 & 5,93 & 2.57 & 0.00 & 0.00 & 0.00 & 0.00 & 5.45 & 2.31 \\
\hline 14 & 9.09 & 12.83 & 1.05 & 0.00 & 5.40 & 0.07 & 0.00 & 0.00 & 0.00 & 4.25 & 8.46 & 2.94 \\
\hline 15 & 19.76 & 5.85 & 8.09 & 0.00 & 19.34 & 0.45 & 0.00 & 0.00 & 0.00 & 8.97 & 12,10 & 3.97 \\
\hline 16 & 21.70 & 7.27 & 7.08 & 0.00 & 0.66 & 0.19 & 0.00 & 0.00 & 0.00 & 0.00 & 0,00 & 0.15 \\
\hline 17 & 26.36 & 8.57 & 6.70 & 0.00 & 5.52 & 7.47 & 0.00 & 0.00 & 0.00 & 2.42 & 0.00 & 1,34 \\
\hline 18 & 14.34 & 10,00 & 2.86 & 0.10 & 22.72 & 1.12 & 0.00 & 0.00 & 0.00 & 2,11 & 0,00 & 0.57 \\
\hline 19 & 29.79 & 5.10 & 3.08 & 1.81 & 12.61 & 0.00 & 0.00 & 0,00 & 0.03 & $8.5 t$ & 0.00 & 0.19 \\
\hline 80 & 25,06 & 5.76 & 2,69 & 6.87 & 0.03 & 0.00 & 0.00 & 0,00 & 0.09 & 10.40 & 1.14 & 0.00 \\
\hline 21 & 0.00 & $\$ 9.10$ & 0.00 & 0.84 & 0.42 & 0.05 & 0.00 & 0.00 & 0.00 & 0.98 & 1.10 & 0.00 \\
\hline $2 r$ & 0.00 & 28.73 & 3.98 & 0.00 & 0.07 & 0.00 & 0.00 & 0.00 & 0.56 & 4.36 & 0.00 & 2.18 \\
\hline 23 & 5.34 & 20.09 & 19.00 & 0.00 & 0.00 & 8,18 & 0.00 & 0.02 & 1.45 & 8.58 & 0.00 & 0.00 \\
\hline 24 & 0.25 & 10.01 & 7.26 & 0.00 & 0.00 & 11.06 & 0.00 & 0.00 & 0.60 & 0.81 & 0.00 & 0.42 \\
\hline 25 & 3.16 & 10.69 & 12,27 & 0.00 & 0.00 & 4.28 & 0.00 & 0.00 & 0.21 & 4.32 & 8.27 & 0.13 \\
\hline 26 & 6.34 & 10.36 & 7.60 & 0.00 & 0.00 & 0.65 & 0.00 & 0.00 & 5.85 & 7.22 & 11.11 & 2.65 \\
\hline 27 & 14.25 & 52.97 & 1.34 & 0.00 & 0.00 & 1.64 & 0.00 & 0.00 & 17.52 & 0.13 & 20.11 & 0.97 \\
\hline 28 & 7.47 & 8.69 & 0.00 & 3.16 & 0.00 & 0.00 & 0.00 & 0.00 & 20.21 & 5.65 & 6.26 & 15.84 \\
\hline 29 & 1679 & 0.00 & 0.00 & 24,07 & 0.00 & 0.00 & 0.00 & 0.00 & 3,83 & 12,55 & 8.38 & 17.05 \\
\hline 30 & 6.57 & 0.00 & 0.00 & 4.93 & 0,00 & 0.00 & 7.09 & 0,00 & 3.95 & 0.30 & 2.6 & 9.38 \\
\hline 31 & 17.30 & 0.00 & 0.00 & 0.00 & 0.00 & 0.00 & 5.10 & 0.00 & 0.00 & 0.05 & 0.00 & 0.39 \\
\hline dias & 301.81 & 14.67 & 55,17 & 54.19 & 78.02 & 40.52 & 45.41 & 12.27 & 53.70 & 179.36 & 133.32 & 184.76 \\
\hline
\end{tabular}




\begin{tabular}{|c|c|c|c|c|c|c|c|c|c|c|c|c|}
\hline Ilid & Jan & Fev & man & $===$ & 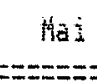 & $\begin{array}{l}\text { Iun } \\
=\end{array}$ & Ju1 & $\begin{array}{r}\text { hgo } \\
\text { L }\end{array}$ & Set & dut & Mou & le: \\
\hline 1 & 7.18 & 26.95 & 8.27 & 10.26 & 0.00 & 0,00 & 0,00 & 8.76 & 7.87 & 0.00 & 16,17 & 0.00 \\
\hline 2 & 6.16 & 31.17 & 4.12 & 2.66 & 0.00 & 0.00 & 0,00 & $0.5 \%$ & 22.39 & 0.00 & 9.77 & 4.11 \\
\hline 3 & 15.35 & 6.28 & 9.85 & 0,00 & 0.00 & 0.00 & 0.00 & 0.00 & 8.01 & 0.00 & 0.00 & 5.19 \\
\hline 4 & 16.07 & 6.65 & 10.59 & 0.00 & 0,00 & 0.00 & 0.60 & 0,00 & 4.46 & 0.00 & 0.33 & 1.15 \\
\hline 5 & 9.5 & 4.30 & 8.87 & 0.54 & 10.82 & 0,00 & $0.0 \%$ & 0.00 & 0.12 & 0,00 & 0.00 & 4.97 \\
\hline$b$ & 0.00 & 6.06 & 13.84 & 7.40 & 19.91 & 0.00 & 0.00 & 0.00 & 0.00 & 2.39 & 1.96 & 1.65 \\
\hline$T$ & 9.47 & 3,46 & 26.46 & 8.16 & 0.00 & 0,00 & 0.89 & 0.00 & 0.00 & 18,17 & 2,74 & 21,30 \\
\hline 8 & 15.43 & 0.00 & 10.32 & 0.15 & 0.00 & 0,00 & 0.00 & 0.00 & 0.00 & 28,32 & 7.20 & 6.63 \\
\hline 9 & 36.00 & 0.00 & 9.19 & 0.00 & 0.00 & 0.00 & 0,37 & 1.36 & 0.00 & 1.65 & 9.24 & 0.00 \\
\hline 10 & 18.43 & 4.53 & 0.27 & 0.00 & 0.00 & 0.00 & 0.00 & 0.75 & 0.00 & 3.85 & 8.34 & 0.00 \\
\hline 11 & 7.61 & 5.97 & 0.00 & 0.00 & 10.40 & 0.00 & 0.00 & 1.52 & 0,00 & 0.00 & 3.79 & 0.00 \\
\hline 12 & 2.55 & 3,69 & 0.00 & 0.00 & 5.60 & 0.00 & 0.00 & 0.00 & 0.00 & 14.48 & 9.64 & 5.28 \\
\hline 13 & 5.60 & 15.80 & 0.96 & 0.00 & 5.04 & 0.00 & 0.00 & 0.00 & 0.00 & 5.42 & 6.11 & 19.43 \\
\hline 14 & 0.00 & 5.48 & 1.33 & 0.00 & 0.54 & 0.00 & 0.00 & 0.00 & 0.00 & 0.06 & 0.00 & 0.35 \\
\hline 15 & 0,00 & 0.00 & 0.00 & 0.00 & 0.73 & 0.00 & 0.00 & 0.09 & 0.00 & 0.00 & 8.66 & 23.38 \\
\hline 16 & 0.38 & 0.00 & 0.00 & 0.00 & 0.00 & 0.00 & 0.00 & 0,00 & 0.00 & 0,60 & 8,26 & 7.02 \\
\hline 17 & 1,13 & 0.25 & 2,06 & 0.00 & 0.00 & 0.00 & 0.00 & 0.00 & 0.00 & 1.18 & 7.29 & 1.09 \\
\hline 18 & 26.67 & 0.00 & 0,00 & 0.00 & 0.00 & 0.00 & 0.00 & 0.00 & 0.00 & 2.05 & 517 & 0.09 \\
\hline 19 & 0.00 & 0,00 & 0.80 & 0,00 & 0,00 & 0.00 & 0,00 & 0,00 & 2,20 & 0.70 & 0.00 & 3.26 \\
\hline 20 & 0.00 & 14,59 & 0.07 & 0.00 & 0.26 & 0.00 & 0.00 & 0.00 & 7.84 & 0.00 & 0.00 & 26.84 \\
\hline 2 & 0.00 & 50.59 & 2.74 & 0.00 & 1.21 & 0,00 & 0.00 & 0.00 & 0.70 & 2,51 & 0.00 & 27.09 \\
\hline$g$ & 0.00 & 9.05 & 4.58 & 0.00 & 4.90 & 0,00 & 0.57 & 0,00 & 0.00 & 24.16 & 0.00 & 53.48 \\
\hline 23 & 0.02 & 14.79 & 0.00 & 0.00 & 0.39 & 0.00 & 0.00 & 0,00 & 0.00 & 17.02 & 0.00 & 41.37 \\
\hline 24 & 0.00 & 26.16 & 0.05 & 0.09 & 0.00 & 0.00 & 0.00 & 0.05 & 0.00 & 0.82 & 0.00 & 3.46 \\
\hline 25 & 1,82 & 3.84 & 1.48 & 1.67 & 0.00 & 0.00 & 0.00 & 0.09 & 0.00 & 0.00 & 0,00 & 0.00 \\
\hline 26 & 3.72 & 2,98 & 2,36 & 0.97 & 0.00 & 0,00 & 0.00 & 0.19 & 0.00 & 0.08 & 0,00 & 3.53 \\
\hline 27 & $27.5 \mathrm{~A}$ & 1.18 & 6.99 & 0,00 & 0.00 & 0.00 & 0.00 & 0.00 & 7.66 & 21.11 & 0.00 & 12.05 \\
\hline 20 & 9.52 & 0,30 & 0.01 & 0,00 & 0.00 & 0.00 & 0.00 & 0.00 & 23.21 & 26,00 & 0,00 & 12,7 \\
\hline 29 & 6.80 & 0.00 & 0.00 & 0.00 & 0.00 & 0.00 & 0.00 & 0.00 & 17.61 & 1.35 & 0.00 & 0.41 \\
\hline 30 & 7.00 & 0.00 & 0.09 & 0,00 & 0.00 & 0.00 & 1.27 & 0.26 & 2.49 & 1,47 & 0.00 & 0.00 \\
\hline 31 & 6.96 & 0.00 & 0.08 & 0.00 & 0.00 & 0.00 & 5.82 & 1.64 & 0.00 & 6.01 & 0.00 & 0.00 \\
\hline & 41,01 & & & 31.90 & 59.80 & 0.00 & 8.92 & 15.30 & 104.51 & 179.40 & 104,75 & 280.70 \\
\hline
\end{tabular}


FRECTPITACOES MWIIAS - UTARIAS E HEHSAIS

METOUO VE THTESEH
BACIA IO RYO CORUMHATAI
A $10: 196$

TABLA : $5,6,10$

\begin{tabular}{|c|c|c|c|c|c|c|c|c|c|c|c|c|}
\hline Uì & $J_{a n}$ & Fen & Har & ther & Hai & Jun & 301 & Ago & $5 \in t$ & Out & How & liez \\
\hline$\cdots$ & & & & & & & & & & & & \\
\hline 1 & 0.00 & 15.21 & 3.89 & 2.47 & 0.04 & 0.01 & 0.00 & 0,00 & 0.00 & 0.56 & 0,00 & 0.00 \\
\hline 2 & 3.55 & 8.56 & 27.86 & 0.45 & 5.23 & 0,00 & 0,00 & 0.00 & 0.00 & 0.69 & 0.41 & 0.00 \\
\hline 3 & 6.98 & 3.95 & 5.29 & 0.00 & 4.09 & 0.71 & 0.00 & 0.00 & 0.00 & 0,00 & 0.88 & 6.30 \\
\hline 4 & 7.50 & 26.91 & 2.04 & 0.09 & 0.03 & 0.11 & 0.00 & 0.00 & 0,00 & 0.00 & 1.68 & 5.69 \\
\hline 5 & 22,33 & 7.95 & 7.45 & 0.68 & 0.00 & 1.47 & 0.01 & 0.00 & 0.00 & 0.00 & 0.00 & 8.03 \\
\hline 6 & 31.43 & 6.31 & 17.76 & 0.36 & 0.00 & 4.47 & 0,00 & 0.00 & 0,00 & 0,00 & 0.00 & 3.59 \\
\hline 7 & 2,16 & 5,81 & $2 \varepsilon_{3} 34$ & 0.04 & 0.02 & 6.38 & 0.00 & 0.02 & 6.78 & 0.00 & 0.00 & 2,77 \\
\hline 8 & 0.65 & 15.03 & 1.17 & 0.02 & 0.01 & 3.89 & 0.00 & 0.00 & 12.32 & 0.00 & 0.00 & 13,10 \\
\hline 9 & 18.76 & 0.72 & 0.41 & 0.23 & 0.00 & 0.26 & 0,02 & 0.01 & 6.79 & 0.00 & 0.00 & 11.21 \\
\hline 10 & 18.29 & 1.93 & 0.00 & 0.00 & 0.03 & 0.31 & 0.44 & 0,00 & 6.86 & 1.44 & 0.00 & 8.36 \\
\hline 11 & $26.2 L_{2}$ & 16.54 & 0.44 & 0.02 & 0.01 & 7.08 & 1.03 & 0.00 & 0.25 & 4.86 & 2.79 & 2.63 \\
\hline 12 & $30.5 \mathrm{i}$ & 0.00 & 4.88 & 0.32 & 0.02 & 18,06 & 0.91 & 0,00 & 14.62 & 0.00 & 1.01 & 0.29 \\
\hline 13 & 9.13 & 0.00 & 13.46 & 8.45 & 0.04 & 16.41 & 0.00 & 0,00 & 20.40 & 0.00 & 3,55 & 6.14 \\
\hline 14 & 7.00 & 4,85 & 6.58 & 1.39 & 0.00 & 5.33 & 0.00 & 0,49 & 3.49 & 0.00 & 16.03 & 9.70 \\
\hline 15 & $12_{2} ; 06$ & 11.49 & 6.23 & 0.45 & 0.00 & 2.25 & 0.03 & 1.22 & 0.07 & 4.10 & 13.49 & 0.70 \\
\hline 16 & 10.33 & 3.20 & 0.00 & 0.00 & 0.02 & 0.11 & 0.09 & 0.63 & 0,00 & 24,67 & 11.00 & 11.14 \\
\hline 17 & 5.27 & 14.33 & 6.17 & 0.00 & 0.03 & 0.09 & 0.25 & 0.00 & 0.00 & $16 \times 89$ & 18,92 & 18.42 \\
\hline 18 & 1,75 & 43.22 & 14.57 & 0.22 & 0.02 & 0.03 & 0.03 & 0.00 & 0.00 & 9.31 & 1.79 & 6.91 \\
\hline 19 & 8.90 & 1,49 & 4,85 & 0.11 & 0.04 & 0.03 & 0.00 & 0.01 & 0,00 & 12.61 & 0.21 & 5.59 \\
\hline 20 & 34,06 & 10.23 & 0.00 & 0.83 & 0.01 & 0.03 & 0.00 & 0.00 & 9.28 & 22.21 & 0,00 & 3.14 \\
\hline 21 & 29.73 & 1.10 & 0.00 & 0.96 & 0.02 & 0.01 & 0.01 & 0.00 & 3.57 & 39.94 & 5.39 & 31,10 \\
\hline 22 & 26.90 & 15.95 & 0.00 & 0.02 & 0.01 & 0,00 & 2,16 & 0.00 & 0,00 & 13.49 & 24,12 & 14.32 \\
\hline 23 & 12.53 & 0.41 & 0.79 & 0.03 & 0.03 & 0.00 & 0.57 & 0.00 & 0.00 & 2.39 & 41.33 & 2.90 \\
\hline 84 & 25,85 & 4,47 & 12,19 & 0.51 & 0.00 & 0.00 & 1.85 & 0.00 & 0.00 & 7.20 & 5.84 & 0.47 \\
\hline 25 & 7.53 & 1.49 & 0.20 & 1.34 & 0.04 & 0.00 & 0.00 & 0.00 & 0.00 & 13.68 & 5.48 & 1.09 \\
\hline 26 & 3.09 & 4,02 & 3.08 & 0.08 & 0.23 & 0.01 & 0,00 & 0.00 & 0.00 & 28.82 & 3,34 & 3.77 \\
\hline 27 & 3,59 & 0.00 & 0.00 & 7.21 & 0.02 & 0.01 & 0.00 & 0.00 & 0,00 & 12,63 & 5.61 & 4.62 \\
\hline 28 & 0.59 & 0.00 & 0.94 & 0.00 & 0.01 & 0.00 & 0.00 & 0.09 & 0.00 & 1.22 & 6,12 & 9.83 \\
\hline 29 & 2.52 & 0.00 & 7.25 & 2.36 & 0.00 & 0.00 & 0.00 & 0.00 & 0.00 & 2.43 & ${ }_{2}, 02$ & 13.22 \\
\hline 30 & 14.70 & 0.00 & 2.31 & 0.01 & 0.00 & 0,00 & 0.00 & 0,00 & 0.33 & 0,00 & 0.00 & 7.11 \\
\hline 31 & 5.17 & 0.00 & 2.27 & 0.00 & 0.00 & 0.00 & 0.00 & 0.00 & 0.00 & 0.00 & 0.00 & 0.91 \\
\hline Medias & 389.04 & 25.47 & 174.36 & 22.70 & 10.00 & 67.06 & 7.40 & 2.47 & 84.76 & 217.2 & 171.05 & 213.05 \\
\hline
\end{tabular}


PREOPTTACOES MEUIAS - IIARIAS E MENGAIS

METONO WE THIESGEH
BACIA IOO RYO CORUMBATAI
Ak50: 1968

TAETLA : $5,6,11$

\begin{tabular}{|c|c|c|c|c|c|c|c|c|c|c|c|c|}
\hline Iía & Jan & Peu & Har & fato & ha & Jun & $\mathrm{JuI}$ & Ago & Set & Dut & Hov & IEI \\
\hline 1 & 1,36 & 0.00 & 0.00 & $0.3 t$ & 0,00 & 0.00 & 0.00 & 0.00 & 0.00 & 2.21 & 2,45 & 15.76 \\
\hline 2 & 28.78 & 0,00 & 0.00 & 0,00 & 0.00 & 0,00 & 0.00 & 0,00 & $3.5 \mathrm{~A}$ & 0.02 & 0.75 & 14.82 \\
\hline 3 & 13,49 & 0.00 & 2,01 & 0.44 & 0.00 & 0.00 & 0.00 & 0.00 & 6.19 & 0.00 & 6.27 & 15.54 \\
\hline 4 & 17.34 & 0.00 & 4,93 & 0.73 & 0.00 & 0.00 & 0.00 & 0.94 & 3.13 & 0.00 & 0.18 & 4.20 \\
\hline 5 & 1.33 & 0.03 & 5.30 & 0.25 & 0.00 & 0.00 & 0.00 & 2.21 & 1.50 & 0.00 & 0.00 & 12.65 \\
\hline 6 & 1.33 & 1.07 & 3.78 & 0.00 & 0.00 & 0.00 & 0.00 & 0.01 & 0.00 & 0.00 & 1.48 & 0.35 \\
\hline 7 & 0.00 & 0.00 & $L_{2} 4 E$ & 0.00 & 0.10 & 0.00 & 0.00 & 0.54 & 0.00 & 0.00 & 0.00 & 0.02 \\
\hline 8 & 0.00 & 0.03 & 14,41 & 0.00 & 0.20 & 0.00 & 0.51 & 5.29 & 0.03 & 0.00 & 0.00 & 4.28 \\
\hline q & 0.00 & 0.00 & 9.07 & 0.00 & 0.00 & 0.00 & $0.8 \%$ & 2.95 & 0.00 & 0.00 & 0.00 & 0.00 \\
\hline 10 & 2.35 & 0.66 & 9.22 & 0,00 & 0.00 & 0.00 & 2.90 & 2.01 & 0.00 & 0.00 & 2.90 & 0.00 \\
\hline 11 & 12.23 & 1,86 & 6.54 & 0.00 & 1.19 & 0.00 & 0.00 & 0.00 & 0.00 & 0.00 & 0.15 & 0.00 \\
\hline 12 & 19.00 & 0.00 & 12.01 & 0.00 & 0.00 & 0.00 & 0.00 & 0.00 & 0.00 & 0.00 & 1.45 & 0.00 \\
\hline 13 & 25.22 & 1,95 & 15.20 & 0.00 & 0.00 & 0.00 & 0.00 & 0,00 & 0.00 & 0.00 & 0,00 & 0,00 \\
\hline 14 & 9.41 & 11,35 & 5.45 & 0,00 & 1.41 & 0.00 & 0.00 & 0.00 & 0.00 & 0.00 & 0.00 & 0.00 \\
\hline 15 & 17.11 & 14.28 & 2.54 & 0,00 & 2.57 & 0,00 & 0.00 & 0,00 & 0.00 & 0.00 & 0.00 & 0.37 \\
\hline 16 & 16.60 & 13,35 & 5.55 & 0.00 & 0.02 & 0.00 & 0.00 & 0.00 & 0.00 & 25.25 & 0.49 & 3.23 \\
\hline 17 & 18,06 & 3.83 & 4.77 & 0,00 & 1.82 & 0.00 & 0.00 & 0.00 & 0.00 & 11,38 & 1.40 & 2.95 \\
\hline 18 & 14.61 & 0.00 & 0.00 & 7.20 & 0.00 & 0.09 & 0.00 & 0.00 & 0.00 & 23.20 & 1.03 & 0.99 \\
\hline 19 & 12.59 & 0.00 & 0.00 & 6.59 & 0.00 & 4.00 & 0.00 & 0.00 & 0.00 & 5.00 & 0.00 & 2,06 \\
\hline 20 & 11.60 & 4.04 & 0.00 & 5.00 & 0.00 & 23,35 & 1.41 & 0.00 & 0.76 & 4,34 & 0.00 & 0.00 \\
\hline 21 & 22,30 & 8.02 & 0.28 & 2,73 & 0.00 & 5.64 & 3.93 & 0.00 & 0.00 & 0.03 & 0.00 & 3,60 \\
\hline 22 & 22.69 & 7.48 & 0.00 & 0.01 & 0.00 & 0.01 & 2,37 & 0.00 & 0.00 & 14.12 & 0.00 & 0.25 \\
\hline 23 & 4.96 & 12.00 & 0.00 & 0.00 & 0.00 & 0.00 & 0.00 & 0.00 & 0.00 & 28.44 & 0.00 & 0.04 \\
\hline 24 & 1.89 & 16.93 & 0.00 & 0.00 & 0.00 & 0.00 & 0.00 & 0.00 & 0.00 & 3.84 & 0.00 & 0.28 \\
\hline 25 & 7.01 & 0.02 & 0.00 & 0.00 & 0.00 & 0.49 & 0,00 & 0.00 & 0.05 & 1.22 & 0.00 & 2.17 \\
\hline 26 & 0.00 & 0.01 & 0.00 & 0.00 & 0.00 & 0.00 & 0.00 & 0.00 & 0.13 & 0.35 & 14.79 & 5.81 \\
\hline 27 & 0.00 & 0.16 & 1.33 & 0.00 & 0.00 & 0.00 & 0.00 & 0.00 & 0.05 & 1.91 & 19.66 & 8.14 \\
\hline 28 & 0.00 & 0.36 & 0.77 & 0.00 & 0.00 & 0.00 & 0.00 & 0.00 & 0.00 & 0.15 & 17.74 & 7.38 \\
\hline 29 & 0.00 & 0.00 & 0,00 & 0.04 & 0.00 & 0.00 & 0.00 & 0.00 & 2.17 & 0.00 & 15.75 & 4,84 \\
\hline 30 & 0,00 & 0.00 & 3.46 & 0.00 & 0.00 & 0.00 & 0.00 & 3.19 & 2,24 & 1.97 & 13.11 & 6.44 \\
\hline 31 & 0.00 & 0.00 & 0.00 & 0.00 & 0.00 & 0.00 & 0.00 & 0.20 & 0.00 & 2.59 & 0.00 & 5.47 \\
\hline & .28 & 97.43 & 113.04 & 23.25 & 7.31 & 33.66 & 12,01 & 17.34 & 19.77 & 125,96 & 99.62 & 121,54 \\
\hline
\end{tabular}




\begin{tabular}{|c|c|c|c|c|c|c|c|c|c|c|c|c|}
\hline Iita & Jan & Fev & Mar & $\mathrm{Ab}:$ & Mai & Jur: & JuI & Ago & Set & Dut & Hov & We? \\
\hline & & & & & & & & & & & $m=:=z$ & \\
\hline 1 & 0.01 & 0.00 & 10.05 & 5.39 & 0.00 & 15.80 & 0.00 & 0.07 & 0.00 & 8.38 & 1.77 & 11,9 \\
\hline 2 & 0.00 & 11.50 & 10.63 & 2.15 & 0.00 & 2.91 & 0.00 & 9.68 & 0.00 & 0.91 & 1.84 & 2,29 \\
\hline 3 & 3.51 & 11.52 & 13.55 & 0,00 & 0,02 & 0.78 & 0.00 & 7.93 & 0.00 & 4.89 & 2.35 & 0.00 \\
\hline 4 & 10.79 & 1.71 & 7.19 & 14.83 & 0.00 & 0.00 & 0.00 & 0.09 & 2,20 & 16.13 & 0.00 & 0.00 \\
\hline 5 & 0.54 & 0.33 & 9,80 & 17.19 & 0.00 & 0.00 & 0.00 & 0.00 & 0.28 & 25.76 & 0.00 & 0.00 \\
\hline$b$ & 1.45 & 0.00 & 1.17 & 1.63 & 0,00 & 0.00 & 0.00 & 2.47 & 0.00 & 9.46 & 0.17 & 7.33 \\
\hline 7 & 0.83 & 0.49 & 0.35 & 0.00 & 0.00 & 0.00 & 0,00 & 2.18 & 0.00 & 1.40 & 2.26 & 3.47 \\
\hline 8 & $7.8 \mathrm{i}$ & 7.73 & 0.84 & 4.10 & 0.00 & 0.00 & 0.00 & 0.00 & 0.00 & 0.00 & 5,39 & 0.00 \\
\hline 9 & 1.08 & 1,53 & 0.00 & 0.52 & 0.00 & 0.00 & 0.23 & 0.00 & 0.00 & 1.44 & 12.26 & 0,03 \\
\hline 10 & 1.55 & 1.28 & 2.47 & 0.00 & 0.00 & 0.00 & 0.63 & 0.00 & 0.00 & 7.57 & 3.54 & 0,57 \\
\hline 11 & 6.39 & 0.49 & 0.25 & 0.00 & 0.00 & 0.00 & 0.00 & 0.10 & 0.00 & 0.00 & 0.00 & 4,00 \\
\hline 12 & 2.75 & 0,00 & 0.00 & 0.06 & 0.00 & 0.00 & 1,42 & 0,00 & 0.40 & 0.00 & 9.73 & 13.00 \\
\hline 13 & 3.61 & 0.96 & 1.77 & 0.74 & 0.00 & 0.00 & 4.75 & 0,00 & 0.00 & 0,00 & 39.86 & 18.67 \\
\hline 14 & 4.89 & 10.74 & 0,00 & 0.00 & 0.00 & 0.00 & 1.00 & 0.38 & 0.00 & 0.00 & 50.55 & 14.91 \\
\hline 15 & 0.65 & 19.16 & 0.00 & 0.00 & 0.00 & 0.00 & 0.00 & 2.38 & 0.00 & 0.00 & 22.54 & 0.00 \\
\hline 16 & 1.11 & 0.84 & 0.00 & 0.00 & 0.00 & 0.00 & 0.00 & 2.16 & 0.00 & 0.05 & 25.06 & 0.00 \\
\hline 17 & 0.00 & 0.54 & 0.00 & 0,36 & 0.00 & 0.00 & 0.03 & 0.00 & 0.00 & 0.31 & 25.19 & 0.00 \\
\hline 18 & 1.19 & 4.55 & 0.00 & 0.12 & 0.00 & 0.00 & 0.00 & 0.00 & 0.76 & 9.08 & 12.73 & 0.49 \\
\hline 19 & 1.38 & 26.61 & 0.00 & 0.00 & 0.00 & 0.00 & 0.00 & 0.00 & 2.17 & 18.11 & 12.98 & 0.00 \\
\hline 20 & 0.45 & 34,59 & 0.00 & 0.00 & 0.00 & 0.00 & 0.00 & 0.00 & 11.17 & 2.08 & 28.78 & 4.84 \\
\hline 21 & 5.13 & 1,11 & 6.63 & 0.00 & 0.00 & 0.09 & 0.00 & 0.00 & 1.20 & 0.00 & 2.95 & 0.82 \\
\hline 22 & 12.96 & 0.04 & 2.39 & 0.00 & 0.00 & 0.43 & 0.00 & 0.00 & 0.00 & 9.97 & 1.72 & 11.21 \\
\hline 23 & 17.97 & 1.78 & 0.00 & 0,20 & 2.84 & 0.00 & 0.00 & 0.00 & 0.00 & 3.97 & 0.00 & 29.54 \\
\hline 24 & 7.93 & 7.98 & 0.00 & 0.00 & 2.91 & 0.00 & 0.00 & 0.00 & 0.00 & 6.33 & 0.00 & 3.96 \\
\hline 25 & 7.13 & 1.43 & 0.28 & 0.00 & 0,00 & 0.48 & 0.00 & 0.00 & 0.64 & 0.00 & 0.00 & $5.8 \mathrm{~g}$ \\
\hline 26 & 0,07 & 5.04 & 2,02 & 0.00 & 0.00 & 0.00 & 0.00 & 0.00 & 5.54 & 0.00 & 0.00 & 0.34 \\
\hline 57 & 10.47 & 7.11 & 7.74 & 0.00 & 0,00 & 0.00 & 0.00 & 0.00 & 0.03 & 0.99 & 0.00 & 0.00 \\
\hline 28 & 3.89 & 8.25 & 13.31 & 5.26 & 0.00 & 0,00 & 0.00 & 0.03 & 0.00 & 0.00 & 0,00 & 0.00 \\
\hline 29 & 7,85 & 0.00 & 7.61 & 3.42 & 8.33 & 0.00 & 0.00 & 0.00 & 24.04 & $0,0 \pi$ & 8.07 & 0.95 \\
\hline 30 & 0.00 & 0.00 & 0.25 & 0.00 & 13,60 & 0.00 & 0,00 & 0,00 & 40.99 & 10.90 & 10.01 & 1.84 \\
\hline 31 & 0.00 & 0.00 & 4.50 & 0.00 & 2,18 & 0,00 & 0.00 & 0.00 & 0.00 & 6.15 & 0,00 & 34.59 \\
\hline Nedias & 123,39 & 169.31 & 102,40 & 55.97 & 29.80 & 20.49 & 8,06 & 27.47 & 89.44 & 144.15 & 279.96 & 172.67 \\
\hline
\end{tabular}




\begin{tabular}{|c|c|c|c|c|c|c|c|c|c|c|c|c|}
\hline IIIz & Jan & Fev & Han & $A b_{n}$ & ha 1 & Jun & $J_{U 1}$ & Ago & Set & Out & Hou & Dez \\
\hline 1 & 17.51 & 0.76 & 0,54 & 5,98 & 1,16 & 0.00 & 0.72 & 0.00 & 0.00 & $3.4 \overline{7}$ & 0,00 & 18.07 \\
\hline 2 & 1.58 & 2.20 & 0.60 & 92.72 & 0.38 & 0.00 & 0.65 & 0.00 & 0.00 & 6.21 & 7.81 & 0.57 \\
\hline 3 & 4.29 & 3.80 & 0.81 & 13.55 & 0,00 & 0.00 & 0.00 & 0.00 & 0.00 & 6.17 & 7.06 & 0.00 \\
\hline 4 & 12.52 & 3.66 & 0.00 & 4.10 & 0.00 & 0.00 & 0,00 & 0.00 & 0.00 & 11.2 & 7.41 & 0.00 \\
\hline 5 & 4.72 & 3.74 & 0.00 & 2.02 & 0.00 & 0.00 & 0.00 & 0.00 & 0.00 & 9.91 & 0.00 & 0.00 \\
\hline 6 & 3,15 & 3.59 & 2.45 & 0.84 & 3.25 & 0.00 & 0,00 & 0.00 & 4.37 & 0.20 & 0,36 & 0.00 \\
\hline 7 & 3.23 & 0.00 & 2.81 & 0.00 & 27.82 & 0.00 & 0.00 & 0.00 & 5.65 & 0.00 & 17.77 & 0.18 \\
\hline 8 & 6.67 & 0.00 & 8.50 & 0.00 & 28.58 & 0.03 & 0.00 & 0.00 & 0.00 & 1.72 & 33.18 & 2.14 \\
\hline 9 & 17.70 & 0.94 & 6.22 & 0.00 & 3.30 & 0.00 & 0.00 & 0.00 & 0.20 & 2,61 & 18,28 & 3,85 \\
\hline 10 & 9.56 & 4.73 & 9.53 & 0.00 & 0.33 & 0.47 & 1.18 & 0.00 & 5.07 & 0.48 & 0.00 & 7.50 \\
\hline 11 & 0,00 & 7.28 & 8.72 & 0.00 & 0.00 & 0.00 & 0.34 & 0.00 & 6.42 & 0.00 & 0.00 & 2.31 \\
\hline 12 & 0.00 & 10.84 & 17.13 & 0.03 & 0.03 & 0.00 & 6.72 & 0.00 & 0.53 & 5,65 & 24.11 & 3.80 \\
\hline 13 & 12.19 & 17.39 & 11.75 & 0.00 & 0.00 & 0.25 & 3.49 & 0,00 & 4.38 & 7.65 & 1.63 & 2.73 \\
\hline 14 & 35.80 & 11.76 & 8.02 & 0.00 & 0.00 & 0.51 & 0.15 & 0.00 & 1.70 & 0.00 & 4.39 & 11.50 \\
\hline 15 & $65,5 i$ & 32.47 & 1.52 & 0.00 & 0.00 & $1 x_{x} 91$ & 0.03 & 0.00 & 7.08 & 2.16 & 3.39 & 1.61 \\
\hline 16 & 77.21 & 51.20 & 2,80 & 0.00 & 0.00 & 1.41 & 0.00 & 0.00 & 0.81 & 0.34 & 0.00 & 5.80 \\
\hline 17 & 68.50 & 6.66 & 1.29 & 0.00 & 0.00 & 0.03 & 0.00 & 0.00 & 5.91 & 0.00 & 1.14 & 0.91 \\
\hline 18 & 53.21 & 86.86 & 3,03 & 0.00 & 0.00 & 0.47 & 0.00 & 0.00 & 0.00 & 0.99 & 0.18 & 0.69 \\
\hline 19 & 42.63 & 19.81 & 1.26 & 1.87 & 0.39 & 0.00 & 0.00 & 0.00 & 0.00 & 0,42 & 0.00 & 21.61 \\
\hline 20 & 13.17 & 7.31 & 0,15 & 0.70 & 0.18 & 0.00 & 0.00 & 0.00 & 0.38 & 14.87 & 0.60 & 45.80 \\
\hline 21 & 8.43 & 46.89 & 0.00 & 0.00 & 1.15 & 0.00 & 0.00 & 0.00 & 0.96 & 0.00 & 1.53 & 19.39 \\
\hline 22 & 2.07 & $1 \overline{4} .48$ & 0.00 & 0.00 & 0,00 & 2.56 & 0.11 & 0.00 & 0.21 & 1.97 & 7.05 & 0.58 \\
\hline 23 & 0.00 & 7.77 & 0.33 & 0.00 & 0.00 & 25.84 & 0.00 & 0.00 & 0.09 & 4.92 & 0.94 & 0.00 \\
\hline 24 & 0.00 & 4.77 & 1.43 & 0.00 & 0.00 & 7.61 & 2.11 & 0.00 & 0.00 & 1.39 & $1.0 t$ & 12.66 \\
\hline 25 & 2,39 & 2.05 & 0.00 & 0,00 & 0.00 & 0.00 & 0.00 & 11.61 & 0.00 & 3.09 & 0.00 & 0.90 \\
\hline 26 & 6.55 & 0.00 & 0.00 & 0.00 & 0.00 & 0.58 & 0.00 & 29.39 & 0.00 & 4.40 & 0.00 & 6.89 \\
\hline 27 & 0.00 & 0.34 & 0.00 & 0.00 & 0.00 & 1.25 & 0.00 & 31.15 & 0.00 & 1.49 & 0.33 & 0.27 \\
\hline 28 & 0.00 & 0.00 & 0.00 & 0.42 & 0.00 & 0.00 & 0.00 & 11.02 & 14.20 & 0.00 & 0.40 & 0,00 \\
\hline 29 & 0.00 & 0.00 & 0.00 & 11.11 & 0.00 & 0.00 & 0.00 & 11.59 & 11.90 & 0.00 & 4.84 & 0.26 \\
\hline 30 & 4.30 & 0.00 & 0.00 & 3.69 & 0.00 & 0.00 & 0.00 & 13.87 & 2.13 & 0.00 & 33,34 & 4.47 \\
\hline 31 & 17.37 & 0.00 & 1.64 & 0.00 & 0.00 & 0.00 & 0.00 & 3.78 & 0.00 & 0.00 & 0.00 & 7.70 \\
\hline & 492.24 & 266.30 & 90.53 & 67,03 & 66.68 & $42_{4} 92$ & 15.50 & 112.41 & 71.99 & 91.35 & 176.70 & 187,89 \\
\hline
\end{tabular}


PRECIFITACOES MEUTAS - MIARTAS D HEKSAIS

ANO : 1971

METUTO IE THIESSEH

BACTA WO RTO CORUKEATA

TABELA : $5,6,14$

\begin{tabular}{|c|c|c|c|c|c|c|c|c|c|c|c|c|}
\hline ไ1: & Jan & Fev & Har & $\mathrm{Abu}^{*}$ & hai & Jun & JuI & Ago & Set & Dut & Hou & Dez \\
\hline & & & & 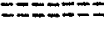 & . & $==z$ & & & & & & \\
\hline 1 & 20.29 & 17.52 & 0,00 & 0.00 & 0.00 & 0.00 & 0.80 & 0.00 & 2.21 & 25.35 & 5.68 & 14.44 \\
\hline 8 & 16.11 & 0.30 & 0.25 & 0,00 & 20.30 & 0.00 & 0.20 & 0.00 & 0.26 & 4.82 & 27.73 & 0.79 \\
\hline 3 & 1.39 & 2,24 & 0.08 & 0.39 & 28.13 & 0.00 & 0.00 & 0,00 & 0.23 & 2.75 & 2.77 & 2,32 \\
\hline 4 & 1,78 & 0.25 & 2.73 & 0.09 & 0.75 & 0.00 & 1.96 & 0.00 & 0,00 & 4,55 & 6.11 & 8.73 \\
\hline 5 & 7.35 & 0.00 & 14.75 & 0.00 & 19.44 & 0.00 & 3.65 & 0.00 & 0.72 & 9.67 & 0.00 & 0.99 \\
\hline 6 & 11.94 & 3,02 & 21.27 & 0.00 & 0.16 & 0.70 & 1.19 & 0.00 & 3,27 & 0.88 & 0.00 & 0.00 \\
\hline $\bar{i}$ & 11.59 & 17.28 & 2.51 & 0.69 & 0.00 & 0.00 & 0.00 & 0.00 & 2.06 & 10.5 & 0.00 & 0.00 \\
\hline 8 & 0.32 & 0.31 & 4.09 & 2.86 & 4.90 & 0.84 & 0.00 & 0.00 & 5.26 & 29.75 & 0,00 & 2,38 \\
\hline 9 & 10.33 & 2.99 & 3.22 & 15.52 & 0.16 & 0.30 & 0.00 & 0.00 & 4.79 & 0.29 & 0,04 & 10.59 \\
\hline 10 & 0,63 & 5.98 & 9.95 & 3,92 & 0.00 & 1.48 & 0.00 & 0.00 & 3.04 & 0.64 & 0.65 & 2.30 \\
\hline 11 & 1.14 & 2,66 & 10.15 & 0.00 & 0.00 & 4.72 & 0.00 & 0.00 & 4.60 & 12.64 & 0.00 & 0.00 \\
\hline 12 & 4.73 & 1.39 & 3.41 & 0.03 & 0.00 & 8.00 & 0.00 & 2.39 & 5.38 & 16.77 & 5.09 & 6.64 \\
\hline 13 & 6.77 & 3.52 & 2.47 & 5.13 & 0.00 & 4.82 & 0.00 & 0.00 & 0.00 & 0.47 & 13.75 & 3.64 \\
\hline 14 & 6.52 & 2.73 & 0.00 & 10.07 & 0.00 & 0.22 & 0,00 & 0.00 & 0.00 & 0.00 & 2,17 & 24.10 \\
\hline 15 & 2.27 & 11.14 & 0,00 & 0.00 & 0.00 & 7.35 & 0.00 & 0.10 & 0.00 & 5,44 & 1.50 & 15.27 \\
\hline 16 & 0.03 & 0,00 & 1.05 & 4.01 & 0.00 & 15,28 & 0.00 & 0.00 & 0.00 & 11.41 & 0.00 & 0.93 \\
\hline 17 & 0.82 & 0,00 & 0.67 & 0.72 & 0.00 & 11.87 & 0.00 & 0.00 & 0.00 & 8,16 & 0.00 & 0.00 \\
\hline 10 & 0.00 & 0,00 & 0.00 & 0.00 & 0.00 & 26.03 & 0.00 & 0,00 & 0.00 & 4.68 & 0.50 & 8.81 \\
\hline 19 & 0.00 & 6.58 & 0.00 & 0.00 & 0.00 & 22.19 & 0.00 & 0.00 & 0.00 & 0.00 & 1.88 & 9.39 \\
\hline 20 & 1,43 & 17.10 & 0.76 & 1.33 & 0.00 & 10.09 & 0,00 & 0.00 & 0.00 & 0.00 & 1.41 & 5.17 \\
\hline 21 & 0.66 & 14.81 & 0.64 & 8.13 & 0.00 & 4.35 & 0.00 & 0.00 & 0.00 & 0.00 & 0.00 & 3.98 \\
\hline 25 & 0.03 & 3.5 & 7.20 & 10.24 & 0.00 & 0.35 & 0.00 & 0.00 & 0.00 & 0.00 & 0.02 & 4.46 \\
\hline 23 & 0.00 & 0.13 & 10.81 & 7.30 & 0.00 & 1.40 & 0.00 & 0.00 & 0,83 & 0.09 & 0.63 & 9.31 \\
\hline 24 & 0.00 & 1.97 & 25.93 & 1,36 & 7.11 & 0,00 & 0.00 & 0.00 & 7.85 & 0.73 & 0.52 & 5.87 \\
\hline 25 & 0.00 & 4.48 & 14.08 & 0.00 & 12.10 & 0.00 & 0,00 & 0.17 & 12.38 & 3.05 & 10.00 & 5.78 \\
\hline 26 & 0.00 & 9.04 & 10.16 & 0.00 & 6.21 & 0.00 & 0.02 & 0.06 & 7.72 & 11.80 & 11.11 & 1.84 \\
\hline 27 & 0.14 & 0.00 & $3,7 t$ & 0.00 & 0.00 & 0.00 & 0.71 & 0.50 & 0.00 & 3.02 & 2.35 & 5.80 \\
\hline 28 & 0.00 & 0,00 & 19.25 & 0.00 & 0.00 & 0.00 & 0.27 & 0,00 & 1.18 & 0.09 & 0,00 & 6.56 \\
\hline 29 & 3.53 & 0,00 & 5.53 & 0.00 & 0,00 & 0.00 & 6.30 & 0.00 & 4.94 & 0.00 & 0,17 & 6.26 \\
\hline 30 & 7.00 & 0.00 & 2.28 & 0.00 & 0,00 & 0.00 & 9.37 & 0.00 & 4.18 & 0.04 & 7.28 & 3.34 \\
\hline 31 & 18,29 & 0.00 & 1.94 & 0.00 & 0.00 & 0.00 & 0.39 & 0.21 & 0.00 & 0,00 & 0.00 & 0.00 \\
\hline & & & 177.94 & $=72$ & & & 24.86 & 3.43 & 70.84 & & . & 169.69 \\
\hline
\end{tabular}


PRECIPITACOES MEUAS - UIARIAS E MEHGASS

ANO : 1972

METULO ME THESSES

BACIA IO KO CORUMEATAI

TAEELA: $: 5,6,15$

\begin{tabular}{|c|c|c|c|c|c|c|c|c|c|c|c|c|}
\hline in & $\operatorname{Ian}$ & Fen & 要ar & Atro & ria & Jun & IUI & Ago & Get & Dut & hos & Le? \\
\hline$i$ & 046 & 4754 & 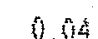 & 3954 & 000 & 000 & 000 & 000 & 026 & 635 & 8.17 & $3944)$ \\
\hline 2 & 215 & 530 & 855 & 0.10 & 064 & 0.00 & 0.00 & 000 & 0.00 & 176 & 14.89 & $04 \frac{4}{41}$ \\
\hline 3 & 101 & 1207 & 567 & 3.66 & 165 & 0,00 & 0.00 & 175 & 000 & 10,99 & 61 & $\begin{array}{l}4,31 \\
300\end{array}$ \\
\hline$\dot{a}$ & 194 & 1197 & 1.52 & 25.91 & 0.98 & 0.00 & 0.00 & 2134 & 0,00 & 34.20 & 15,44 & $\begin{array}{r}7.68 \\
12.38\end{array}$ \\
\hline 5 & 215 & 45 & 0.09 & +11 & 000 & 0.00 & 212 & 1340 & 212 & 2099 & 3.70 & $\begin{array}{r}14.00 \\
745\end{array}$ \\
\hline$b$ & 0,1 & 20 & 1.5 & 0.00 & 0,00 & 0.00 & 0.00 & 11,94 & 19.79 & 5.25 & 0,00 & 0.2 \\
\hline 7 & 5.13 & 3.64 & 7.20 & 0,1 & 0.00 & 0.00 & 1.70 & 10.66 & 0.85 & 13.79 & 0.00 & 2.51 \\
\hline 8 & 28.48 & 0.84 & 0,00 & 1285 & 3,66 & 0,00 & 18.96 & 0,00 & 0.00 & 1,17 & 0.64 & 0,00 \\
\hline$q$ & 9.66 & 10.03 & $5.9 t$ & 0,00 & 578 & 0.00 & 0.89 & $0.1 \frac{k}{1}$ & 0.00 & 1.31 & 8.65 & 0.00 \\
\hline 10 & 27.55 & 4.49 & 4,52 & 0,00 & 0.00 & 0.00 & 12,57 & 0.00 & 1.10 & 7.68 & 1.04 & 0.00 \\
\hline 11 & 5.62 & 14.78 & 0.02 & 0.00 & 0,00 & 0.00 & 0,98 & 0.00 & 6.07 & 54.06 & 4.02 & 0.00 \\
\hline 12 & 4.86 & 1.22 & 0.10 & 0.00 & 0.00 & 0.00 & 25.42 & 0.11 & 0,00 & 0.37 & 5.85 & 16.74 \\
\hline 13 & 0.00 & 1.96 & 0.41 & 0,02 & 0.00 & 0.00 & 59.08 & 0.66 & 0.00 & 0.00 & 4.37 & 0.00 \\
\hline 14 & 0.00 & 0.46 & 4.87 & 0.03 & 0.00 & 0.00 & 0.08 & 0.00 & 0.16 & 0,00 & 6.67 & 0.00 \\
\hline 15 & 0.00 & 9.61 & 2.90 & 2.03 & 0.00 & 0.00 & 2.21 & 0,00 & 0.00 & 37.57 & 2.51 & 0.00 \\
\hline 16 & 0.00 & 55.19 & 5.41 & 1.23 & 0.00 & 0.00 & 18.28 & 0.00 & 0.00 & 0,00 & 2.63 & 0.00 \\
\hline 17 & 0.00 & 1.18 & 1.04 & 0.00 & 0.00 & 0.00 & 0.78 & 0.00 & 0.00 & 0.00 & 4.46 & 0.00 \\
\hline 18 & 1.06 & 5.54 & 0,00 & 0.00 & 0.00 & 8.36 & 0.03 & 0,00 & 0.00 & 0.00 & 17.41 & 0.00 \\
\hline 17 & 3.37 & $3,5 i$ & 0,00 & 0.00 & 0.00 & 1,70 & 0.00 & 0.00 & 0,00 & 0.00 & 6.96 & 0,53 \\
\hline 20 & 1.92 & 45.72 & 0.00 & 0.00 & 0.00 & 0.00 & 0.00 & 0,00 & 0.00 & 0.00 & 27.21 & 1.14 \\
\hline 21 & 10.43 & 23.73 & 0.00 & 0.00 & 0.00 & 0.00 & 0.00 & 0.10 & 0.00 & 0.00 & 2.29 & 0.00 \\
\hline 22 & $37 \times 89$ & 10.60 & 0.00 & 0,00 & 0.73 & 0,00 & 0.00 & 1,13 & 1.70 & 0.00 & 0.00 & 0.43 \\
\hline 23 & 47.64 & 23.27 & 16.17 & 0.00 & 4.38 & 0.00 & 0.00 & 3.94 & 15.62 & 0.00 & 0.61 & 45.26 \\
\hline 34 & 32,09 & 30,81 & 11.76 & 0.00 & 5.87 & 0.00 & 0.00 & 7.07 & 2.93 & 0.00 & 0.07 & 11.58 \\
\hline 25 & 2.22 & 1.51 & 1.63 & 0.00 & 33.46 & 0.00 & 0.00 & 0.00 & 7,95 & 0.00 & 1.77 & 9.14 \\
\hline 20 & 2.78 & 7.64 & 19.90 & 0.00 & 0,00 & 0.00 & 15.27 & 0.00 & 2,19 & 0,00 & 2.27 & 1.80 \\
\hline 27 & 19.64 & 10.56 & 0.02 & 0.00 & 0.00 & 0,00 & 4.43 & 0,00 & 2.53 & 0.00 & 0.75 & 0.80 \\
\hline 28 & 1.23 & 12.46 & 0.00 & 0.00 & 0.00 & 0.00 & 0.00 & 0.00 & 7.97 & 0,00 & 0.00 & 8.24 \\
\hline 29 & 4,35 & 0.21 & 0.00 & 0.00 & 0.00 & 0.00 & 0.00 & 0.55 & 9.64 & 8,30 & 0.00 & 8.08 \\
\hline 30 & 5,07 & 0.00 & 0.00 & 0,00 & 0.00 & 0.00 & 0.00 & 7.58 & 2.62 & 16,43 & 0.00 & 5.95 \\
\hline 31 & 5.36 & 0.00 & 14.14 & 0.00 & 0.00 & 0.00 & 0.00 & 0,10 & 0,00 & 0.02 & 0.00 & 9.60 \\
\hline dits & 263.87 & $312.4 r_{2}$ & 13.28 & 84.59 & 56.33 & 10.16 & 162.80 & 80.07 & 83,50 & 214,18 & 143.65 & 105,28 \\
\hline
\end{tabular}




\begin{tabular}{|c|c|c|c|c|c|c|c|c|c|c|c|c|}
\hline $\mathrm{VIi}$ & Jan & Fet & mar & Abir & $M_{i} i$ & int & Tul & Ago & Set & but & Hots & liet \\
\hline 1 & 2.43 & 16.44 & 0,00 & 12,64 & 0.00 & 0.00 & 0.02 & 0.00 & 0.00 & 0.00 & 32.23 & 0.00 \\
\hline 2 & 0.00 & 0.58 & 3.63 & 3.74 & 0.00 & 0.00 & 0.40 & 0.00 & 38.28 & 0,00 & 7.02 & 0.00 \\
\hline 3 & 0.5 & 0.49 & 11.00 & 1.37 & 0,00 & 0,00 & 24.28 & 0.00 & 21.15 & 0,00 & 35.67 & 3.45 \\
\hline 4 & 0.44 & 15.26 & 20.62 & 1.79 & 0.80 & 0.00 & 0.00 & 0.00 & 0.00 & 0,00 & 0.00 & 33.80 \\
\hline 5 & 5.74 & 13.22 & 6.20 & 0,03 & 0,00 & 0.00 & 0,00 & 0.02 & 0.00 & 0.00 & 0.55 & 3.70 \\
\hline 6 & 10,32 & 24.30 & 0,00 & 5.65 & 1.09 & 0.00 & 0.00 & 17.31 & 0.00 & 0.00 & 1.87 & 16,46 \\
\hline 7 & 548 & 5.79 & 0.19 & 2,65 & 0.07 & 0.00 & 0.05 & 0.00 & 3.00 & 11,13 & 0.00 & 33.73 \\
\hline 8 & 0.00 & 0.00 & 12.3 & 10.53 & 0.37 & 0.00 & 0.08 & 0.00 & 0,00 & 0.00 & 0.50 & 27.3 \\
\hline 9 & 2,85 & 0.00 & 31.47 & $A, 07$ & 0.00 & 0.00 & 0.00 & 0.00 & 0.46 & 3.99 & 0,00 & 1.87 \\
\hline 10 & 10.66 & 0.00 & 1.23 & 11.23 & 20.24 & 0.00 & 0.00 & 0.00 & 3.09 & 0.09 & 0.05 & 0.00 \\
\hline 11 & 13.30 & 2.61 & 0.00 & 10.94 & 0.14 & 0.00 & 0.00 & 0.00 & 0.00 & 13,06 & 2.40 & 0.00 \\
\hline 12 & 3.14 & 0.00 & 0.00 & 13.85 & 3.82 & 0.00 & 0,00 & 0,00 & 0.00 & 12.65 & 1.96 & 0.19 \\
\hline 13 & 14.26 & 36.51 & 0.00 & 13.84 & 0.03 & 0.00 & 0.02 & 0.00 & 0,00 & 1.47 & 16.37 & 0.19 \\
\hline 14 & 1.07 & 8.98 & 0.00 & 0.11 & 0.00 & 0.00 & 0.00 & 0.00 & 0.00 & 0.00 & 14.51 & 12.39 \\
\hline 15 & 3.45 & 17.90 & 0.00 & 1.50 & 0.00 & 0.00 & 0.00 & 0.00 & 0.60 & 0.00 & 0.00 & 3.56 \\
\hline 16 & 8.82 & 12.85 & 0.00 & 3.17 & 0,00 & 0.00 & 0.00 & 0.00 & 0.00 & 0.00 & 0.00 & 8.72 \\
\hline il & 5.90 & 3,15 & 0.00 & 3.55 & 0.00 & 0.00 & 0.02 & 0.00 & 0.00 & 0.00 & 0.49 & 11.77 \\
\hline 18 & 0.00 & 0,00 & 0.00 & 0.00 & 0.00 & 6.35 & 0.41 & 0.00 & 0.00 & 9.10 & 18,33 & 42.50 \\
\hline 19 & 0.00 & 1.68 & 0.60 & 3.75 & 0.00 & 9.03 & 2.33 & 0.00 & 0.00 & 33.81 & 19.37 & 8.66 \\
\hline 20 & 5.32 & 5.04 & 0.00 & 0.36 & 0.00 & 0.00 & 0.02 & 0.00 & 0.00 & 0,00 & 0,00 & 19.90 \\
\hline 21 & 8.01 & 26.32 & 0.97 & 18.76 & 0.00 & 0.00 & 0.00 & 0.00 & 0.00 & 0.00 & 0.00 & 34.98 \\
\hline 22 & 5,12 & 0.00 & 7.24 & 3,27 & 21.59 & 0.00 & 5.55 & 0.00 & 0.06 & 0.00 & 0.00 & 7.92 \\
\hline 23 & 15.66 & 0.00 & 8.43 & 5.48 & 0,02 & 0.00 & 0.05 & 0.00 & 0.00 & 0.00 & 0.00 & 1.01 \\
\hline 24 & 0,98 & 0.21 & 5.61 & 7.92 & 0.00 & 0.00 & 0.00 & 0.00 & 0.00 & 0.00 & 0.00 & 15.07 \\
\hline 25 & 510 & 875 & 0,00 & 0.00 & 0,05 & 1.10 & 0.00 & 0.00 & 0.00 & 0.00 & 2.70 & 16.31 \\
\hline 8 & 2,00 & 6.07 & 6.32 & 0.00 & 1.20 & 0.00 & 0.05 & 0.00 & 3.48 & 0.00 & 0.77 & 13,38 \\
\hline 27 & 0.00 & 3.69 & 0.00 & 3.03 & 0.00 & 8.01 & 0.00 & 0.00 & 0.41 & 4.00 & 0.00 & 0.00 \\
\hline 28 & 0.00 & 4.92 & 0,00 & 8.08 & 0.00 & 0.56 & 13,34 & 0.09 & 0.00 & 1.06 & 0.00 & 5.13 \\
\hline 29 & 0.00 & 0.00 & 1.73 & 0.00 & 0.00 & 0.10 & 0.02 & 0,00 & 0.00 & 0.00 & 0.00 & 39.21 \\
\hline 30 & 0.40 & 0,00 & 15.71 & 0,00 & 0,00 & 0.00 & 0.00 & 0.00 & 0,00 & 0.00 & 0.00 & 44.34 \\
\hline 31 & 2.70 & 0.00 & 31.72 & 0,00 & 0.00 & 0.00 & 0.05 & 0.00 & 0,00 & 29.47 & 0.00 & 21.72 \\
\hline & 70 & .75 & $=56$ & .93 & 49.42 & .21 & 46.57 & 17.42 & 70.53 & 119.85 & & 429.51 \\
\hline
\end{tabular}




\begin{tabular}{|c|c|c|c|c|c|c|c|c|c|c|c|c|}
\hline Ilía & $\mathfrak{j} 3 n$ & Fot & Har & Abr & $\mathrm{H}_{a}$ & Jun & JuI & Agt: & Set & 0ut: & Hou & Hez \\
\hline & & & & & & & $\theta_{0}$ & $n 0$ & & & & \\
\hline 1 & 26.07 & 11,10 & 0.00 & 0.00 & 0.00 & 0.00 & 0.00 & 0.00 & 0.00 & 0.00 & 0.00 & 12.53 \\
\hline 3 & 15.76 & 9.61 & 0.00 & 3.58 & 0.00 & 0.00 & 0.00 & 0.00 & 0.00 & 11,30 & 0.00 & 4.90 \\
\hline 3 & 3.16 & 2.51 & 0.00 & 11.58 & 0.00 & 1.04 & 0.00 & 0.00 & 0.13 & 1.26 & 0.00 & $D_{0} 0$ \\
\hline 4 & 0.00 & 0.00 & 0.00 & 5.61 & 0.00 & 0.25 & 0.00 & 0.00 & 0.00 & 2.14 & 0.00 & 87.30 \\
\hline 5 & 1.45 & 0.00 & 0.64 & 3,12 & 0.00 & 0.70 & 0.00 & 0,00 & 0,00 & 15.44 & 1,20 & 24.30 \\
\hline 6 & 4.88 & 0.00 & 0.12 & 0.15 & 0,00 & 0.13 & 0.00 & 0.00 & 0.00 & $0.3 \%$ & 0.44 & 47.18 \\
\hline 7 & 6.36 & 0,00 & $2.0 ?$ & 0.00 & 0.00 & 0.88 & 0.00 & 0.00 & 0,00 & 0,00 & 2.57 & 0.23 \\
\hline 8 & 4,90 & 0.00 & 6.47 & 0.00 & 0.02 & 0.38 & 0.00 & 0.00 & 0.00 & 0.00 & 0.00 & 2.70 \\
\hline 9 & 0.37 & 0.00 & 8.19 & 0.00 & 0.00 & 0.00 & 0.00 & 0.00 & 0.00 & 0.29 & 0.00 & 0.00 \\
\hline 10 & 3.28 & 0.00 & 2.60 & 0.00 & 0.00 & 1.43 & 0.00 & 0.00 & 0.00 & 0.41 & 0.00 & 0,00 \\
\hline 11 & 13.52 & 0.00 & 9.78 & 1.27 & 0.05 & 3.62 & 0.00 & 0.00 & 0.00 & 0.00 & 0.46 & 0.00 \\
\hline 12 & 28.40 & 3.16 & 28.09 & 0,00 & 0,00 & 54,86 & 0.00 & 0.00 & 0,00 & 0.00 & 0.00 & 0.00 \\
\hline 13 & 2.79 & 0.27 & $2 \times 15$ & 0.00 & 5.35 & 0.00 & 0.00 & 0.61 & 0.00 & 0.00 & 6,38 & 11.22 \\
\hline 14 & 22.71 & 6.02 & 45.16 & 2,70 & 0,17 & 0.00 & 0.00 & 0.00 & 0.00 & 0.00 & 0.69 & 9.80 \\
\hline 15 & 5.78 & 6.52 & 13.93 & 0.00 & 0.03 & 0.00 & 0,00 & 6.89 & 0.00 & 0.00 & 0.00 & 15.80 \\
\hline 16 & 17.66 & 0.20 & 2.51 & 0.00 & 0,00 & 0.00 & 0.00 & 0.25 & 0.00 & 0.00 & 0.00 & 0.00 \\
\hline 17 & 21.50 & 1.96 & 14.65 & 0.00 & 0.00 & 0.00 & 0.00 & 0,00 & 0.00 & 27.99 & 0.00 & 1,70 \\
\hline 18 & 1.99 & 4.27 & 72.68 & 0.19 & 0.02 & 0.00 & 0.00 & 0.28 & 0.00 & 0.00 & 0.00 & 23.90 \\
\hline 19 & 3.50 & 1.18 & 29.42 & 0.00 & 0.55 & 0,0 & 0.00 & 0.00 & 0.00 & 817 & 0.00 & 27.60 \\
\hline 50 & $\$ .70$ & 3.34 & 68.35 & 0.00 & 2,47 & 0.00 & 0,00 & 0.00 & 0.49 & 6.38 & 0.00 & 1,27 \\
\hline $2 \mathrm{I}$ & 0.00 & 0.00 & 8.00 & 0.00 & 0.00 & 0,00 & 0.00 & 0.00 & 2,71 & 4.50 & 41,68 & 26.36 \\
\hline 22 & 4.25 & 1,50 & 0.41 & 0.00 & 0.02 & 6.88 & 0.00 & 0,00 & 0,00 & 14,04 & 6.17 & 20.98 \\
\hline 23 & 0.00 & 4.78 & 1.06 & 0.00 & 0.00 & 0.04 & 0.00 & 0.00 & 0.00 & 0.00 & 10.12 & 21,56 \\
\hline 24 & 0.96 & 14.66 & 2.84 & 0.00 & 0.00 & 0.00 & 0.00 & 0,00 & 0.00 & 0.00 & 0.00 & 8,86 \\
\hline 25 & 0.98 & 0.90 & 19.64 & 1.66 & 0.14 & 18.39 & 0.00 & 0.00 & 0.00 & 6.25 & 0.00 & 1.75 \\
\hline 26 & 10.24 & 3,88 & 8.42 & 3.63 & 0.00 & 20.26 & 0.00 & 0,00 & 0.00 & 6.77 & 0.00 & 0.27 \\
\hline 27 & 1.78 & 0.00 & 0.00 & 0.05 & 0.00 & 16.12 & 0.00 & 0,00 & 3.36 & 2.55 & 2.46 & 8.77 \\
\hline 88 & 25.78 & 0.00 & 0.00 & 0.00 & 0.00 & 0.00 & 0.00 & 0.00 & 2.79 & 9.16 & 14.73 & 30.61 \\
\hline 29 & 4.12 & 0.00 & 0.00 & 0.00 & 0.00 & 0.00 & 0.00 & 0.60 & 18.66 & 36.06 & 2.09 & 4.21 \\
\hline 30 & 12.39 & 0.00 & 0.00 & 0,00 & 0.00 & 0.00 & 0.00 & 0.00 & 1.93 & 9,31 & 1.83 & 32,34 \\
\hline 31 & 24.28 & 0.00 & 0.00 & 0.00 & 0.00 & 0.00 & 0.00 & 0.00 & 0,00 & 0.47 & 0.00 & 0.54 \\
\hline hedias & 270.44 & 75,80 & 347,30 & 33.54 & 8.82 & 126,95 & 0.00 & 2,03 & 30.07 & 159.94 & 90.81 & 378.80 \\
\hline
\end{tabular}




\begin{tabular}{|c|c|c|c|c|c|c|c|c|c|c|c|c|}
\hline Ino & Jan & Fen & Mar & Atr? & Ha & Jun & JuI & Ago & set & Gut & hou & IE \\
\hline 1 & 15.30 & 2.06 & 1.02 & 0.00 & 0.43 & 0.00 & 0.79 & 0.00 & 0.00 & 31.78 & 8.72 & 34,30 \\
\hline 8 & 19.30 & 5,03 & 2,52 & 0,00 & 1.14 & 0,00 & 0,00 & 0,00 & 0.00 & 0.00 & 7.63 & 10.5 \\
\hline 3 & 0.00 & 17.58 & 4.35 & 0.00 & 0.50 & 0.06 & 1.73 & 0.00 & 0.13 & 5.28 & 0.03 & 0.37 \\
\hline 4 & 0,45 & 4.26 & 0,10 & 0.00 & 1.65 & 0.08 & 15,88 & 0.00 & 0.00 & 14.65 & 0,00 & 13.44 \\
\hline 5 & 0.03 & 10.66 & 0.67 & 0.00 & 0.43 & 0.38 & 0.40 & 0.00 & 0.00 & 6.80 & 0.00 & 0.00 \\
\hline 6 & 0.00 & 28.70 & 1.50 & 0.00 & 7.35 & 0.00 & 0.44 & 0,00 & 0.00 & 10.20 & 0.00 & 8.31 \\
\hline 7 & 8.15 & 27.93 & 0.38 & 0.00 & 4.49 & 0.00 & 0.06 & 0,00 & 0.00 & 2.59 & 12.00 & 2.90 \\
\hline 8 & 1.21 & 34.90 & 0.82 & 0.00 & 0.35 & 0.00 & 0.00 & 0.00 & 0.00 & 33.85 & 0,00 & 0.19 \\
\hline g & 0.15 & 16.42 & 0.23 & 0.00 & 0.00 & 0.00 & 0.00 & 0.00 & 0.00 & 2.76 & 0.12 & 0.00 \\
\hline 10 & 2.80 & 29.24 & 8.65 & 7.07 & 0.00 & 0,00 & 0.00 & 0.00 & 0.00 & 1.13 & 1.03 & 13,17 \\
\hline 11 & 12.45 & 0.00 & 1.19 & 19.36 & 0.00 & 0.00 & 0.00 & 0.00 & 0.00 & 0.00 & 0.58 & 0.00 \\
\hline 12 & 1.98 & 0.00 & 0.00 & 0.40 & 0.00 & 0.00 & 0.00 & 0.00 & 0,00 & 8.70 & 1.95 & 0.00 \\
\hline 13 & 17.77 & 0.00 & 0.00 & 0.00 & 0.00 & 0.00 & 0.00 & 0.00 & 0.00 & 0.00 & 0.00 & 39.35 \\
\hline 14 & 6.24 & 2.66 & 0.14 & 4,30 & 0.00 & 0.00 & 0.00 & 0,00 & 0.00 & 0.11 & 0.97 & 9.23 \\
\hline 15 & 32.26 & 9.13 & 5.01 & 1,13 & 0.00 & 0.00 & 0.00 & 0.00 & 0.00 & 2.95 & 0.00 & 5.52 \\
\hline 16 & 6.74 & 4.54 & 4.30 & 12.85 & 0.00 & 0.03 & 0.00 & 0,00 & 0.00 & 0.18 & 4.59 & 0.00 \\
\hline 17 & 2.40 & 5.20 & 0.00 & 0,00 & 0.00 & 0.00 & 5.79 & 0.00 & 0.00 & 1.06 & 9.65 & 0,00 \\
\hline 18 & 0.70 & 0.63 & 0,00 & 0.00 & 0.00 & 0.00 & 7.50 & 0.00 & 0.00 & 7.16 & 24.47 & 0.33 \\
\hline 19 & 5.49 & 7.95 & 0.00 & 0,00 & 0.00 & 0.00 & 0.00 & 0,00 & 0.00 & 10.72 & 3.69 & 16.89 \\
\hline 20 & 1.85 & 9.88 & 0.00 & 0,00 & 0.04 & 0.00 & 0.00 & 0.00 & 0.00 & 0.00 & 1.24 & 3.22 \\
\hline $\bar{Z} \mathbf{i}$ & 0.00 & 3.35 & 5.46 & 0.60 & 0.00 & 0.00 & 0.00 & 0,00 & 0.00 & 0.00 & 43.54 & 0.00 \\
\hline $2 z$ & 0.00 & 17.42 & 3.72 & 0.00 & 0.00 & 0.00 & 0.00 & 0.00 & 0.00 & 0.00 & 2.44 & 0,58 \\
\hline 23 & 0.00 & 22.30 & 0.00 & 0.00 & 0.00 & 0.00 & 0.00 & 0.00 & 0.00 & 0,00 & 3.25 & 13.80 \\
\hline 24 & 0.00 & 18.59 & 1.41 & 0.00 & 0.00 & 0.00 & 0.00 & 0.00 & 1.59 & 0.00 & 5.95 & 5.70 \\
\hline 25 & 2,74 & 3,63 & 6.06 & 0,00 & 0.00 & 0.01 & 0.00 & 0.00 & 0.04 & 0.18 & 29.18 & 40.91 \\
\hline 26 & 8,81 & 0.95 & 0.00 & 0,00 & 0.00 & 0.00 & 0.00 & 0.00 & 2.14 & $1.5 \%$ & 51.88 & 21.44 \\
\hline 27 & 0.89 & 6,35 & 0.00 & 0.00 & 0.00 & 0.00 & 0.00 & 0.00 & 8.99 & 0,95 & 1.54 & 13.17 \\
\hline 28 & 0.00 & 21.90 & 0.00 & 0.00 & 0.00 & 0.00 & 0.00 & 0.00 & 4.70 & 0.00 & 0.36 & 10,89 \\
\hline 29 & 2.42 & 0,00 & 0.00 & 0.00 & 0.00 & 1.40 & 0.00 & 0,00 & 0.00 & 0.00 & 5.49 & 2,53 \\
\hline 30 & 84.95 & 0.00 & 0.17 & 0.00 & 0,00 & 0.00 & 0.00 & 0,00 & 20.72 & 3,80 & 17.54 & 19.31 \\
\hline $3 i$ & 0.86 & 0.00 & 3.84 & 0.00 & 0.00 & 0.00 & 0.00 & 0.00 & 0,00 & 4.00 & 0.00 & 3.17 \\
\hline & 176,06 & 311.10 & 51,54 & 45.11 & 16,38 & 1,96 & 32.59 & 0.00 & 38,51 & 140.46 & 235.74 & 287.68 \\
\hline
\end{tabular}


PRECIPITACOES MEIIAS - IITARIAS E HEHSAIS

ANO : 1976

METOUO ME THISSSE

EACTA DO RIO CORLHBATAI

TABELA : 5.6 .19

\begin{tabular}{|c|c|c|c|c|c|c|c|c|c|c|c|c|}
\hline Di & Jan & Fev & Mar & Ator & Hai & Jun & JuI & $\mathrm{AgO}$ & $5 e t$ & Gut & Hou & Lez \\
\hline & & & & & & & $x=2=$ & & $x=0=0$ & & & \\
\hline 1 & 4.52 & 20.30 & 6.56 & 0.00 & 0.00 & 0.00 & 0.32 & 0.00 & 0.00 & 0.90 & 3.34 & 0.00 \\
\hline 2 & 12,14 & 12.01 & 7.64 & 0.00 & 0.00 & 0.00 & 19.83 & 0.00 & 0.00 & 0.00 & 0.00 & 9.51 \\
\hline 3 & $3 n .77$ & 25.26 & 6.96 & 0.00 & 0.00 & 0.06 & 68.44 & 0.00 & 0.00 & 0.00 & 0.00 & 0.00 \\
\hline 4 & 4,78 & 2.90 & 7.07 & 0,00 & 0.00 & 0.12 & 23.32 & 0.00 & 0.00 & 0.00 & 0.15 & 0.00 \\
\hline 5 & 20.45 & 10.90 & 0.00 & 1.01 & 0.47 & 9.83 & 0.00 & 0.00 & 1.83 & 0.5 & 5.8 & 4.50 \\
\hline 6 & 3.62 & 7.04 & 0.00 & 0.00 & 4.15 & 59.18 & 0.00 & 1.88 & 15.22 & 8.77 & 19.09 & 14.47 \\
\hline 7 & 1.30 & 20.74 & 1.61 & 0.21 & 0.00 & 0.00 & 0.00 & 1.06 & 14.13 & 0.00 & 0.00 & 0.00 \\
\hline 8 & 7.10 & 32,19 & 4.05 & 0.00 & 0,00 & 0.03 & 0.66 & 0.00 & 4.68 & 1.75 & 0.00 & 0.57 \\
\hline f & 4.06 & 12.80 & 9.00 & 0.37 & 0.00 & 0.00 & 10.47 & 0.00 & 0.00 & 41.56 & 0.00 & 22,33 \\
\hline 10 & 0.00 & 2.01 & 0.66 & 6.62 & 21.96 & 0.45 & 6,55 & 6.97 & 0.00 & 21.31 & 0.03 & 0.03 \\
\hline 11 & 6.99 & 0.00 & 5.36 & 7.56 & 0.41 & 3,04 & 0.00 & 1.09 & 0.21 & 0.00 & 0,00 & 0.00 \\
\hline 12 & 27.96 & 0.00 & 12.93 & 13.74 & 4.62 & 0.00 & 0.00 & 15.65 & 1.90 & 0.00 & 0.00 & 0.74 \\
\hline 13 & 0.03 & 0.00 & 0.58 & 14.41 & 0.02 & 0.69 & 0.00 & 14.10 & 3.86 & 0.00 & 5.01 & 4.02 \\
\hline 14 & 0,00 & 0.00 & 0.39 & 28,28 & 0,00 & 0.88 & 0.00 & 84.84 & 18.62 & 0.00 & 0.35 & 2.19 \\
\hline 15 & 5.51 & 0.00 & 0.00 & 17.81 & 0.00 & 0.02 & 0.00 & 0.35 & 3.88 & 0.00 & 0.00 & 0.52 \\
\hline 16 & 10.95 & 5.39 & 0.00 & 0,00 & 0,00 & 0.03 & 0,00 & 0.00 & 26.16 & 0,00 & 0,00 & 15.80 \\
\hline 17 & 0.00 & 3,5 & 0,00 & 0.00 & 2,91 & 0,00 & 0,00 & 0.00 & 0.22 & 1.77 & 5.58 & 8.99 \\
\hline 18 & 0.93 & 36.06 & 49.52 & 0.00 & 5,44 & 0.00 & 0,00 & 0,00 & 0,00 & 7.38 & 0.00 & 4.66 \\
\hline 19 & 0.02 & 17.39 & 16.77 & 0.00 & 24.21 & 0.00 & 0.00 & 2.94 & 0.00 & 11.26 & 0.00 & 0.00 \\
\hline 20 & 2.99 & 2.45 & 47.42 & 0.00 & 11.25 & 0,00 & 0.00 & 8.27 & 0,00 & 2.94 & 40.10 & 0,12 \\
\hline $2 \mathrm{i}$ & 15.68 & 27.08 & 10.16 & 2.21 & 1.47 & 0.00 & 0.12 & 0.65 & 0.00 & 0.00 & 24.85 & 7.39 \\
\hline 22 & 3.59 & 0.40 & 2.47 & 0.00 & 10.15 & 0.00 & 0.00 & 0.00 & 0.00 & 0.00 & 4.74 & 0.00 \\
\hline 23 & 0.56 & 22.92 & 0.00 & 9.45 & 0.00 & 0.00 & 0,00 & 0.00 & 4.35 & 0.07 & 0.00 & 11,84 \\
\hline 24 & 0.00 & 27.81 & 13.80 & 0.00 & 0.00 & 0,00 & 0.00 & 0.00 & 0.00 & 2.90 & 0.00 & 1,94 \\
\hline 25 & 0.00 & 0.15 & 6.73 & 0.00 & 0.03 & 0.00 & 0.00 & 0.00 & 0.00 & 20.08 & 0.00 & 4.43 \\
\hline 86 & 0.51 & 4.93 & 3.06 & 0.00 & 0.19 & 0.00 & 0,00 & 0.00 & 0.00 & 10,18 & 1.05 & 13.74 \\
\hline $2 \pi$ & 16.33 & 47.39 & 5.39 & 0.00 & 0.57 & 0.00 & 0.00 & 0.00 & 27.43 & 1.19 & 7.60 & 28,33 \\
\hline 28 & 9.01 & 13.19 & 0.49 & 0.00 & 10.50 & 0.00 & 0.00 & 0.00 & 21.81 & 0.12 & 7.47 & 36.29 \\
\hline 29 & 6.20 & 4.72 & 0.00 & 0.00 & 56.10 & 1.40 & 0.00 & 0.00 & 3.15 & 0.00 & 7.45 & 0.00 \\
\hline 30 & 1.75 & 0.00 & 0.00 & 0.49 & 1.52 & 0,00 & 0.00 & 0.00 & 0.16 & 0.00 & 0.00 & 0.00 \\
\hline 31 & 10.24 & 0.00 & 0.00 & 0.00 & 0.00 & 0.00 & 0.00 & 0.00 & 0.00 & 0.43 & 0.00 & 0.48 \\
\hline & 99 & & & 102.16 & 155.97 & 84.67 & & & & & & \\
\hline
\end{tabular}


PRECTPITACOES MEUIAS - IIARIAS E WEHSAIS

4h60: 1977

METONO IE THIESSE

BACIA UO FIO CORLHBATAI

TADELA : $5,6,20$

\begin{tabular}{|c|c|c|c|c|c|c|c|c|c|c|c|c|}
\hline Ilia & Jan & Fet: & Har & Abr & Hai & Jun & Iul & $A 90$ & Set & Out & Hou & Mez \\
\hline & & & & & & & & & & 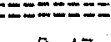 & & \\
\hline 1 & 6.35 & 20.24 & 0,00 & 16.36 & 0.29 & 0.49 & 0.05 & 0.00 & 0.00 & 2,47 & 0.00 & 10.60 \\
\hline 2 & 4.90 & 0.05 & 0.09 & 0.00 & 0.06 & 1,32 & 0.00 & 0.00 & 7.39 & 32.35 & 35.03 & 23.21 \\
\hline 3 & 4.63 & 0.00 & 1.18 & 0.00 & 0.59 & 0.30 & 0.00 & 0.00 & 0.00 & 0.00 & 0.00 & 29.31 \\
\hline 4 & 5.29 & 0.77 & 1.30 & 3.73 & 0,00 & 2.31 & 0.00 & 0.00 & 0.00 & 0.00 & 6.17 & 34,70 \\
\hline 5 & 6.78 & 7.86 & 2.39 & 21.82 & 0.02 & 25.32 & 0.00 & 0.00 & 0.00 & 0,0 & 0.39 & 10.91 \\
\hline$b$ & 13,03 & 0.11 & 0.00 & 0,00 & 0.00 & 26.79 & 0.00 & 0.00 & 1.76 & 4.38 & 0.00 & 9.11 \\
\hline 7 & 33.63 & 0.62 & 4.79 & 0.00 & 0.00 & 0.00 & 0.00 & 0.00 & 16.71 & 0.00 & 3.31 & 2.62 \\
\hline 8 & 1.66 & 3.52 & 3.70 & 0.00 & 0.00 & 0.09 & 0.00 & 0.00 & 19.75 & 0.00 & 0.00 & 16.87 \\
\hline 5 & 0.00 & 1.19 & 0.12 & 35,55 & 0.00 & 0,00 & 0.00 & 0.00 & 1.45 & 0.00 & 0.00 & 0.15 \\
\hline 10 & 0,00 & 0.00 & 0.00 & 21.98 & 0.00 & 0.05 & 0.00 & 0,00 & 0.00 & 0.00 & 0.00 & 0.00 \\
\hline 11 & 2.78 & 0.00 & 0.00 & 0.10 & 0.00 & 0.00 & 0.00 & 0.00 & 0.00 & 0.00 & 1.19 & 13.65 \\
\hline 12 & 0.70 & 3.53 & 0.44 & 0.05 & 0.00 & 0.00 & 0.00 & 0.00 & 0.00 & 0.00 & 16.50 & 0.00 \\
\hline 13 & 0.59 & 0.00 & 0.00 & 0.00 & 0.00 & 0,00 & 0.00 & 0.00 & 0.00 & 1.36 & 30.25 & 0,00 \\
\hline 14 & 0.00 & 0.00 & 6.04 & 0,00 & 0.05 & 0.00 & 0.00 & 0.00 & 0.00 & 0.00 & 0,00 & 0.00 \\
\hline 15 & 35.46 & 0.00 & 7.99 & 0.00 & 0.00 & 2.97 & 0.00 & 0.00 & 0.00 & 0.00 & 26.58 & 0.00 \\
\hline 16 & 1.06 & 1.27 & 0.33 & 0.00 & 0.00 & 0.65 & 0.00 & 0.00 & 0.00 & 0.00 & 8.82 & 0.00 \\
\hline 17 & 41.38 & 0.00 & 8.69 & 0,19 & 1.52 & 0,00 & 0.00 & 0.00 & 0.65 & 7.92 & 2.42 & 0.00 \\
\hline 18 & 1.83 & 0.00 & 0.00 & 0.00 & 0.43 & 0.00 & 3.88 & 0.00 & 0.00 & 0.46 & 1.01 & 0.20 \\
\hline 19 & 45.61 & 0.00 & 1.00 & 6.16 & 0.00 & 0.00 & 0,11 & 0.00 & 1.32 & 1.17 & 13.11 & 31,62 \\
\hline 20 & 31.39 & 0.00 & 16.75 & 11.10 & 0.03 & 0.00 & 0,00 & 0.00 & 3.23 & 0.00 & 0.00 & $6, A 4$ \\
\hline 21 & 0.00 & 0.66 & 9.25 & 15.63 & 0,00 & 0.00 & 0.00 & 0.00 & 11,47 & 0.00 & 6.04 & 12,00 \\
\hline 22 & 0.00 & 0.00 & 15.53 & 0.00 & 0.00 & 0.00 & 0.00 & 0,00 & 0.00 & 0.00 & 0,05 & 40.93 \\
\hline 23 & 1.14 & 0.00 & 7.75 & 0.00 & 0,00 & 0.46 & 0.21 & 0.00 & 3,73 & 0,00 & 12,39 & 31.30 \\
\hline 84 & 14.30 & 12.50 & 7.01 & 0.00 & 0.00 & 0.00 & 0,00 & 0.00 & 29.09 & 0,00 & 10.17 & 12.54 \\
\hline 25 & 13.66 & 0.00 & 1.91 & 0,00 & 0,00 & 4.31 & 7.23 & 0.00 & 3,60 & 0.20 & 0.65 & 0.00 \\
\hline 26 & 9.26 & 5.55 & 8.30 & 0.00 & 0.00 & 0.07 & 0.00 & 0.00 & 0.23 & 0.15 & 6.24 & 0.00 \\
\hline 27 & 85.33 & 0.00 & 1.25 & 0.00 & 0,00 & 0,00 & 0.00 & 0.00 & 0.01 & 3.32 & 0.00 & 0.00 \\
\hline 28 & 6.12 & 0.00 & 1.30 & 0.00 & 0.00 & 0,00 & 0.00 & 0.00 & 0,00 & 8.14 & 12.58 & 0,00 \\
\hline 29 & 7.35 & 0.00 & 19.94 & 0.00 & 0.00 & 0.00 & 0.00 & 3.18 & 0.00 & 15,62 & 3,09 & 0.00 \\
\hline 30 & 8.12 & 0.00 & 19.54 & 0.00 & 0.00 & 0.00 & 0.00 & 21.67 & 0.00 & 0.07 & 22.19 & 0.00 \\
\hline 31 & 23.51 & 0.00 & 7.96 & 0,00 & 0.17 & 0.00 & 0.00 & 22.49 & 0.00 & 0.00 & 0.00 & 15.57 \\
\hline & 344.12 & 57.87 & 154.60 & 132.67 & 3.16 & 65.13 & 11.48 & 47.34 & 100.39 & 77.61 & 218.86 & 301,71 \\
\hline
\end{tabular}




\begin{tabular}{|c|c|c|c|c|c|c|c|c|c|c|c|c|}
\hline $\mathrm{Dia}$ & Jan & Fou & Har & $A \mathrm{~b}^{2} \mathrm{r}$ & $\mathrm{Mai}$ & Jun & Jul & $\mathrm{AgO}$ & Set & out & hou & leze \\
\hline & & & & & & $x=-+$ & & & $x=-$ & $=-$ & $z=z=$ & $z=z=z$ \\
\hline 1 & 3.47 & 0.00 & 0.25 & 0.00 & 0.79 & 0.01 & 0.00 & 0.00 & 2.90 & 0.00 & 7.20 & 0.00 \\
\hline 2 & 11,53 & 0.00 & 0,86 & 4.25 & 0.02 & 0.00 & 0.00 & 0.00 & 1.28 & 0.00 & 0.00 & 0,00 \\
\hline 3 & 2,01 & 0.00 & 7.27 & 0,00 & 0.00 & 0.00 & 0.00 & 0.00 & 0.79 & 0.00 & 0.00 & 1.70 \\
\hline 4 & 0.00 & 0.00 & 10.54 & 0.00 & 0,00 & 0.00 & 0.08 & 0.00 & 0.00 & 0.00 & 23,36 & 0.60 \\
\hline 5 & 0.19 & 9.11 & 2.40 & 0.00 & 0.00 & 0.04 & 0.00 & 0,00 & 2,16 & 0.00 & 14.07 & 0.90 \\
\hline 6 & 0.57 & 4.53 & 5.23 & 0.00 & 0.00 & 0.00 & 0.00 & 0.00 & 24.86 & 0.00 & 15,02 & 0.50 \\
\hline 7 & $\vec{T} . A C^{2}$ & 24.46 & 3.88 & 0.00 & 0.00 & 0.00 & 0.00 & 0.00 & 0.05 & 0.00 & 0.60 & 20,04 \\
\hline 8 & 3.55 & 0.00 & 24.91 & 0.00 & 0.00 & 2.65 & 1.48 & 0.00 & 3.30 & 0.00 & 0.00 & 33.24 \\
\hline$\overline{7}$ & 19.03 & 0.00 & 12.79 & 0.00 & 0.00 & 31.73 & 0.09 & 0.00 & 0.00 & 0.00 & 0.00 & 47.18 \\
\hline 10 & 27.48 & 0.00 & $18.5 \%$ & 0.00 & 0.00 & 0.65 & 0.00 & 0.00 & 0.00 & 0.00 & $0.7 i$ & 13.64 \\
\hline 11 & 19.89 & 0.00 & 3.5 & 0,00 & 0.00 & 0.00 & 0.00 & 0.00 & 0.00 & 4.36 & 36.02 & 0.00 \\
\hline 12 & 10.10 & 6.72 & 0,00 & 0.00 & 0,00 & 0.05 & 0.01 & 0.00 & 0.00 & 0.00 & 24,31 & 0,00 \\
\hline 13 & 4.45 & 5.74 & 0.00 & 0.00 & 0.00 & 0.00 & 0.00 & 0.00 & 0.00 & 0.00 & 0,50 & 0.00 \\
\hline 14 & 10.24 & 22.64 & 0.76 & 0.00 & 0.00 & 0.00 & 0.02 & 0.30 & 0,00 & 4.69 & 0.00 & 0.21 \\
\hline 15 & 6.75 & 0.00 & 0.00 & 0,00 & 0.00 & 0.00 & 0.00 & 0.44 & 0.82 & 0.47 & 0.00 & 19.88 \\
\hline 16 & 8.77 & 3.92 & 0.00 & 0.00 & 0.00 & 0.00 & 34.90 & 0.00 & 6.54 & 0.00 & 0.00 & 7.54 \\
\hline 17 & 5.75 & 0.00 & 0.00 & 0.00 & 21,56 & 0.00 & 0.00 & 0.00 & 25,95 & 6.07 & 43,99 & 17.23 \\
\hline 18 & 0,00 & 4.97 & 0.00 & 0.00 & 13,08 & 0.00 & 6.89 & 0,00 & 3,35 & 0.12 & 3.98 & 0,00 \\
\hline 19 & 0.00 & 0.42 & 0.00 & 0.00 & 8,11 & 0.00 & 0.05 & 0.00 & 0.60 & 22.63 & 0.00 & 0.00 \\
\hline 20 & 0.00 & 10.71 & 0,00 & 0.00 & 0.00 & 0.02 & 0,00 & 0.00 & 0.00 & 6.67 & 10.11 & 0.00 \\
\hline 21 & 1.65 & 3.46 & 0.00 & 2.59 & 17.48 & 0.00 & 24.51 & 0.00 & 0.00 & 0.00 & 1.44 & 0.00 \\
\hline 28 & 5.35 & 5.63 & 0.00 & $0.6 \pm$ & 0.00 & 0.00 & 13.55 & 0.06 & 0.00 & 0.00 & 9.72 & 0.21 \\
\hline 23 & 0.06 & 2.99 & 0.00 & 9.24 & 0.17 & 0.06 & 3.3 & 0.00 & 0.00 & 0.00 & 2.85 & 2.38 \\
\hline 24 & 0.00 & 0,00 & 0.20 & 1.94 & 0.07 & 0.00 & 2.15 & 0.00 & 0.00 & 0.00 & 9.81 & 18.25 \\
\hline 25 & 0.00 & 0.00 & 7.74 & 0.00 & 0.00 & 0.40 & 0.53 & 0.00 & 0.00 & 0.00 & 0.00 & 0.00 \\
\hline 26 & 0.00 & 0,00 & 0.15 & 0.00 & 0.05 & 0.14 & 0.02 & 0.60 & 0.00 & 0.00 & 0.00 & 0.09 \\
\hline 27 & 2,06 & 1.83 & 2.03 & 0.00 & 0.04 & 0.00 & 0.00 & 0,02 & 0.00 & 0.00 & 0,15 & 48.56 \\
\hline 28 & 6.38 & 20.35 & 3.79 & 0.00 & 0.00 & 0,00 & 0.00 & 0.00 & 0.00 & 2,36 & 54.42 & 24.58 \\
\hline 29 & 0.00 & 0.00 & 8.37 & 0.00 & 0.00 & 0.00 & 0.00 & 0.00 & 0,00 & 18.67 & 0,00 & 1.49 \\
\hline 30 & 17.17 & 0.00 & 1,88 & 0.02 & 2.92 & 0.00 & 0.00 & 0.00 & 0,00 & 2.28 & 0.00 & 5.26 \\
\hline 31 & 10.78 & 0,00 & 0.41 & 0.00 & 0.79 & 0.00 & 0.00 & 0.00 & 0.00 & 9.99 & 0.00 & 0.47 \\
\hline ketias & 188.65 & 127.48 & 115,68 & 18.65 & 65.08 & 35.75 & 67.60 & 0.82 & 71.92 & 77.51 & 257.07 & 258,12 \\
\hline
\end{tabular}


FLUVI OGRAMA ANUAL DE VAZOES MEDI AS DE 7 DI AS CONSECUTI VOS. 1973 - Flu 4D-OZ1

Tabela 4.7.1

\begin{tabular}{|c|c|c|c|c|c|}
\hline DI A & MES & VAZZOO & DIA & MES & VAZAO \\
\hline 11 & JAN & 26.470 & 12 & JUL & 11.102 \\
\hline 18 & JAN & 27,892 & 19 & JUL & 10,391 \\
\hline 25 & JAN & 24,088 & 26 & JUL & 10,171 \\
\hline 01 & FEV & $16.6 \mathrm{e1}$ & 02 & $A C O$ & 10.614 \\
\hline 08 & FEV & 25,913 & 09 & $A G O$ & 11,871 \\
\hline 15 & FEV & 34,979 & 16 & $A G O$ & 10,528 \\
\hline $\mathrm{ez}$ & FEV & 40,880 & 23 & $A O O$ & 0.175 \\
\hline 01 & MAR & 26.078 & 30 & $A G O$ & 8,715 \\
\hline 08 & MAR & 31.210 & 06 & SET & 15,898 \\
\hline 15 & MAR & 32,005 & 13 & SET & 9.670 \\
\hline 22 & MAR & 15,573 & 20 & SET & 8.456 \\
\hline 29 & MAR & 17.710 & 27 & SET & 8,263 \\
\hline 05 & ABR & 33,645 & $* 04$ & OUT & 8.188 \\
\hline 12 & ABR & 28,068 & 11 & OUT & 8,816 \\
\hline 19 & $A B R$ & 30,580 & 18 & OUT & 9,255 \\
\hline 26 & $\mathrm{ABR}$ & 31,892 & 25 & OUT & 20,524 \\
\hline 03 & MAI & 16.357 & 01 & NOV & 20,360 \\
\hline 10 & MAI & 18,089 & 08 & NOV & 32,399 \\
\hline 17 & MAI & 16,635 & 15 & NOV & 13,203 \\
\hline 24 & MAI & 14,566 & 22 & NOV & 19,746 \\
\hline 31 & MAI & $16.31 \mathrm{Z}$ & 28 & NOV & 0,022 \\
\hline 07 & JUN & 12,932 & 06 & $D E Z$ & 12,659 \\
\hline 14 & JUN & 11,371 & 13 & $D E Z$ & 36,417 \\
\hline 21 & JUN & 11,236 & 20 & DEZ & 34.113 \\
\hline 28 & JUN & 15.582 & 27 & $D E Z$ & 72,313 \\
\hline 05 & JUL & 11,972 & & & \\
\hline
\end{tabular}


FLUVI OGRAMA ANUAL DE VAZOES MEDI AS DE 7 DI AS CONSECUTI VOS. 1974 - Flu 4D-OZ1

Tabola 4.7.2

\begin{tabular}{|c|c|c|c|c|c|}
\hline DIA & MES & VAZAO & DI A & MES & VAZAO \\
\hline 07 & JAN & 100,341 & 08 & JUL & 13,496 \\
\hline 14 & JAN & 57,926 & 15 & JUL & 13,305 \\
\hline 21 & JAN & 107,108 & 22 & JUL & 11,790 \\
\hline 28 & JAN & 37,936 & 29 & JUL & 9.693 \\
\hline 04 & FEV & 58.626 & 05 & $A G O$ & 9,353 \\
\hline 11 & FEV & 24,005 & 12 & $A G O$ & 9.142 \\
\hline 18 & FEV & 19.550 & 19 & $A G O$ & 9.181 \\
\hline 25 & FEV & 24,086 & 26 & $A G O$ & 8,828 \\
\hline 04 & MAR & 18,101 & 02 & SET & 8,010 \\
\hline 11 & MAR & 19.855 & $\infty$ & SET & 7,790 \\
\hline 18 & MAR & 84.762 & 16 & SET & 7,759 \\
\hline 25 & MAR & 167,321 & 23 & SET & 7,635 \\
\hline 01 & $A B R$ & 40,000 & 30 & $S E T$ & 7.862 \\
\hline 08 & ABR & 37,680 & 07 & OUT & 8,445 \\
\hline 15 & $A B R$ & 29,131 & 14 & OUT & 7,302 \\
\hline $2 \mathrm{e}$ & $A B R$ & 24,166 & 21 & OUT & 7,394 \\
\hline 29 & $A B R$ & 22,923 & 28 & OUT & 10,473 \\
\hline 06 & MAI & 17,404 & 04 & NOV & 17,661 \\
\hline 13 & MAI & 10,804 & 11 & NOV & 6.624 \\
\hline 20 & MAI & 16,951 & $* 18$ & NOV & 0.307 \\
\hline 27 & MAI & 16,202 & 25 & NOV & 10,897 \\
\hline 03 & JUN & 13,403 & oe & $D E Z$ & 9.802 \\
\hline 10 & JUN & 12.561 & $\infty$ & DEZ & 43,629 \\
\hline 17 & JUN & 18,141 & 16 & $\mathrm{DEZ}$ & 40,548 \\
\hline 24 & JUN & 15,470 & 23 & $D E Z$ & 53.000 \\
\hline 01 & JUL & 25,687 & 52 & $D E Z$ & 52,568 \\
\hline
\end{tabular}


FLUVI OGRAMA ANUAL DE VAZEOS MEDI AS DE 7 DI AS CONSECUTI VOS. 1975 - FI U $4 \mathrm{D}-021$

Tabela 4.7 .3

\begin{tabular}{|c|c|c|c|c|c|}
\hline DI A & MES & VAZスO & DI A & MES & VAZKO \\
\hline 13 & JAN & 27,603 & 14 & JUL & 9.783 \\
\hline 20 & JAN & 50,895 & 21 & JUL & 10,000 \\
\hline 27 & JAN & 17.600 & 28 & JUL & 9.783 \\
\hline 03 & $\mathrm{FEV}$ & 34,942 & 04 & $A G O$ & 9,435 \\
\hline 10 & FEV & 135,605 & 11 & $A G O$ & 9.132 \\
\hline 17 & FEV & 87,960 & 18 & $A G O$ & 9,132 \\
\hline 24 & FEV & 66.380 & 25 & $A G O$ & $8,11 \mathrm{z}$ \\
\hline 03 & MAR & 28,339 & 01 & SET & 6,989 \\
\hline 10 & MAR & 44,096 & 08 & SET & 7.139 \\
\hline 17 & MAR & 22,815 & 15 & SET & 6,910 \\
\hline 24 & MAR & 21,514 & 22 & SET & 6,834 \\
\hline 31 & MAR & 20,251 & * $2 \theta$ & SET & 6.760 \\
\hline 07 & ABR & 18,408 & 06 & OUT & 10,791 \\
\hline 14 & ABR & 19,468 & 13 & OUT & 14,735 \\
\hline 21 & $A B R$ & 19.624 & 20 & OUT & 9.484 \\
\hline 28 & $A B R$ & 13,383 & 27 & OUT & 7.588 \\
\hline 05 & MAI & $1 \mathrm{e}, 316$ & 03 & NOV & 9,246 \\
\hline 12 & MAI & 12,723 & 10 & NOV & 9,328 \\
\hline 19 & MAI & 11,376 & 17 & NOV & 7,860 \\
\hline 26 & MAI & 10,263 & 24 & NOV & 29.362 \\
\hline $\mathrm{Oz}$ & JUN & 10,483 & 01 & DEZ & 58,780 \\
\hline 08 & JUN & 10,044 & 08 & DEZ & $46.98 \mathrm{e}$ \\
\hline 16 & JUN & 10,044 & 15 & DEZ & 56,500 \\
\hline 23 & JUN & 9,800 & $\mathrm{ee}$ & $D E Z$ & 24,314 \\
\hline 30 & JUN & 9,826 & 29 & $D E Z$ & 72,093 \\
\hline 07 & JUL & 10.713 & & & \\
\hline
\end{tabular}


FLUVI OGRAMA ANUAL DE VAZOES MEDIAS DE 7 DIAS CONSECUTI VOS. $1976-F I U 4 D-021$

Tabel a 4.7.4

\begin{tabular}{|c|c|c|c|c|c|}
\hline DI A & MES & $V A Z Z O$ & DI A & MES & VAZZOO \\
\hline 10 & JAN & 62,635 & 10 & JUL & 73,130 \\
\hline 17 & JAN & 69,696 & 17 & JUL & 32,355 \\
\hline 24 & JAN & 36,372 & 24 & JUL & 22,719 \\
\hline 31 & JAN & 36,313 & 31 & JUL & 19,417 \\
\hline 07 & FEV & 80,332 & 07 & $A G O$ & 17,438 \\
\hline 14 & FEV & 70,932 & 14 & $A G O$ & 31,486 \\
\hline 21 & FEV & 67,779 & 21 & $A G O$ & 26,422 \\
\hline 28 & FEV & 142,311 & 28 & $A G O$ & 17,798 \\
\hline 06 & MAR & 83,342 & $* 04$ & SET & 13,547 \\
\hline 13 & MAR & 47.776 & 11 & SET & 22,175 \\
\hline 20 & MAR & 68,719 & 18 & SET & 34,375 \\
\hline 27 & MAR & 88,698 & 25 & SET & 23,018 \\
\hline 03 & $A B R$ & 35,289 & 02 & OUT & 36,517 \\
\hline 10 & ABR & 28,325 & 09 & OUT & 27,843 \\
\hline 17 & ABR & 67.225 & 16 & OUT & 37,981 \\
\hline 24 & $A B R$ & 57,301 & 23 & OUT & 21,541 \\
\hline 01 & MAI & $\mathrm{eE}, \mathrm{2e1}$ & 30 & OUT & 25,363 \\
\hline 08 & MAI & 22,270 & 06 & NOV & 16,491 \\
\hline 15 & MAI & 33,141 & 13 & NOV & 16,269 \\
\hline $2 e$ & MAI & 39.497 & 20 & NOV & 18,568 \\
\hline 29 & MAI & 45.742 & 27 & NOV & 38,621 \\
\hline 05 & JUN & 66.776 & 04 & $\mathrm{DEZ}$ & 21,002 \\
\hline 12 & JUN & 90,893 & 11 & $\mathrm{DEZ}$ & 25,643 \\
\hline 18 & JUN & 32,434 & 18 & DEZ & 19.860 \\
\hline 26 & JUN & 25,700 & 25 & $\mathrm{DEZ}$ & 37,030 \\
\hline 03 & JUL & 33,641 & & & \\
\hline
\end{tabular}


Fluvi OgRAMA ANUAL DE VAZOES MEDIAS DE 7 DI AS CONSECUTI VOS. 1977 - Flu $4 \mathrm{D}-021$

Tabela 4.7 .5

\begin{tabular}{|c|c|c|c|c|c|}
\hline DT A & MES & VAZAO & $D I A$ & MES & VAZAO \\
\hline 00 & JAN & 42.086 & 10 & JUL & 9,828 \\
\hline 16 & JAN & 45,546 & 17 & JUL & 9,565 \\
\hline 23 & JAN & 99.831 & 24 & JUL & 8,826 \\
\hline 30 & JAN & 55.852 & 31 & JUL & 8.018 \\
\hline$O B$ & FEV & 67,497 & $O 7$ & $A G O$ & 7,530 \\
\hline 13 & FEV & 30,780 & 14 & $A O O$ & 7,530 \\
\hline 20 & FEV & 22,374 & 21 & $A G O$ & 7.177 \\
\hline 27 & FEV & 22,779 & 28 & $A G O$ & 7,100 \\
\hline$O B$ & MAR & 17,012 & 04 & SET & 12,449 \\
\hline 13 & MAR & 16.730 & 11 & $S E T$ & 9,137 \\
\hline 20 & MAR & 18,714 & 18 & SET & 8,358 \\
\hline 27 & MAR & 29.531 & 25 & SET & 22,710 \\
\hline 03 & $\mathrm{ABR}$ & 64,639 & oz & OUT & 12.560 \\
\hline 10 & $A B R$ & 40,559 & $0 \theta$ & OUT & 14,062 \\
\hline 17 & ABR & 31.019 & 16 & OUT & 7,637 \\
\hline 24 & $A B R$ & 23,090 & 23 & OUT & 6,407 \\
\hline 01 & MAI & 18,117 & * 30 & OUT & 4,992 \\
\hline 08 & MAI & 16,261 & 06 & NOV & 7,971 \\
\hline 15 & MAI & 13,778 & 13 & NOV & 18,340 \\
\hline 22 & MAI & 12.908 & 20 & $\mathrm{NOV}$ & 22,150 \\
\hline 20 & MAI & 12,408 & 27 & NOV & 24,202 \\
\hline 05 & JUN & 12,237 & 04 & DEZ & 29,563 \\
\hline 12 & JUN & $2 \mathrm{e}, 505$ & 11 & $D E Z$ & 96,101 \\
\hline 19 & JUN & 13,667 & 18 & $D E Z$ & 33,903 \\
\hline 26 & JUN & 11.149 & 25 & $D E Z$ & 91,653 \\
\hline 03 & JUL & 10,352 & & & \\
\hline
\end{tabular}


FLUVI OGRAMA ANUAL DE VAZOES MEDI AS DE 7 DI AS CONSECUTI VOS. $1978-F 1$ u 4D-OZ1

Tabela 4.7 .6

\begin{tabular}{|c|c|c|c|c|c|}
\hline DIA & MES & VAZXO & DI A & MES & $V A Z X O$ \\
\hline 08 & JAN & 43,032 & 08 & JUL & 7.853 \\
\hline 15 & JAN & 62,704 & 16 & JUL & 15,251 \\
\hline 2e & JAN & 33,506 & 23 & JUL & 16,615 \\
\hline 29 & JAN & 17.711 & 30 & JUL & 9,655 \\
\hline 05 & $\mathrm{FEV}$ & 18,347 & 06 & $A G O$ & 8,437 \\
\hline 12 & FEV & 24,081 & 13 & $A G O$ & 7,816 \\
\hline 19 & $F E V$ & 23.451 & 20 & $A G O$ & 7,899 \\
\hline 26 & FEV & 16,230 & 27 & $A G O$ & 7,013 \\
\hline 05 & MAR & 18,117 & 03 & SET & 7.656 \\
\hline 12 & MAR & 25,210 & 10 & SET & 10.161 \\
\hline 19 & MAR & 15,461 & 17 & SET & 8,737 \\
\hline 26 & MAR & 12,081 & 24 & SET & 9.250 \\
\hline 02 & ABR & 14.569 & 01 & OUT & 7,101 \\
\hline 00 & $A B R$ & 11,067 & 08 & OUT & 6,687 \\
\hline 16 & $A B R$ & 0.913 & 15 & OUT & 6,549 \\
\hline 23 & ABR & 9,914 & $\mathrm{ez}$ & OUT & 9,887 \\
\hline 30 & $A B R$ & 10,003 & * 29 & OUT & 6,154 \\
\hline 07 & MAI & 0,044 & Os & NOV & 13.873 \\
\hline 14 & MAI & 7,977 & 12 & NOV & 20,824 \\
\hline 21 & MAI & 14,336 & 19 & NOV & 26,374 \\
\hline 28 & MAI & 11,030 & 26 & NOV & $\mathrm{ez}, 414$ \\
\hline 04 & JUN & 10.046 & 03 & $D E Z$ & 29,208 \\
\hline 11 & JUN & 13,754 & 10 & DEZ & 49,976 \\
\hline 18 & JUN & 0.957 & 17 & $\mathrm{DEZ}$ & 35,340 \\
\hline 25 & JUN & 9,301 & 24 & $D E Z$ & 29,390 \\
\hline oz & JUL & 8,613 & & & \\
\hline
\end{tabular}


5. RESULTADOS.

- presente capitulo mostra a aplicação da metodologia descrita no ltem 4, a bacia do Rio Corumbatal na seça da Fazenda Recreio representada pelo posto fluviometrico 4D-021. aplicaçăo esta correspondente a "existencia de muitos dados de precipitação (21 anos) e poucos dados de vazăo $C B$ anos)" conforme o objetivo do trabal ho.

Os dados pluviometricos correspondem aos anos de 1958 a 1978 para 7 postos distribuidos na bacia hidrografica do Rio Corumbatal, com observaçós di ari as de alturas de chuva, representadas pela média diária obtida com a aplicação do metodo de Thiessen Ctabelas 4.6.1 a 4.6. 21). Os dados fluviometricos correspondem aos anos de 1973 a 1978 e săo representados pelas vazöes médias de 7 dias consecuti vos (tabelas 4.7 .1 a 4.7 .6$)$.

Dos valores medios das alturas diarias de chuva determinados pelo metodo, foram selecionados, para cada ano de observaçáo, os valores do número de dias consecutivos sem chuva (tsc). Esses valores estäo 
representados na tabela (5.1).

Tabel a 5.1

Numero de dias consecutivos sem chuva (t.e).

Anos : de 1958 a 1978.

Bacia : Rio Cor umbatal.

$\begin{array}{rrrr}\text { ANO } & t \text { } & \text { ANO } & t 8 c \\ 1958 & 56 & 1969 & 110 \\ 1959 & 88 & 1970 & 82 \\ 1960 & 52 & 1971 & 96 \\ 1961 & 174 & 1972 & 43 \\ 1962 & 80 & 1973 & 41 \\ 1963 & 227 & 1974 & 93 \\ 1964 & 70 & 1975 & 87 \\ 1965 & 94 & 1976 & 33 \\ 1968 & 113 & 1977 & 84 \\ 1967 & 86 & 1978 & 67 \\ 1988 & 117 & & \end{array}$

A tabela (5.2) determinada a partir dos dados da tabela (5.1) permite o levantamento da curva de frequeriela do número de dias corsecuti vos sem chuva para a bacia do Rio Corumbatal (fig. 5.1). Essa curva e obtida plotando-se num papel de probabilidade aritmetico os tres pares de pontos notaveis da distribuiça normal: (15,87\%;

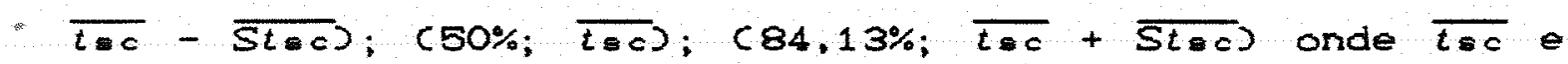
Stac representam as estimativas da media e do desvio padrão do número de dias consecutivos sem chuva, obtidos 
pela aplicação das formulas (5.3) e (5.4). A verificação do a justamento do número de dias consecutivos sem chuva (tsa) a distribuiçáo normal fol felta pelo teste do "QUI-QUADRADO". Para o nivel de significancia $\alpha=0,05$ e 17 graus de 1 iberdade, o valor de Qui-Quadrado observado foi de 8,10 , enquanto seu valor tabelado e de 28,9 . Logo, a hipótese de que a distribuição de tso se ajusta a distribuifão normal deve ser aceita.

TABELA (5. 2) - Frequencia de tac.

Bacia do Rio Cor umbatal

\begin{tabular}{|c|c|c|c|}
\hline ORDEM & $t=c$ & $P=\frac{1}{n+1}$ & $F=1-P$ \\
\hline 1 & 227 & 0.0455 & 0,9545 \\
\hline 2 & 174 & 0,0009 & 0,9091 \\
\hline 3 & 117 & 0.1364 & 0.8636 \\
\hline 4 & 113 & 0.1818 & 0.8182 \\
\hline 5 & 110 & 0,2273 & 0.7727 \\
\hline$B$ & 96 & 0.2727 & 0,7273 \\
\hline 7 & $\theta 4$ & 0,3182 & 0.6818 \\
\hline 8 & 83 & 0,3636 & 0.6364 \\
\hline 9 & 87 & 0.4091 & 0.5909 \\
\hline 10 & 86 & 0,4545 & 0.5455 \\
\hline 11 & 84 & 0,5000 & 0.5000 \\
\hline 12 & 80 & 0,5455 & 0.4545 \\
\hline 13 & 70 & 0,5909 & 0.4091 \\
\hline 14 & 67 & 0.6364 & 0.383 \\
\hline 15 & 66 & 0,6818 & 0.3182 \\
\hline
\end{tabular}


ccont.

$\begin{array}{lccc}\text { ORDEM } & t=c & P=\frac{1}{n+1} & F=1-P \\ 16 & 62 & 0,7273 & 0,2727 \\ 17 & 56 & 0,7727 & 0,2273 \\ 18 & 52 & 0,8182 & 0,1818 \\ 10 & 43 & 0,8636 & 0,1364 \\ 20 & 41 & 0,9091 & 0,0909 \\ 21 & 33 & 0,9545 & 0,0455 \\ & & & \\ & & & \end{array}$




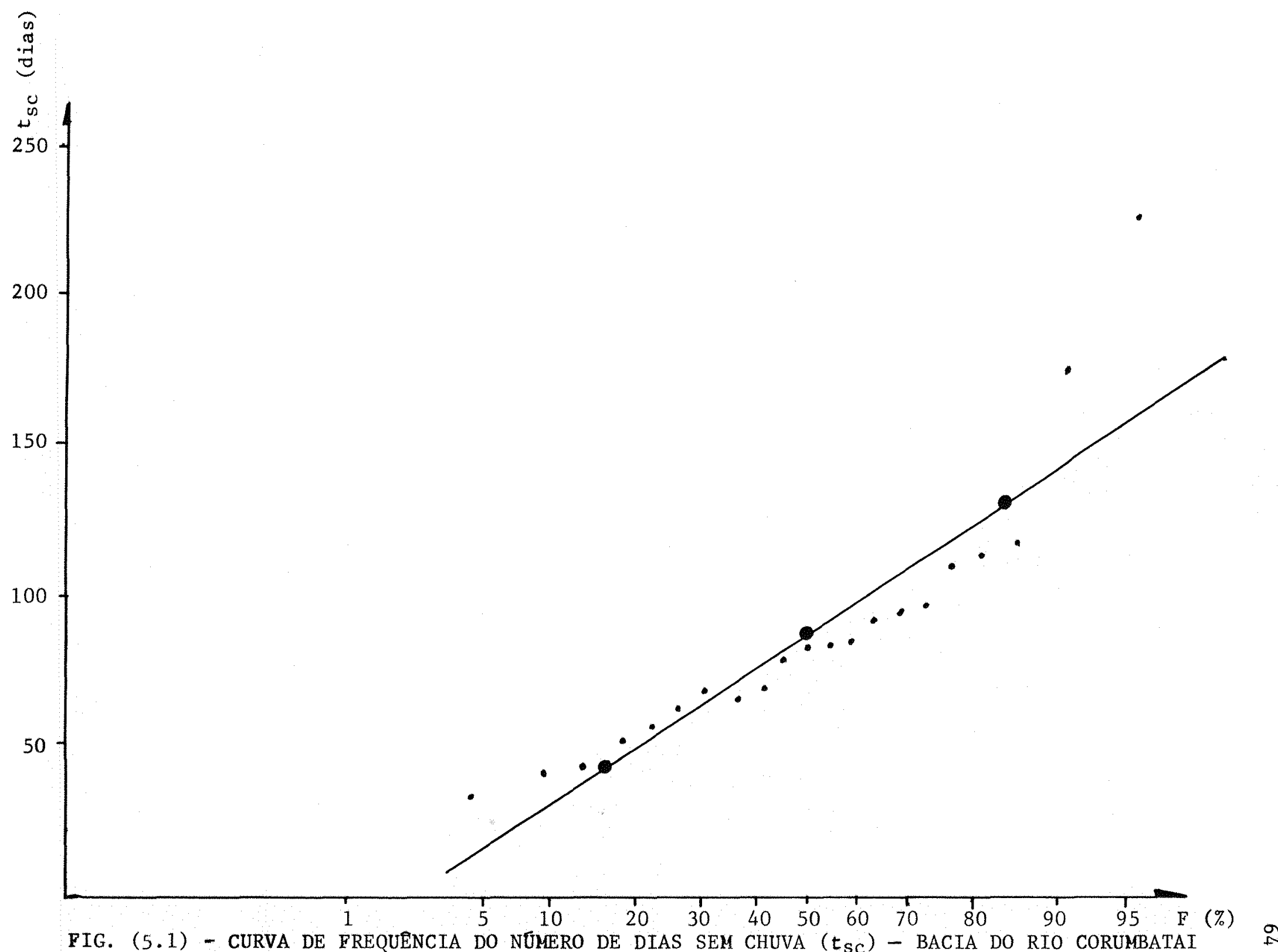


A partir das vazóes medias de 7 dias consecutivos (tabelas 4.7 .1 a 4.7 .6 ), foram elaborados, para cada ano de observaçăo, os hidrogramas anuais representados nas figuras (5.2) a (5.7). Esses hidrogramas mostram as vazbes $Q_{0}$ Cinicio da estiagem, Omin, e o periodo do escoamento basico (t). que estão indicados na tabela (5.3)

TABELA 5.3 - Curva de depleção do Rio Corumbatal - Fazenda Recreio.

$\begin{array}{lccc}\text { ANO } & Q_{0} & \text { Qmin } & t \\ 1973 & 8,715 & 8,168 & 35 \\ 1974 & 8,010 & 6,307 & 77 \\ 1975 & 6,989 & 6,760 & 28 \\ 1976 & 17,438 & 13,547 & 28 \\ 1977 & 7,530 & 4,992 & 84 \\ 1978 & 7,613 & 6,154 & 63\end{array}$

A fig. 5.8. obtida deslocando-se os valores de $Q_{0}$ para uma mesma data, permite a determinação de um unico valor de a, que representara a bacla hidrografica do Rio Cor umbatal.

Nessa figura está mostrada a reta representativa de a para a Bacia do Rio Corumbatai; $c \alpha=0,0025)$ 


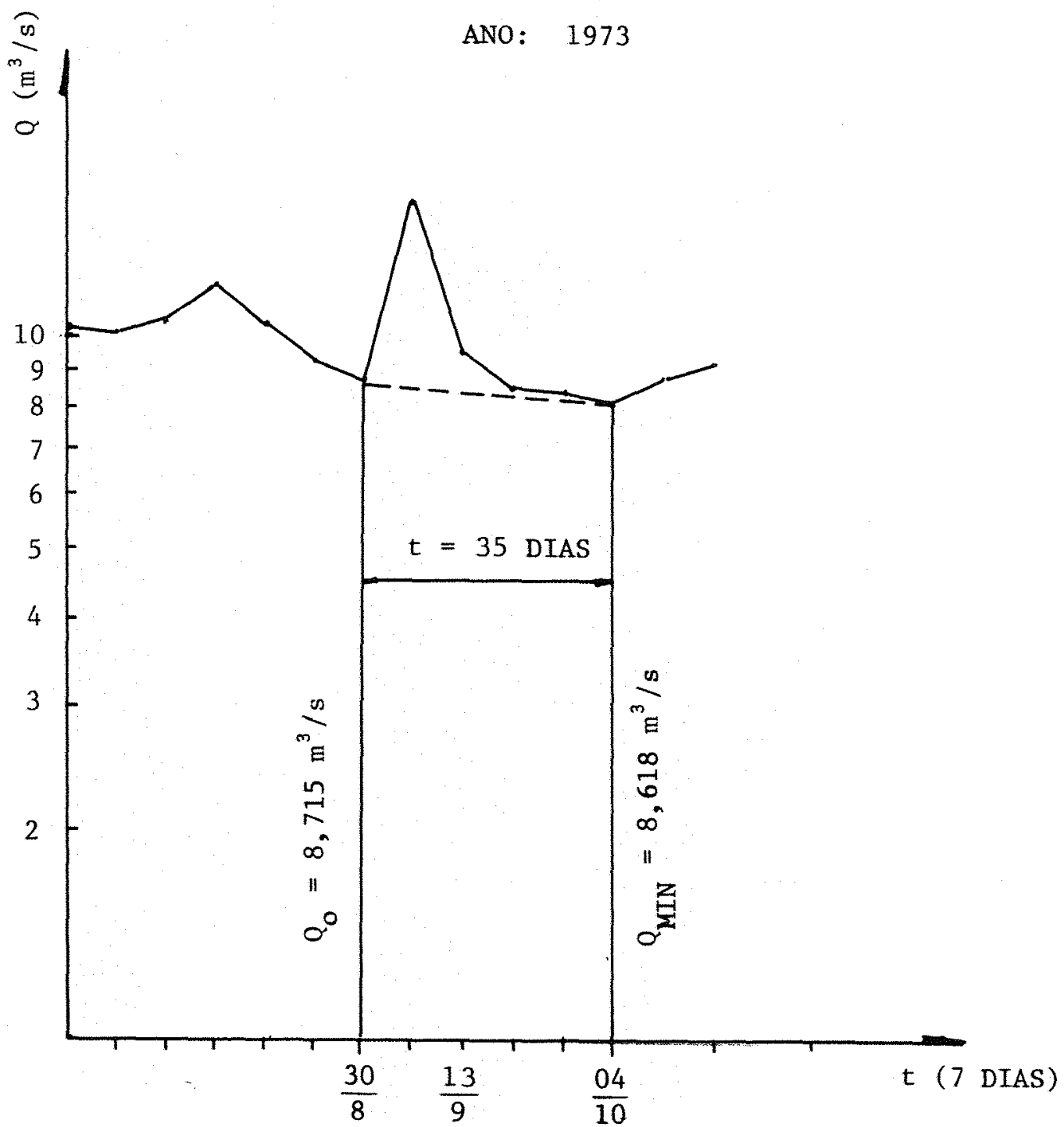

FIG. 5.2

HIDROGRAMA DAS VAZÕES MEDIAS DE 7 DIAS CONSECUTIVOS RIO CORUMBATAI - FAZENDA RECREIO POSTO FLUVIOMETRICO - 4D - 021 


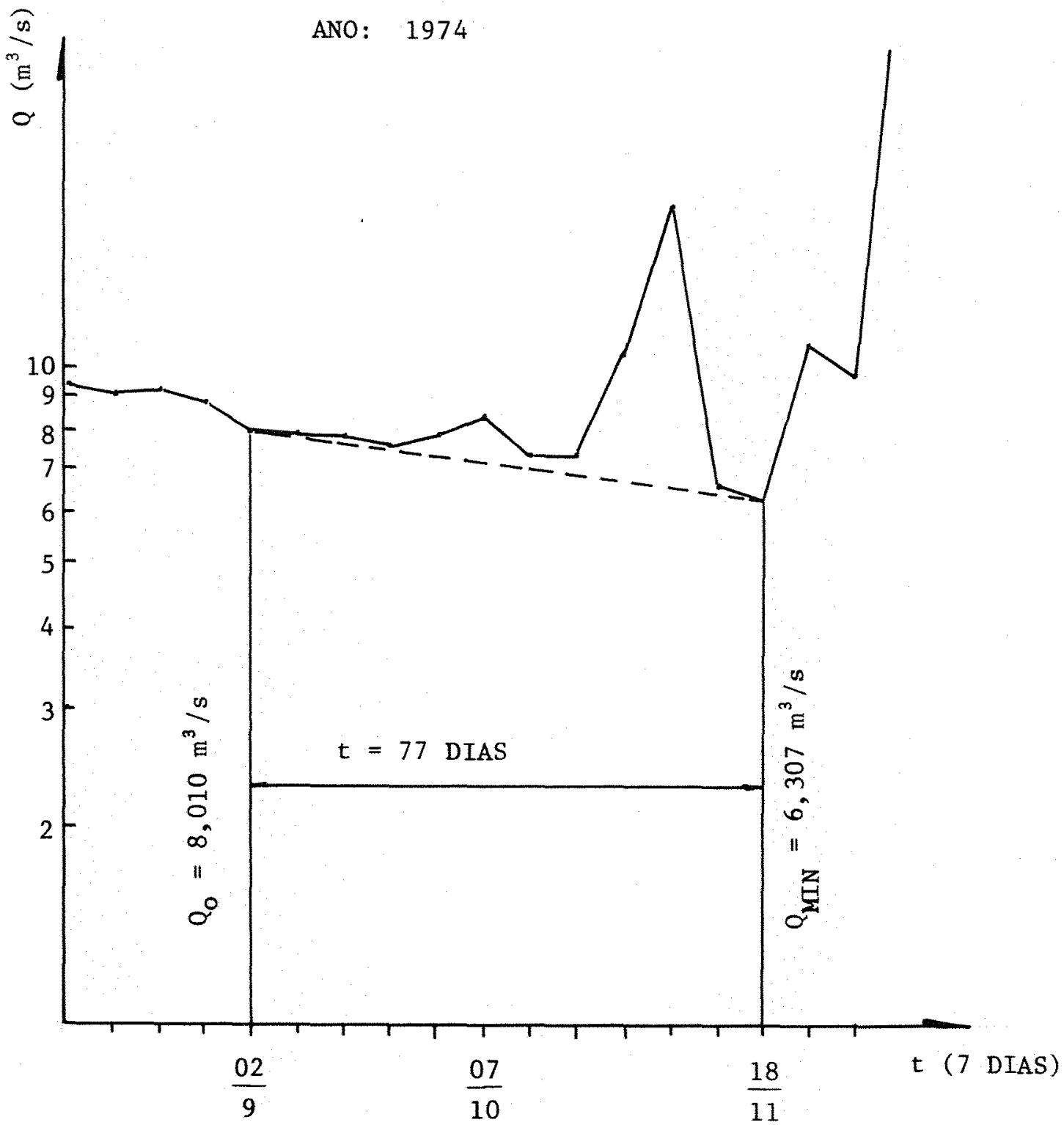

FIG. 5.3

HIDROGRAMA DAS VAZÕES MEDIAS DE 7 DIAS CONSECUTIVOS RIO CORUMBATAI - FAZENDA RECREIO

POSTO FLUVIOMETRICO - $4 \mathrm{D}-021$ 
ANO: 1975

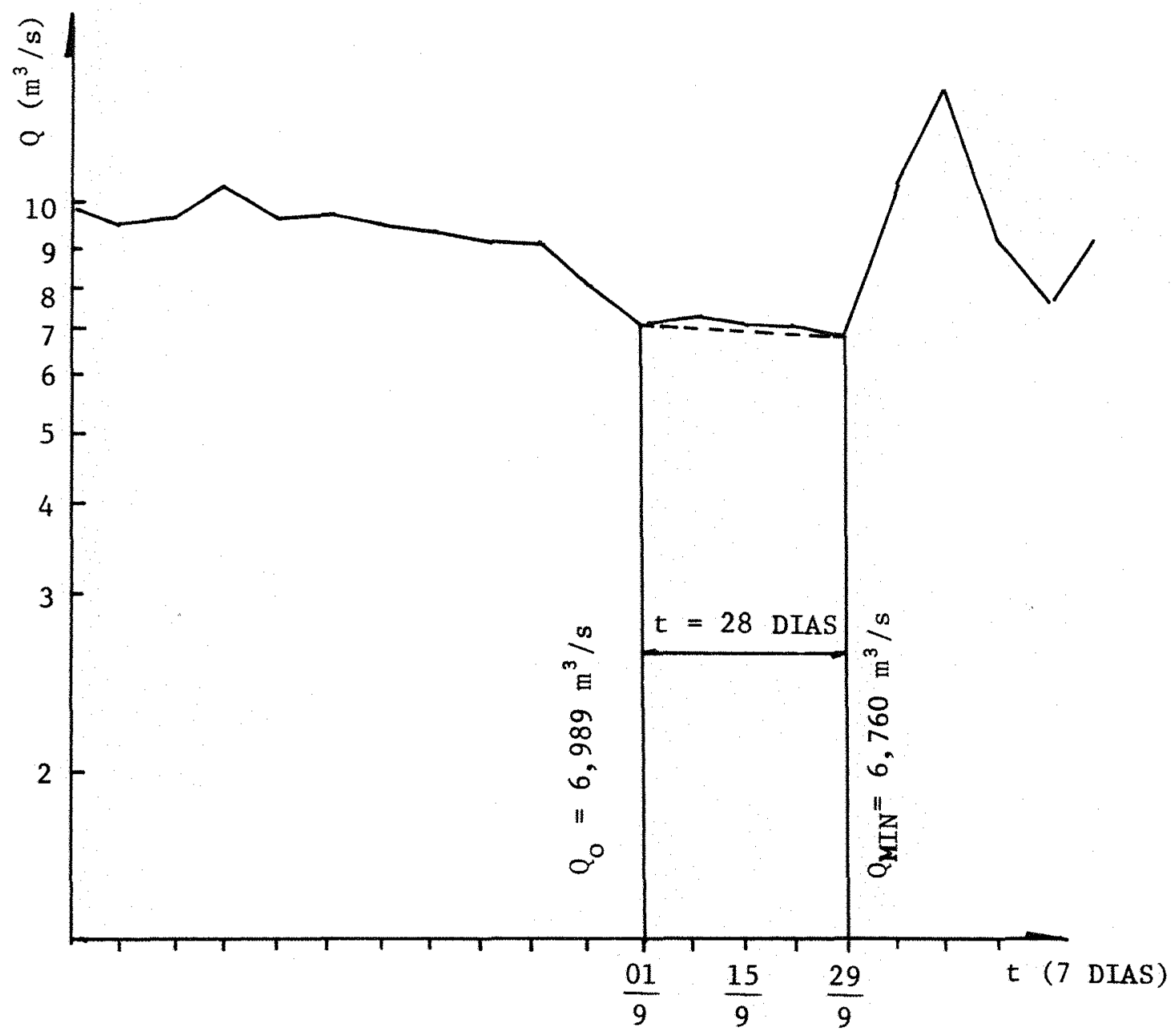

FIG. 5.4

HIDROGRAMA DAS VAZÕES MEDIAS DE 7 DIAS CONSECUTIVOS

RIO CORUMBATAI - FAZENDA RECREIO

POSTO FLUVIOMETRICO - 4D - 021 


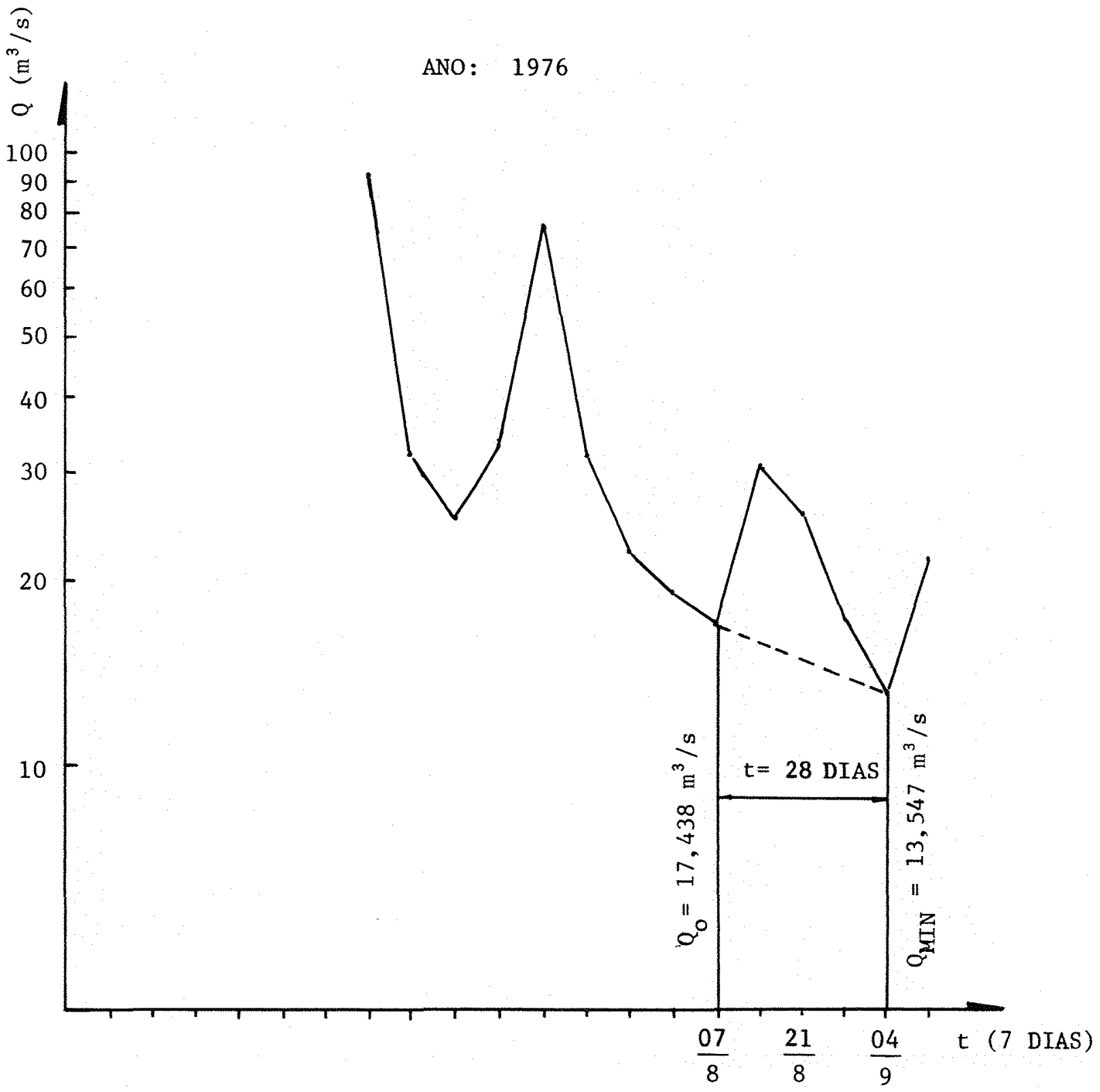

FIG. 5.5

HIDROGRAMA DAS VAZÕES MEDIAS DE 7 DIAS CONSECUTIVOS RIO CORUMBATAI - FAZENDA RECREIO POSTO FLUVIOMETRICO $\quad 4 \mathrm{D}-021$ 


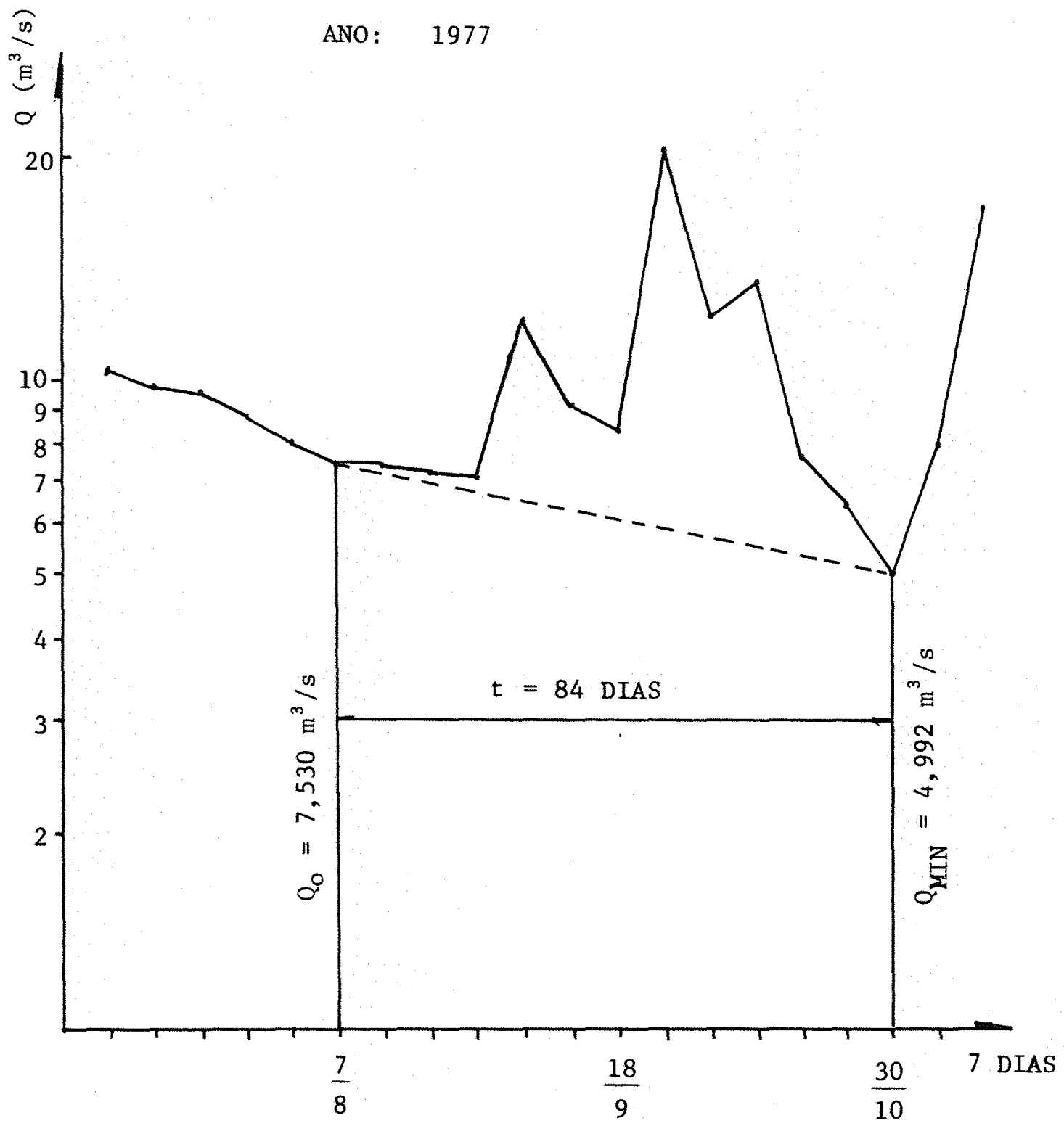

FIG. 5.6

HIDROGRAMA DAS VAZÕES MEDIAS DE 7 DIAS CONSECUTIVOS RIO CORUMBATAI - FAZENDA RECREIO

POSTO FLUVIOMETRICO - 4D - 021 


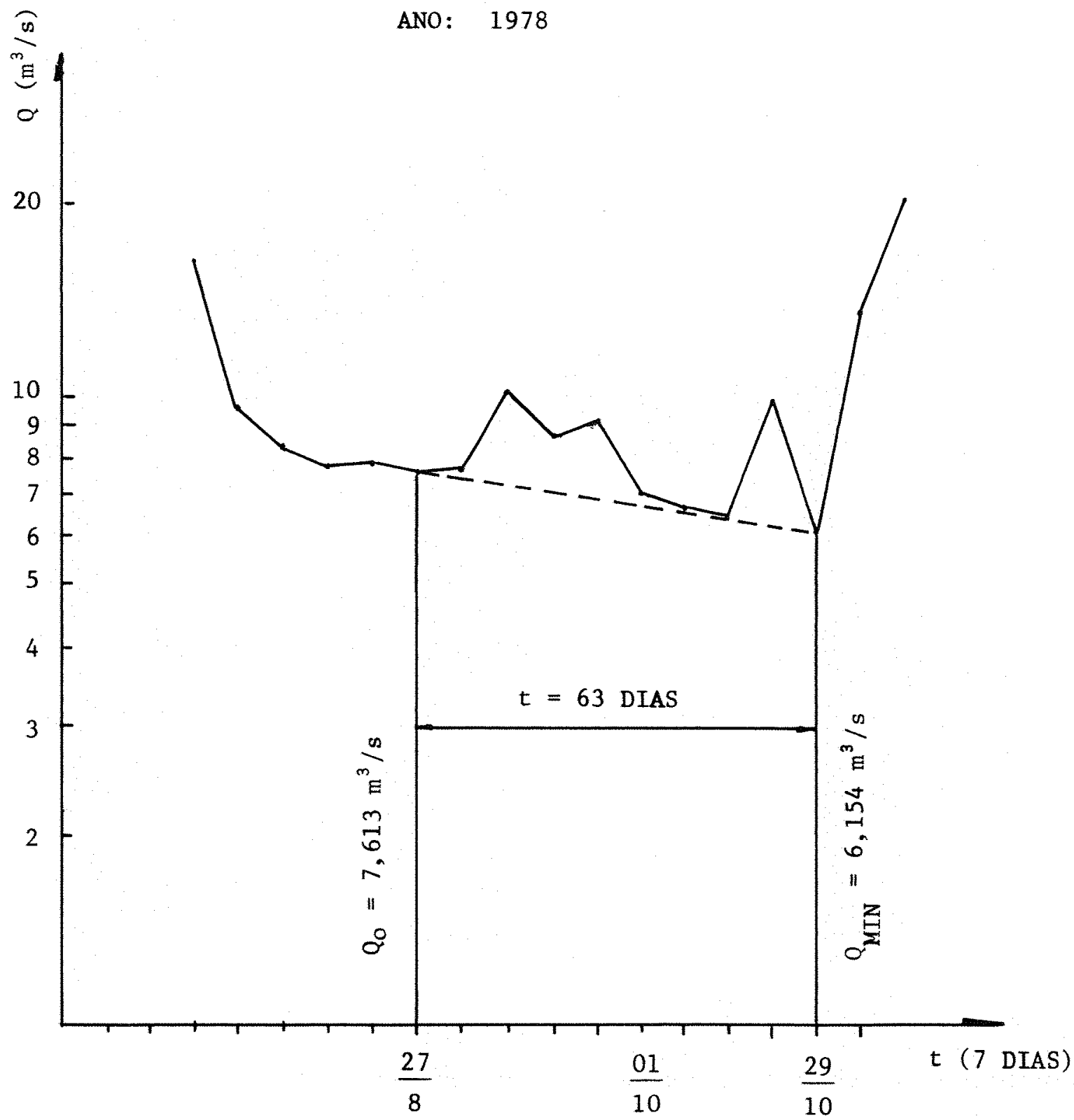

FIG. 5.7

HIDROGRAMA DAS VAZÕES MEDLAS DE 7 DIAS CONSECUTIVOS RIO CORUMBATAI - FAZENDA RECREIO POSTO FLUVIOMETRICO - 4D - 021 


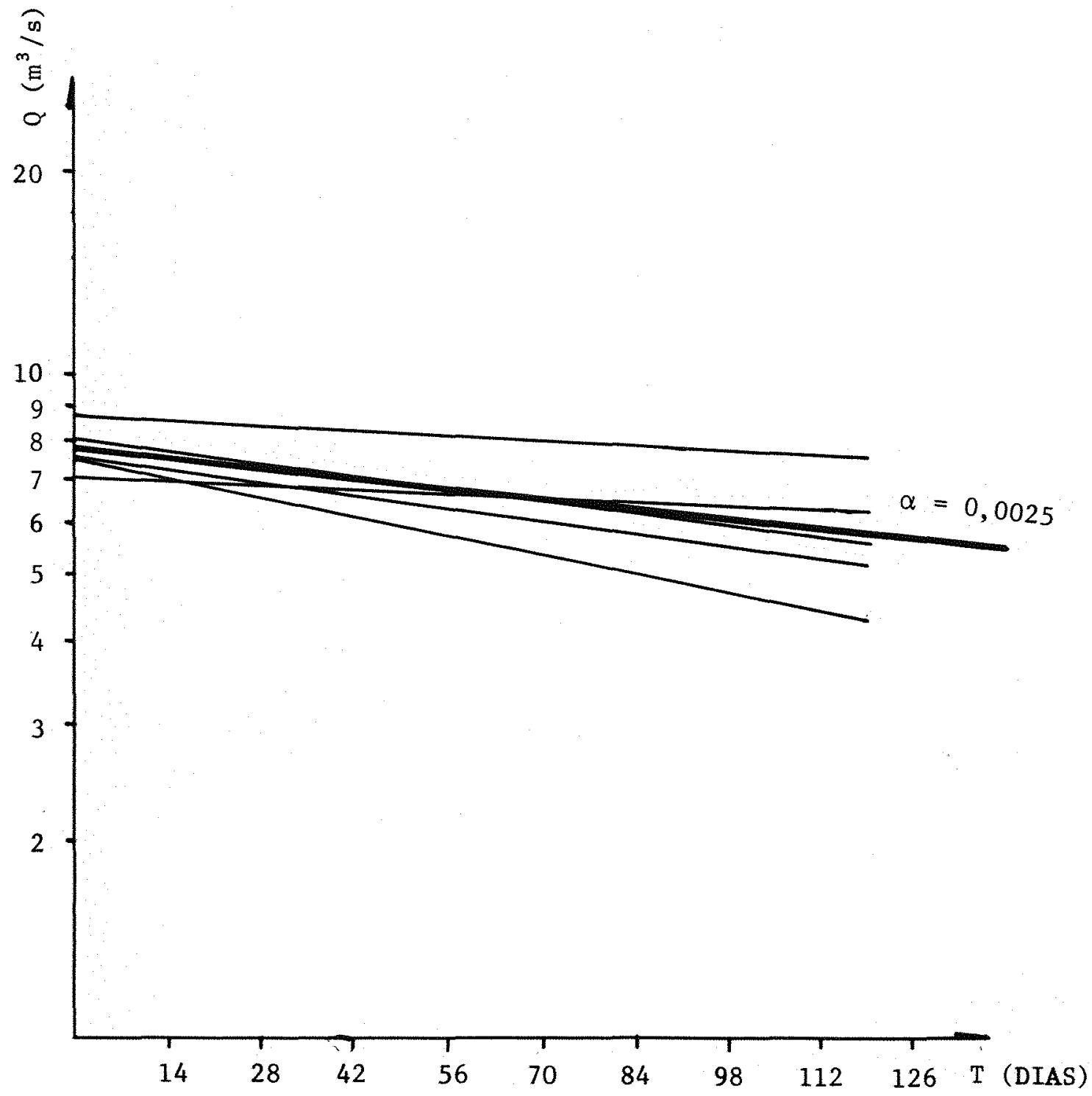

PIG. 5.8 - VALORES DE $\alpha$ - BACIA DO RIO CORUMBATAI 
Dos dados de precipitação media mensal inseridos nas tabelas $(4.6 .1)$ a $(4.6 .21)$, foram selecionados os valores de Pm, e, da tabela (5.1) os valores de tac para o periodo compreendido entre os anos de 1973 a 1978, periodo esse em que existem valores observados de $t$ e

A tabela (5.4) mostra os valores de $t$ e tSc - $Q_{0}$ e Pm para aquele periodo, e sua finalidade e determinar as correlaçóes entre essas variaveis, tendo em vista, que a aplicação da metodologia requer a substituiçăo de $t$ por $t$ so e LnQ por $P m$.

TABELA 5.4 - Valores de $t, t a c, Q_{0}$ e Pm para o periodo em que existem valores observados de $t$ e $Q_{0}(1973 \mathrm{a}$ 18785 .

$\begin{array}{lllccc}\text { ANO } & t & t . c & Q_{0} & \text { LnQ } & \text { Pm } \\ 1973 & 35 & 41 & 8.715 & 2.1650 & 735.52 \\ 1974 & 77 & 93 & 8,010 & 2.0807 & 592.48 \\ 1975 & 28 & 87 & 6.989 & 1,9443 & 463.41 \\ 1976 & 28 & 33 & 1.438 & 2.8587 & 1050.77 \\ 1977 & 84 & 84 & 7.530 & 2.0189 & 756.37 \\ 1978 & 63 & 67 & 7.813 & 2,0299 & 991.48\end{array}$

Com os dados da tabela (5.4). foram 
estimadas, pelo método dos minimos quadrados, as retas de regressão linear entre $t$ e toc e entre $L n Q_{0}$ e $P m$ - figuras $(5.9)=(5.10)$

$$
\begin{array}{cc}
t=10,88+0,82 \mathrm{tgc} & (5.1) \\
e & \\
\mathrm{LnQ}_{0}=1,44+0,00097 \mathrm{Pm} & \text { (5.2) }
\end{array}
$$

Determinou-se tambem o coeficiente de correlaçăo $r=0,62$, e o coeficiente de determinação $r^{2}=0.38$, para verificaçăo do grau de associação entre te tsc. O coeficiente de determinação mostra que $38 \%$ da variancia de $t$ explicada pela regressão.

- grau de associação entre $\mathrm{LnQ}_{0}$ e $\mathrm{Pm}$ apresentou coeficiente de correlaçá $r=0.65$. e coeficiente de determinaçăo $r^{2}=0.42$ mostrando que $42 \%$ da variancia de LnQ é explicada pela regressão.

Considerando que a metodologia sugere o uso de toda serie pluviometrica disponivel, apresentou-se na tabela (5.5), a serie de Pm completa, correspondente aos anos de 1958 a 1978. A determinação do periodo de 6 meses consecutivos fol feita. iniciando-se a contagem a partir do mes em que se inicia o perlodo de dias sem chuva, quando a úlima precipitaça diaria superior a $10 \mathrm{~mm}$ ocorrer na primelra quinzena desse mes. Caso tenha ocorrldo na segunda quinzena, entzo a contagem se iniciara no mes seguinte. 


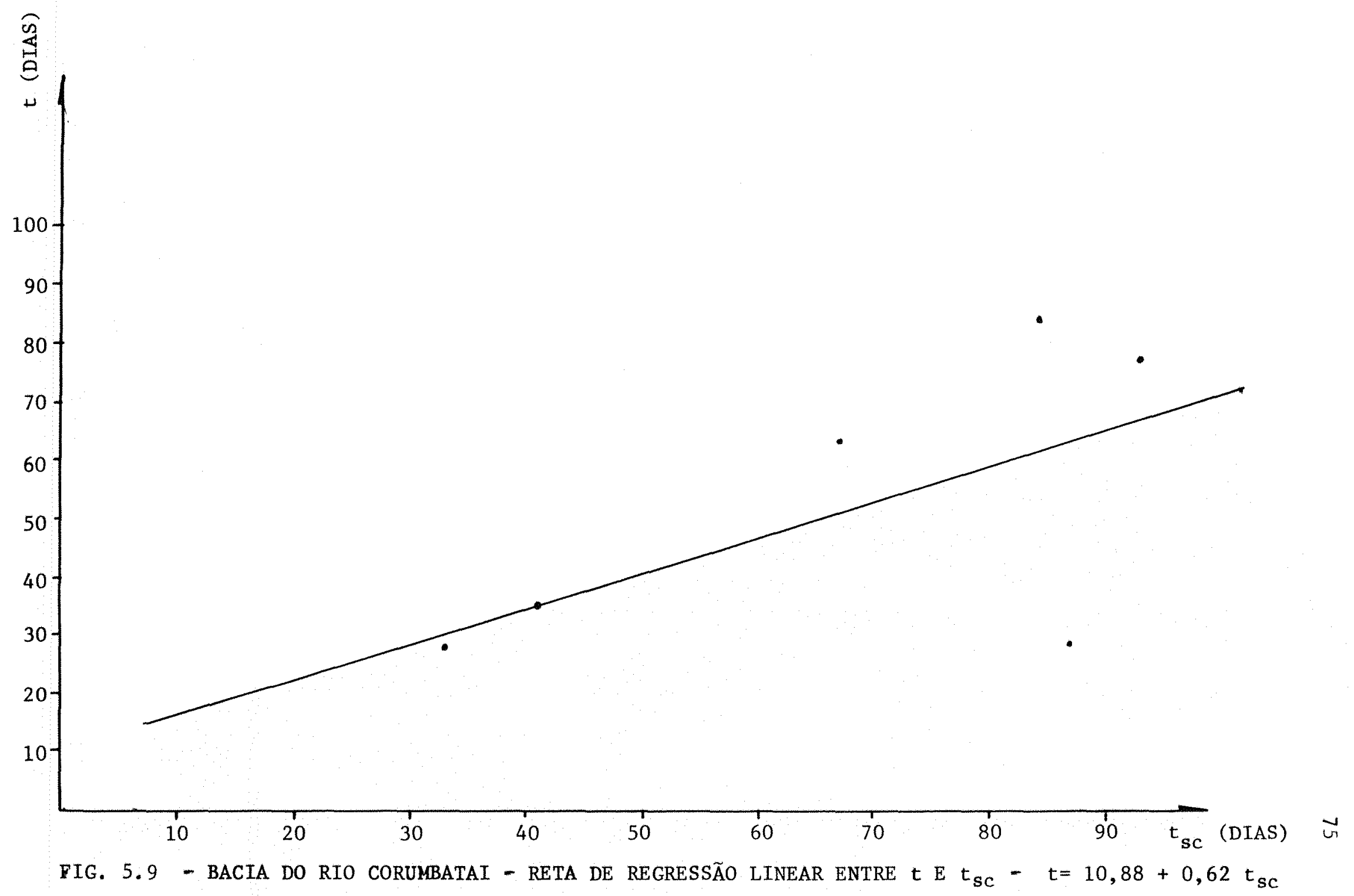




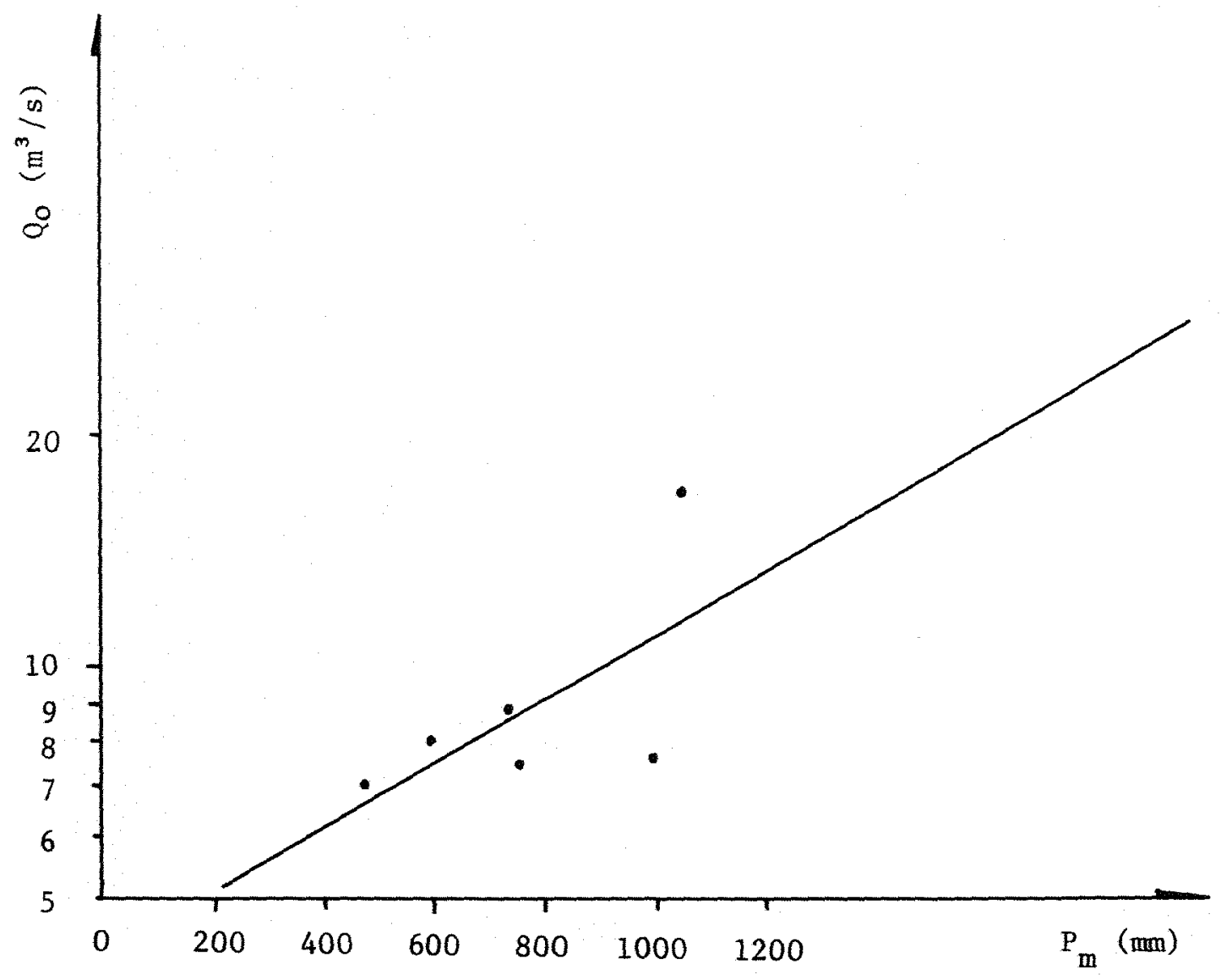

PIG. 5.10 - RETA DE REGRESSÃO LINEAR

ENTRE LnQo e Pm - BA

CIA DO RIO CORUMBATAI. 
TABELA (5.5) - Precipitação media total antecedente de 6 meses - bacia do Río Corumbatal.

$\begin{array}{llll}\text { ANO } & \text { Pm } & \text { ANO } & \text { Pm } \\ 1958 & 577,02 & 1969 & 501,37 \\ 1959 & 745,82 & 1970 & 548,92 \\ 1960 & 641,20 & 1971 & 630,66 \\ 1961 & 1046,90 & 1972 & 840,64 \\ 1962 & 786,08 & 1973 & 735,52 \\ 1963 & 1001,91 & 1974 & 592,48 \\ 1964 & 706,39 & 1975 & 463,41 \\ 1965 & 888,01 & 1976 & 1050,77 \\ 1966 & 886,11 & 1977 & 756,37 \\ 1987 & 888,69 & 1978 & 991,48 \\ 1968 & 287,20 & & \end{array}$

Os valores da tabela (5.5) permitem determinar a distribuição de frequencia da precipitaçăo média antecedente para a bacia do Rio Corumbatal tabela (5.6) e figura (5.11), onde, a estimativa da media e desvio padră das preclpitaçbes săo:

$$
\begin{aligned}
& \overline{P m}=731.76 \mathrm{~mm} \\
& \overline{S_{m}}=203.23 \mathrm{~mm}
\end{aligned}
$$


TABELA 5.6 -Distribuição da frequéncia da precipitaçá media antecedente - Pm - Bacia do Rio cor umbatal.

\begin{tabular}{|c|c|c|c|}
\hline ORDEM & $\mathrm{Pm}$ & $P=\frac{1}{n+1}$ & $F=1-P$ \\
\hline 1 & 287.20 & 0.0455 & 0,9545 \\
\hline$\Xi$ & 463,41 & 0,0909 & 0,9091 \\
\hline 3 & 501.37 & 0.1364 & 0,8636 \\
\hline 4 & 548,92 & 0.1818 & 0,8182 \\
\hline 5 & 577,02 & 0,2273 & 0.7727 \\
\hline 6 & 592,48 & 0.2727 & 0.7273 \\
\hline 7 & 630.66 & 0.3182 & 0,6818 \\
\hline 8 & 641.20 & 0,3636 & 0,6364 \\
\hline 9 & 688.01 & 0.4091 & 0,5909 \\
\hline 10 & 708.39 & 0.4545 & 0,5455 \\
\hline 11 & 735,52 & 0,5000 & 0.5000 \\
\hline 12 & 745.82 & 0.5455 & 0,4545 \\
\hline 13 & 756,37 & 0,5909 & 0.4091 \\
\hline 14 & 786.08 & 0,6364 & 0.3636 \\
\hline 15 & 840,64 & 0,6818 & 0.3180 \\
\hline 16 & 886,11 & 0.7273 & 0.2727 \\
\hline 17 & 888,69 & 0.7727 & 0,2273 \\
\hline 18 & 981,48 & $0.818 \mathrm{e}$ & 0,1818 \\
\hline 18 & 1001.91 & 0.8182 & 0,1818 \\
\hline 20 & 1046,90 & 0.9091 & 0.0909 \\
\hline 21 & 1050.77 & 0,9545 & 0.0455 \\
\hline
\end{tabular}

Das equaçóres $(3.1),(5.1)$ e (5.2) tem-se:

$$
\text { LnOmin }=\operatorname{LnQ}_{0}-\alpha t
$$




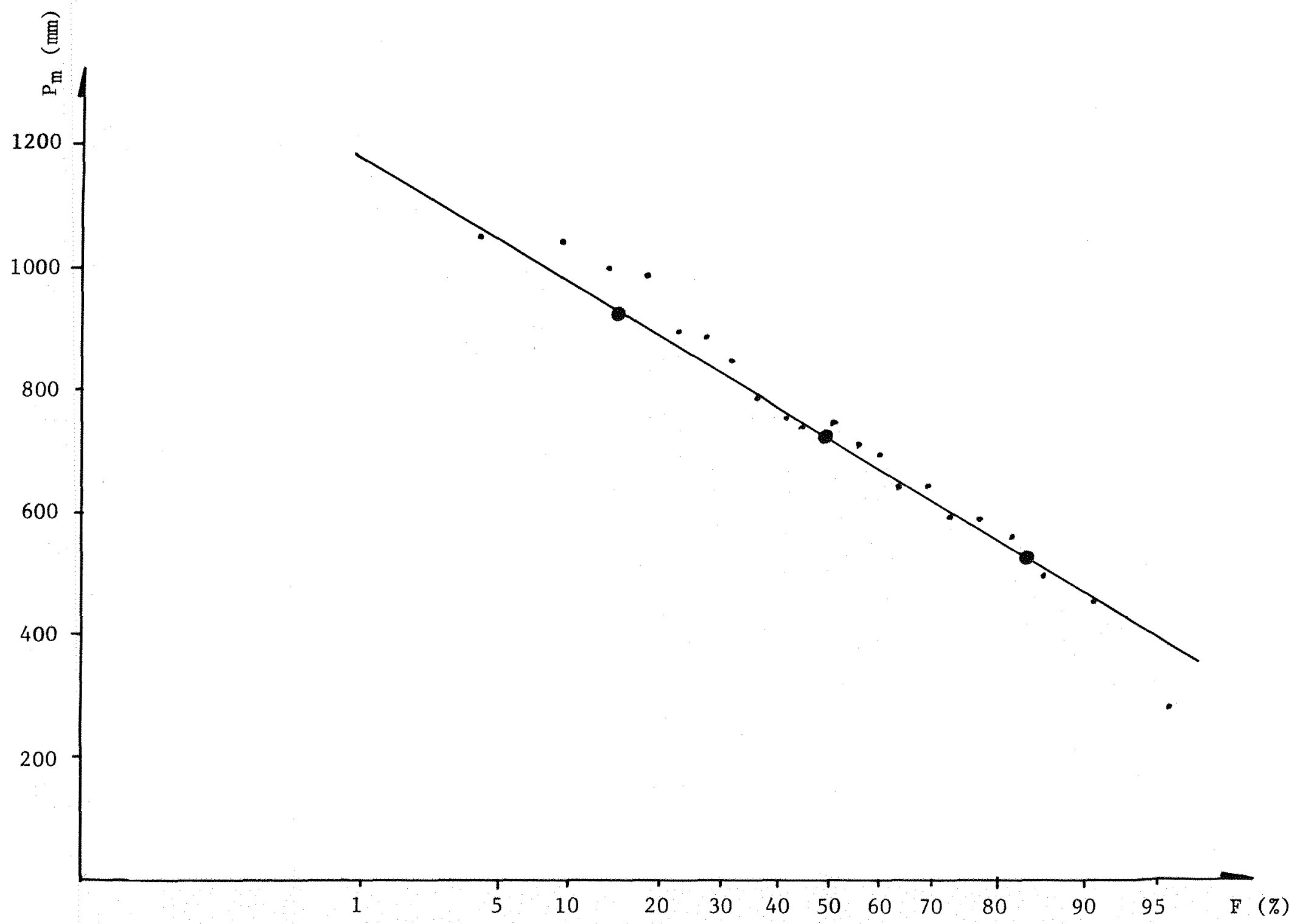

FIG. 5.11 - CURVA DE FREQUÊNCIA DA PRECIPITAÇÃO MEDIA ANTECEDENTE - BACIA DO RIO CORUMBATAI 
LnQmin $=(1.44+0.00097 \mathrm{Pm}-\alpha(10.88+0.62 t \mathrm{sc})(5.3)$

onde a caracteristica constante do aquifero, cujo valor determinado na figura $(5.8) \Leftrightarrow \alpha=0,0025$, sendo $\mathrm{Pm}$. tsc e Lnomin variáveis normalmente distribuidas conforme a descriçăo da metodologia no ltem "3"). Assim:

$$
\begin{aligned}
& \overline{\mathrm{LnQmin}}=(1,44+0.00097 \overline{\mathrm{Pm}}-\alpha(10,88+0.62 \overline{t \mathrm{sc}}) \quad(5.4) \\
& \text { e } \\
& S^{2} L_{n Q m i n}=(0,00097)^{2} S_{P m}^{2}-\alpha^{2}(0,62)^{2} S_{t 8 c} \\
& \text { sendo: } \\
& \overline{P m}=731,76 \mathrm{~mm} ; \overline{t s c}=88,14 \mathrm{dias} \\
& S_{P_{m}}^{2}=(203,23)^{2} \text { e } \alpha=0,0025 \\
& \text { entao: }
\end{aligned}
$$$$
L_{n} Q_{m i n}=1.986 ; S^{2} L n Q_{m i n}=0.0340 \text { e } S L n Q_{m i n}=0,184
$$

A curva de frequencia das vazóes de estiagem figura (5.12) para a bacia do Rio Corumbatal determinada plotando-se num papel de probabilidade aritmetico os tres pares de pontos notávels da distribuição normal: (15,87\%; $\overline{\mathrm{LnQmin}}-\operatorname{SLnQmin} ; \quad$ C50\%; $\overline{\operatorname{LnQmin}} ; \quad 684.13 \% ; \overline{\operatorname{LnQmin}}+$ SLnQmin) onde $\overline{L n Q m i n}$ e SLnOmin representam as estimativas da media e do desvio padrá do logaritmo natural da vazăo minima, obtidos pela aplicação das formulas (5.4) e (5.5).

Da figura (5.12) pode-se determinar os valores das vazbes minimas medias de 7 dias consecutivos para diferentes periodos de retorno.

Para o objetivo do trabalho, a vazão minima 
média de 7 dias consecutivos e periodo de retorno de 10 anos esperada $\theta$ :

$$
\Omega_{7.10}=5.64 \mathrm{~m}^{3} / \mathrm{s}
$$

considerando que a area da bacia hidrografica do Rio Corumbatal na seção da Fazenda Recreio e de $1.648 \mathrm{~km}^{2}$ então. a vazão especifica minima media de 7 dias consecutivos e periodo de retorno igual a 10 anos ser

$$
q_{P .10}=3,4 \geq 1 / \mathrm{s} \times \mathrm{km}^{2}
$$




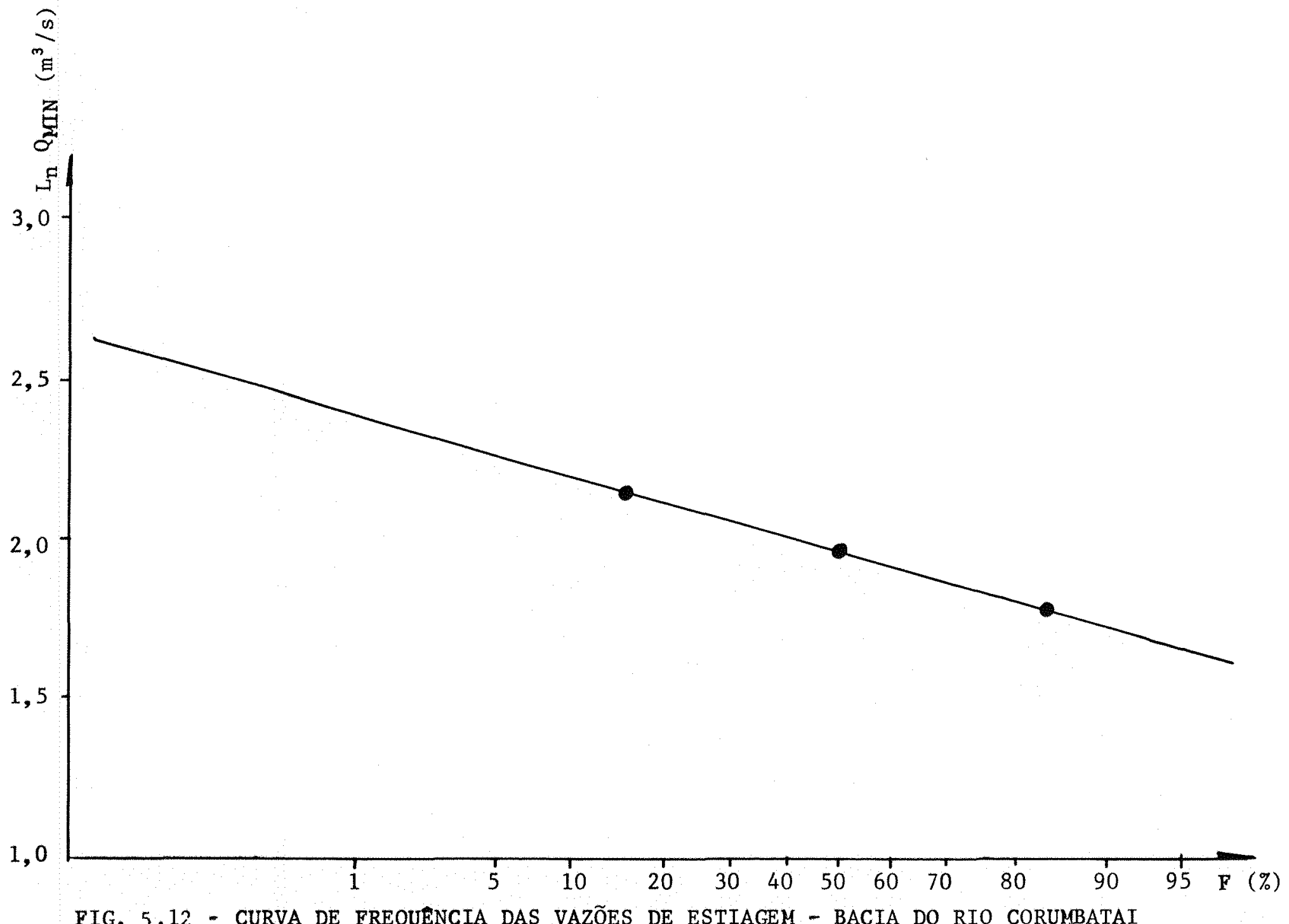


6. CONCLUSOES

- objetivo do trabalho foi determinar a vazão minima media de 7 dias consecutivos e periodo de retorno igual a 10 anos para o Rlo Corumbatal. utilizando-se de metodologia desenvolvida e testada para o Rio Piracicaba, e aplicada para o Rlo Jacare-Guassú.

o valor da vazåo especifica, minima media de 7 dias consecutivos $\odot$ periodo de retorno 10 anos, determinado para a bacia atraves da metodologia, tem valor coerente com outras metodologias desenvolvidas para estudos de estiagem no Estado de Săo Paulo CCETESB-DAEES, e já aplicados pelo autor em estudos de estiagens para projeto de irrigação em cursos d'água da bacia do Rio Piracicaba e Corumbatal CRibeirao Joaquim Bento corrego da Ponte Fundas.

A grande vantagem da metodologia e que a mesma baseia-se em informaç̧es não so de dados pluviometricos como de dados fluviometricos que realmente representam a bacla. Atraves desses dados e possivel determinar importantes parametros hidrologicos como: 
- inicio do periodo de estiagem

- duração da estiagem

- vazăo do inicio da estiagem

- precipitaçoes medias mensais totais que antecedem a estiagem para sua associaçăo com a vazăo do inicio da estiagem

- número de dias consecuti vos sem chuva para sua associação à duração da estiagem

- curva de frequencia do número de dias consecutivos sem chuva

- curva de frequência da precipitação média antecedente

- curva de frequencia das vazठ́es de estiagem. parametros esses de grande importancia na elaboraçao de projetos que envolvem quantificaçós de vazbes minimas. associadas a riscos de num ano qualquer ocorrerem valores menores ou iguais ao valor adotado. 


\section{REFERENCI AS BIBLI OGRAFICAS}

o1 CARTER, R. F. e Putnam, S.A. Low-flow frequency of Georgia streams. U.S. Geological Survey Water Resources I vestigations $77-127,1977$

Oe CETESB, Companhia de Tecnologia de Saneamento Ambiental. Avaliação regional de disponibilidades hidricas em cursos d'água de pequeno médio porte situados nas bacias dos rios Tiete medio superior e Piracicaba, 1981.

03 CETESB, Companhia de Tecnologia de Saneamento Ambiental. Estudo regional de regularizaçáo animal de descargas nas bacias dos rios Tiete medio superior e Piracicaba. 1981

O4 CHANG, M. Boyer, D. G. Estimates of low flow using watershed and climatic parameters, water resouces research, Vol. 13, n. 6, dec. pp $997-1001$.

O5 DAEE, Departamento de Aguas E Energia Elétrica do Estado de São Paulo. Estudo de aguas subterraneas regi Zo administrativa 5., 1981. 
O6 DAEE, Departamento de Aguas e Energia Eletrica do Estado de São Paulo. Regionalização de vazões minimas, médias, curvas de permanencia e volumes de regularização intra-anual em pequenas bacias hidrograficas do Estado de Să Paulo, 1988.

07 DAEE, Departamento de Aguas e Energia Eletrica do Estado de Sao Paulo. Disponibilidade hidrica superficial no Estado de São Paulo. 1986.

O8 DAEE, Departamento de Aguas e Energia Eletrica do Estado de São Paulo. Boletins fluviometricos. Relatórios de dados diarios - Posto 4D-021.

O9 DAEE, Departamento de Aguas e Energia Eletrica do Estado de Sá Paulo - Boletins pluviometricos.

10 FRYE, P. M. e Runner, G. S. A proposed stream flow data program for West Virginia, U.S. Geological Survey, open file report G1, 1970.

11 Institute of Hidrology. Low flow studies, research report n. I Institute of Hidrology, Wallinford, Oxon, Jan. , 1980. 
12 LANNA, A. E., G. Silveira, C. E. Tucci. Regionalização de vazóes minimas na bacia do Rio Jacuí, V Simposio Brasileiro de Hidrologia e Recursos Hidricos, Blumenau. Novembro, 1983.

13 MATTOS. A. Metodo de previsão de estiagens em rios perenes cusando poucos dados de vazão e longas séries de precipitaçãos. São Carlos, 1982.

14. Ministerio da Agricultura - Secretaria Geral - SUPLAN. Aptidão Agricola das terras de São Paulo, 1979.

15 RAMOS. Fábio. Vazóes de estiagem em pequenas bacias hidrograficas do Estado do Parana, VII Congresso Brasileiro de Engenharia Sanitaria, Sal vador. 1973.

16 RIGGS, H. C. Low-flow investigations, U. S. Geological Survey Techiniques of Water Resources Investigations, Boois, 4 chapter B1. U.S. Geological Survey, 1968.

17 WRIGHT, C. E. Catchment characteristics influencing low flows. Water and water engineering. novembro, 468-471, 1970.

18 UEHARA, K. Estudo de vazoes minimas em pequenas bacias hidrograficas, 1979. 